NBER WORKING PAPER SERIES

\title{
DISCRIMINATION AND RACIAL DISPARITIES IN LABOR MARKET OUTCOMES: EVIDENCE FROM WWII
}

\author{
Anna Aizer \\ Ryan Boone \\ Adriana Lleras-Muney \\ Jonathan Vogel \\ Working Paper 27689 \\ http://www.nber.org/papers/w27689 \\ NATIONAL BUREAU OF ECONOMIC RESEARCH \\ 1050 Massachusetts Avenue \\ Cambridge, MA 02138 \\ August 2020
}

We are very grateful to seminar participants from the California Center for Population Research at UCLA, Bonn University, Norwegian school of economics, Vanderbilt University, Emory University,Williams College and Pittsburgh University. We are also very grateful to Claudia Goldin for sharing her education data, and to Nicole Gorton who provided outstanding research assistance. This project was supported by the California Center for Population Research at UCLA, which receives core support (P2C- HD041022) from the Eunice Kennedy Shriver National Institute of Child Health and Human Development (NICHD). This project was supported by the California Center for Population Research at UCLA, which receives core support (P2C- HD041022) from the Eunice Kennedy Shriver National Institute of Child Health and Human Development (NICHD) and the Brown PSTC which receives core support (P2C HD041020) also from the NICHD. The views expressed herein are those of the authors and do not necessarily reflect the views of the National Bureau of Economic Research.

NBER working papers are circulated for discussion and comment purposes. They have not been peer-reviewed or been subject to the review by the NBER Board of Directors that accompanies official NBER publications.

(C) 2020 by Anna Aizer, Ryan Boone, Adriana Lleras-Muney, and Jonathan Vogel. All rights reserved. Short sections of text, not to exceed two paragraphs, may be quoted without explicit permission provided that full credit, including $\odot$ notice, is given to the source. 
Discrimination and Racial Disparities in Labor Market Outcomes: Evidence from WWII Anna Aizer, Ryan Boone, Adriana Lleras-Muney, and Jonathan Vogel

NBER Working Paper No. 27689

August 2020

JEL No. J24,J3,J7,N12,N4

\begin{abstract}
$\underline{\text { ABSTRACT }}$
The 1940s witnessed substantial reductions in the Black-white earnings gap. We study the role that domestic WWII defense production played in reducing this gap. Exploiting variation across labor markets in the allocation of war contracts to private firms, we find that war production contracts resulted in significant increases in the earnings of Black workers and declines in the racial wage gap, with no effect on white workers. This was achieved via occupational upgrading among Black men to skilled occupations. The gains largely persisted through at least 1970. Using a structural model, we show that declines in discrimination (and not migration or changes in productivity) account for all of the occupational upgrading and half of the estimated wage gains associated with the war production effort. Additionally, the war production effort explains one quarter (one seventh) of the overall improvements in racial gaps in occupation allocations (wages) witnessed over this decade. Finally, war spending led to an increase in the high school graduation rate of Black children, suggesting important intergenerational spillovers associated with declines in labor market discrimination.
\end{abstract}

Anna Aizer

Brown University

Department of Economics

64 Waterman Street

Providence, RI 02912

and NBER

anna_aizer@brown.edu

Ryan Boone

Economics Department

University of California, Los Angeles

ryanfboone@gmail.com

\author{
Adriana Lleras-Muney \\ Department of Economics \\ 9373 Bunche Hall \\ UCLA \\ Los Angeles, CA 90095 \\ and NBER \\ allerasmuney@gmail.com \\ Jonathan Vogel \\ Department of Economics \\ University of California at Los Angeles \\ 8283 Bunche Hall \\ Mail Code 147703 \\ Los Angeles, CA 90095 \\ and NBER \\ jonathan.e.vogel@gmail.com
}




\section{Introduction}

Racial disparities in labor market outcomes are persistent and pervasive. Today the unemployment rate of Black men is 3.5 percentage points higher than that of white men and among those who are employed, Black men earn $27 \%$ lower wages. A long theoretical and empirical literature exploring the sources of the labor market disparities generally concludes that both pre-market differences and labor market discrimination play important roles (Lang and Lehmann, 2012; Lang and Spitzer, 2020). These racial gaps in wages have contracted little since 1980; however, there were two previous periods of rapid convergence: the 1940s and the 1960s (see Figure 1). ${ }^{1}$

This paper focuses on the period of the 1940s and examines the role of the large expansion in government contracts to private firms as part of the war production effort in explaining the rapid closing of the wage gap during this period. ${ }^{2}$ The federally funded domestic war production effort, totaling $\$ 3.1$ trillion, combined significant increases in labor demand among private firms with requirements of anti-discriminatory policies in hiring. In the short term these efforts resulted in increased hiring of minorities.

We provide novel evidence on the role of WWII domestic production in explaining the contraction of racial gaps in the post-war era. Using 1920-1970 Census data, we exploit variation across labor markets in war contract spending to identify the effect of the war production effort, essentially comparing changes in outcomes in areas that received more war contracts with changes in outcomes in areas that received fewer war contracts, conditional on initial manufacturing levels.

We find that in areas with greater war contract expenditures, the wages of Black workers rose more than in areas with fewer war contracts; this finding is unaffected by controlling for the local area draft rate. The share of Black workers employed in skilled occupations (and the race-based skilled occupation gap) also improved more in areas with greater defense spending. By contrast, we find no (negative or positive) effects of war contract expenditures on the average outcomes of white men. Nor do we find any effects of WWII expenditures on the labor market outcomes of Black or white women by 1950, consistent with previous work showing that women's gains in the labor market during WWII as a result of mobilization were temporary.

Moreover we show that the gains for Black male workers persisted until at least 1970,

\footnotetext{
${ }^{1}$ For a detailed analysis of long-run trends in Black-white wage gaps see Bayer and Charles (2018).

${ }^{2}$ For the 1960s, researchers have attributed the closing of the gap to economic expansion, increasing educational attainment among Black individuals (Smith and Welch, 1989; Card and Krueger, 1992), affirmative action and the rise of anti-discrimination policies (e.g., Donohue and Heckman, 1991; Miller, 2017), and the rise in the minimum wage (Derenoncourt and Montialoux, 2019).
} 
though with some fading over time. These effects are not driven by endogenous allocation of war contracts: places awarded more war contracts did not show improvements in Black worker outcomes prior to 1940. While WWII expenditures did increase migration of Black workers, our results are not explained by changes in migration levels or by changes in the composition of workers.

To understand the mechanisms behind these reduced-form findings, we develop and estimate a quantitative model. We use the model to investigate the role of various mechanisms - migration, changes in productivity, and declines in discrimination - in explaining our difference-in-difference results, as well as the overall improvements in Black labor market outcomes observed over this period. The model builds on Hsieh et al. (2019). In the model, discrimination is a wedge between the wage an employer pays a Black worker and the actual value of the marginal product of that worker (the wedge is potentially caused by incorrect statistical discrimination, overt racism, etc.). This wedge is allowed to vary freely across regions, occupations, and industries. By appropriately extending Hsieh et al. (2019) to include regions, defined as metropolitan areas, in addition to industries, migration, and trade, we are able to leverage exogenous variation in expenditures across regions to identify the impact of war production on discrimination, measured by this wedge.

We do not identify changes in discrimination as a residual. The identification assumption in the model that allows us to isolate the role played by reductions in discrimination is that the innate productivity of Black workers (relative to whites) in a particular job (e.g. skilled occupations within the defense industry) did not increase by more in metropolitan areas receiving more war contracts. This assumption would be violated if unobserved characteristics of Black workers improved relative to white workers in metropolitan areas receiving more spending. We provide empirical evidence that neither migration nor changes in observable or unobserved worker characteristics drive our results. For example, we observe no Black occupational upgrading in non-defense industries in these same metropolitan areas. We also observe the same pattern of reallocation when we limit the sample to non-migrants. Both of these observations suggest that changes in unobservables are not driving our results.

According to our estimated model, reductions in discrimination (rather than migration or changes in the composition of industries or occupations) account for all of the occupational upgrading and half of the wage gains observed in our difference-in-differences estimates. Turning to aggregate trends in racial gaps over this period, we find that wartime expenditures caused a quarter of the observed change in the Black-white skilled occupation gap and a seventh of the change in the Black-white wage gap. We show that reduc- 
tions in discrimination cause most of these aggregate changes and did so by improving outcomes for Black workers without deteriorating average outcomes for white workers. Our work is the first attempt that we know of that links well-identified evidence of declines in labor market discrimination with changes in aggregate racial gaps, as suggested by Lang and Spitzer (2020).

Neither the empirical work nor the model can identify the precise reason the war production effort produced persistent reductions in labor market discrimination. Our findings are consistent with declines in employer or employee-based discrimination, which could result from explicitly anti-discriminatory policies associated with government spending: Executive Orders (Collins, 2001) and the Human Resource training that came with WWII funds that may have "professionalized" hiring practices (Bianchi and Giorcelli, 2020). Our findings are also consistent with reductions in discrimination that were not driven by explicitly anti-discriminatory policies but resulted from greater exposure of employers and employees to Black workers (Schindler and Westcott, 2017) and learning (Whatley, 1990). Available evidence leads us to conclude that the second channel may be more important. For example, we find similar effects when looking only within the South, where the Executive Order enforcement was ineffective (Collins, 2001). We also show that the effect of war expenditures was particularly strong where war-time labor shortages were more severe, suggesting that exposure is an important mechanism. We discuss this in greater detail in a later section of the paper.

Finally, we examine whether the war production effort generated spillovers to the next generation. We find that high school graduation rates increased more over this period for Black children, particularly for boys, in areas with greater war contract expenditures. Previous work on racial gaps in education has typically focused on changes in school access during this period. The quality and quantity of schooling increased substantially for Black children in the South (Card and Krueger, 1992; Collins and Margo, 2003; Aaronson and Mazumder, 2011; Carruthers and Wanamaker, 2017). Turner and Bound (2003) show that the GI Bill (created for WWII veterans) also improved Black educational levels. We document another reason why the education level of Black children increased in the post-war years: improved labor market outcomes of their parents. ${ }^{3}$ We show that war expenditures did not affect the returns to education, nor did they change school expenditure levels or residential segregation in affected cities. Thus the most plausible mechanism for the increases in education we document is the increase in family incomes associated with

\footnotetext{
${ }^{3}$ Although Margo (1993) hypothesized that improving labor market outcomes for Black workers during the war ultimately improved the education of Black children, to our knowledge, we are the first to document that war expenditures raised Black high school graduation rates.
} 
declines in labor market discrimination.

These findings suggest important intergenerational effects of labor market conditions. While much of the existing literature and policy debate on racial gaps in schooling focuses on disparities in educational inputs for Black and white children, our findings suggest that efforts to reduce the racial gap in schooling should also consider interventions that address existing discrimination in the labor market faced by Black families, or that raise their incomes. This would be consistent with the large body of literature that shows that the single most important determinant of educational outcomes is parental socioeconomic status (Duncan and Magnuson, 2012).

Our work complements previous analyses suggesting WWII improved the standing of Black workers. Collins (2001) shows that Executive Orders limiting discrimination resulted in greater employment of Black workers in defense industries. Ferrara (2020) finds that places with higher casualty rates saw increases in the share of Black men in semiskilled occupations. Maloney (1994) and Margo (1995) suggest that the wage compression due to wartime wage and price controls benefited Black workers who were overrepresented in low wage occupations. Margo (1995) and Collins (2000) conduct wage decomposition exercises and show that skill upgrading significantly contributed to the narrowing of the racial wage gap between 1940 and 1950. Our analysis builds upon this important work and extends it by focusing on a specific mechanism, linking it to a particular policy, and documenting its persistent effects on the labor market outcomes of adults and the human capital accumulation of their children.

\section{Background}

\subsection{Labor market conditions for Black men in $\mathbf{1 9 4 0}$}

In 1940, despite only slightly lower overall rates of employment, prime-age Black men earned half the yearly income as their white counterparts. Indeed, many pre-war surveys found that Black and white men in the same jobs in the same firms typically earned close to the same wage (Billips, 1936; Frazier and Perlman, 1939). Thus the main source of the difference in earnings was the disproportionate share of Black workers in unskilled occupations. Among Black workers, $78.6 \%$ percent were employed in unskilled occupations or as farmers, compared to only $37.5 \%$ of white men. ${ }^{4}$

\footnotetext{
${ }^{4}$ Unskilled occupations are defined as all occupations falling under "Laborers", "Farm Laborers", or "Service workers" occupational categories in the 1950 Census Bureau classifications. All occupations which are not unskilled or farmers are labeled as skilled for our purposes. Because our focus is on metro areas, whether we include farmers as skilled occupations does not meaningfully change our results. See Appendix
} 
Segregation can partially reconcile the large aggregate wage gap with the small wage gaps within an occupation within a firm. Black men were concentrated in lower wage industries and, within these industries, they were concentrated in lower wage firms (Wright, 1986). More importantly, Black men were systematically excluded from better job opportunities within firms and industries. For example, Ford employed the most Black workers among the major automakers in pre-war Detroit, but they were concentrated in uncomfortable and dangerous foundry positions (Foote et al., 2003). Dewey (1952) posited there were two rules of segregation at the time: (1) Black workers almost never were placed in jobs that required giving orders to white workers and (2) Black and white workers did not ordinarily work side by side. Indeed, a 1932 survey of 9,000 Black coal mine workers found only 11 in positions with any authority (Fishback, 1984). ${ }^{5}$ Black men were also barred from joining many unions or forced into segregated "Jim Crow" locals which prevented them from obtaining jobs in many skilled blue collar professions. AFL-affiliated craft unions, such as the Machinists' union, were especially known for these policies. ${ }^{6}$ Limits on promotion even affected hiring into entry-level positions: firms had less incentive to hire Black workers since they could not be promoted even if they showed talent and Black men had less incentive to provide effort since they could not be promoted (Sundstrom, 1994).

The economic status of Black workers had been improving in the decades prior to the war, in great part due to their migration out of the South and into northern manufacturing locations. While the "Great Migration" increased wages (Collins and Wanamaker, 2014), Black workers still faced significant occupational segregation outside of the South. ${ }^{7}$ That northern born Black workers had to compete with southern migrants lowered wages (Boustan, 2009) and intergenerational mobility (Derenoncourt, 2019). For a full review of the Great Migration see Collins (2020); we discuss migration further in Appendix D.3.

Locational or educational differences cannot fully explain occupational segregation. In Appendix Section C.2, we conduct an exercise where we compare the actual distribution of Black workers across occupations to the expected distribution if workers were randomly allocated to jobs conditional on education and location. Following Margo (1995), we adjust reported years of education downward for Black men born in the South to account for school quality differences. Black workers were significantly underrepresented in occupations such as engineers, salesmen, managers, skilled blue-collar work-

Table A1 for occupational shares by category.

${ }^{5}$ Fishback (1984) relates the anecdote that a coal company had to open a separate all-Black mine so they could promote high-achieving Black men without putting them in charge of whites.

${ }^{6}$ See Appendix Table A2 for example unions with discriminatory membership policies.

${ }^{7}$ See Appendix Figure A.1 for indices of occupational segregation by metro area. 
ers, and foremen. ${ }^{8}$ Conversely, we would expect about 45,000 Black janitors and porters in metropolitan areas conditional on education and location. Instead we observe $145,000 .{ }^{9}$

There is also direct evidence that overt discrimination worsened employment outcomes for Black workers. At the onset of WWII, $51 \%$ of war manufacturers reported they did not and would not employ Black workers. In 1944, strikes over the promotion of eight Black workers to streetcar motormen shut down public transportation in Philadelphia, a key wartime manufacturing hub. The shutdown continued for five days and only ended after the government sent 8,000 armed soldiers to break the strike. Philadelphia was not alone. In 1943 there were at least 242 racial incidents in 47 cities due to racial frictions caused by housing shortages, employment conflicts, or outright racism (Sitkoff, 1971). Detroit alone lost three million hours of work in the first six months of 1943 due to strikes over the hiring and promotion of Black workers (Wynn, 1976). ${ }^{10}$ All evidence suggests that widespread discrimination and occupational segregation characterized the labor market for Black men on the eve of WWII.

\subsection{The effects of WWII}

WWII transformed the American labor market in three main respects. First, the dramatic increase in federal expenditures greatly increased labor demand. The U.S. spent roughly \$3.1 trillion dollars to ramp up war-related production, roughly 40 percent of GDP each year in 1943, 1944 and 1945, creating the largest increase in expenditure in U.S. history (Appendix Figure A.3). This was substantially larger than "New Deal" expenditures meant to alleviate the Great Depression (Fishback and Kachanovskaya, 2015). Military equipment contracts accounted for $85 \%$ of this spending; new production facilities accounted for the rest. The Stabilization Act of 1942 limited changes to prices, wages, and salary levels during the war to prevent inflation.

Second, military enlistments dramatically decreased labor supply. About 15.8 million working-age men—equivalent to $40 \%$ of the male labor force in 1940 -served in the

\footnotetext{
${ }^{8}$ Appendix Table A3 shows the most over and underrepresented occupations. We use five education groups and multiply years of education by 0.85 for Black men born in the South with less than 15 years of education to account for school quality differences. Appendix Figure A.2 shows average wages and education by occupation; most occupations with excess Black men are in occupations with the lowest average wage and education levels.

${ }^{9}$ With only 1.27 million Black men employed in metro areas, the excess number of janitors and porters alone is about $8 \%$ of all employed Black men. Conditioning on education could understate segregation since even jobs with more Black men purely due to segregation will also tend to have lower average educational levels since Black men have less education on average.

${ }^{10}$ These strikes and riots had similar counterparts during WWI. For example, there were 26 race-related riots in the "Red Summer" of 1919, including a week long riot in Chicago.
} 
military during WWII. ${ }^{11}$ Additionally, about half a million men died during the war, permanently reducing the labor force further. Previous work has shown that mobilization resulted in an increase in female labor force participation (Goldin, 1991; Acemoglu et al., 2004; Rose, 2018). Large increases in labor demand and decreases in labor supply led to large labor shortages in many industries and cities. ${ }^{12}$

Third, the government enacted several important anti-discrimination measures to ensure maximum labor force utilization. Executive Order 8802 (1941) required manufacturers to assert: "I do hereby reaffirm the policy of the United States that there shall be no discrimination in the employment of workers in defense industries or government because of race, creed, color, or national origin." Executive Order 9346 (1941) established the committee on fair employment practices (FEPC) to hear complaints. The FEPC had little power to directly punish violating companies, but it could publicly shame employers and provide advice on integration. Collins (2001) shows that the share of Black workers employed in defense industries increased in places with more FEPC intervention, suggesting that the executive orders were effective. Some members of Congress disliked the FEPC, resulting in its dissolution after WWII. ${ }^{13}$

We focus on the effects of total war contract expenditures on the labor market outcomes of Black and white workers. Previous work documents both the determinants of war contract allocations across labor markets as well as the consequences of war contract expenditures on aggregate measures of economic development. Rhode et al. (2018) document that war contracts were allocated across the U.S. primarily based on existing industrial capacity and not based on political considerations. Moreover, despite its scope and scale, WWII spending did not significantly affect local per capita economic development nationwide (Fishback and Cullen, 2013) or in the U.S. South (Jaworski, 2017), though it did increase local populations. Brunet (2018) finds a small relative fiscal multiplier for WWII expenditures of 0.2. Garin (2019) finds persistent positive effects of large new manufacturing plants when located in smaller communities. We examine the determinants of the geographic allocation of these funds and their relationship to Black and white economic outcomes before and during the war in the next section.

\footnotetext{
${ }^{11}$ Although some 350,000 women served in the military, they accounted for a small fraction of the total.

${ }^{12}$ We show later in Table 1 that higher war expenditures and draft rates are associated with labor shortages

${ }^{13}$ Additionally some firms receiving defense contracts also received some form of management training. Bianchi and Giorcelli (2020) find that human resource practice training had the largest effect on firm performance after the war.
} 


\section{Data and Empirical approach}

\subsection{Data}

WWII expenditures. The data on war-related expenditures by county are from the War Production Board's Major War Supply Contracts and Major War Facilities Projects which reports cumulative contract and facility expenditures. ${ }^{14}$ War contracts (excluding food and food processing) worth over $\$ 50,000$ are assigned to the county of the primary production plant. The data covers all contracts awarded from June 1940 until September 1945.

Figure 2 shows the spatial distribution of WWII expenditures. War contracts were less likely to be distributed to the South and more likely to be distributed to the Northeast, Midwest, and West coast. With a few exceptions (such as Los Alamos) these expenditures typically went to urban rather than rural areas. ${ }^{15}$ In our baseline analysis we focus on metropolitan areas, aggregating spending up across counties and calculating for each metropolitan area cumulative spending per capita. In 1950 these 147 metro areas covered 55 percent of the U.S. population, and 50 percent of the Black population. More than 90 percent of the Black population living outside of the South lived in metro areas. In our robustness checks we replicate our results using two alternative geographic aggregations: states and commuting zones in Appendix Tables A6 and A7.

The average war contract spending per capita in a given metropolitan area was about $\$ 1,457$ per person in 1940 dollars, with a standard deviation $\$ 1,371$ across metro areas. For comparison, GDP per capita in 1940 was only $\$ 779$. Figure 3 shows a very skewed distribution of expenditures. All metro areas received at least some war contracts but there is significant variation in size: $50 \%$ received less than $\$ 1,000$ per capita while $10 \%$ receive $\$ 3,000$ or more per capita (Panel A). There is substantial variation in expenditures even after we condition on 1940 city-level characteristics (Panel B).

Draft rates. The other major change affecting the labor market of cities was the draft. We construct metro-level draft shares using individual-level data from the WWII Army Enlistment Records. Unfortunately these records only include information on about 9 million of the 16 million individuals who served. ${ }^{16}$ We supplement the data by digitiz-

\footnotetext{
${ }^{14}$ These data are available from the 1947 County Data Book available through ICPSR 02896 (Haines and ICPSR, 2010).

${ }^{15}$ Metro areas are based on Census definitions. They consist of groups of counties and the primary qualification is that the county grouping contains a city of at least 50,000 people.

${ }^{16}$ The primary reason for missin data is the fact that the files only contains Army records and excludes other branches, such as the Navy (The Air Force was still part of the Army during WWII). The secondary reason for missing service members is due to poor quality scans or missing records.
} 
ing select tables from Selective Service System (1956) which contain information on total voluntary and draft enlistments by month and service branch.

There are several complications with interpreting observed enlistment rates. First, voluntary enlistments will be highly endogenous to local conditions. Second, draft regulations provided various exemptions for individuals, such as deferments based on age or marital status. Most importantly for our work, men who worked in industries deemed essential for the war effort could obtain exemptions. Third, areas with net positive inmigration after 1940 (e.g., due to war expenditures) will appear to have higher draft rates. Fourth, individual records are missing in batches related to geographic areas.

To address these endogeneity issues, we construct a predicted draft rate to isolate the major exogenous source due to demographics. First, we create demographic cells based on age, sex, marital status, race, and nativity status for men ages 15-64. Next, we calculate the total number of men drafted for each demographic group at a national level using the individual WWII Army Enlistment records. We assume men not included in our records have the same demographic characteristics on average as people drafted into the Army within a month conditional on race. ${ }^{17}$ For each demographic cell, we then divide by the relevant 1940 national population to create a national draft rate, Draft rate ${ }_{d}$. Finally, we calculate the share of each demographic group in each metro $r$ in 1940, $\pi_{r d}$, and multiply it by the national draft rate for that group to get a predicted draft rate for each metro area:

$$
\text { Pred Draft }{ }_{r}=\sum_{d} \pi_{r d} \text { Draft }_{\text {rate }}
$$

This measure is a function of pre-WWII demographics only, and does not directly depend on economic activity in 1940 . The mean predicted draft rate is $21.2 \%$ of men ages 15-64 and the standard deviation across metro areas is $1.6 \%$. This measure only includes draftees and does not include voluntary enlistments (about 39\% of total enlistments). In Appendix Section B.2 we describe in greater detail how we create this measure and show that our predicted measure predicts the actual draft rate (correlation $=0.25) .{ }^{18}$ Both the actual and predicted draft rates are negatively correlated with war expenditures per capita.

Labor market and education data. Our primary outcomes of interest come from 19201970 individual-level census data from IPUMs (Ruggles et al., 2020) aggregated to the

\footnotetext{
${ }^{17}$ In other words, white men drafted June 1943 by the Navy have similar demographic characteristics as white men drafted in June 1943 by the Army. We condition on race because there is evidence that Black men were significantly more likely to be sent to the Army than the Navy.

${ }^{18}$ Our results are robust to using the actual draft rate, predicted draft rate, or including voluntary enlistments. Results available upon request. Results are also robust to using the casualty rate instead.
} 
race-sex-metro-year level. The individual data contains information on school enrollment and occupation for all census years. Employment is available starting in 1930. Education and wage earnings are only reported starting in 1940. In the $19501 \%$ sample, some of these outcomes were only asked of sample-line persons and are only available for a small share of the population. To improve metro-level variables derived from the smaller 1950 census data, we digitized metro-level aggregates from the 1950 Census Volumes on occupation and income distributions by race and gender.

We define skilled occupations as individuals reporting an occupation falling under "Profession, Technical;" "Managers, Officials, and Proprietors;" "Clerical and Kindred;" "Sales workers;" "Craftsmen;" or "Operatives" categories. ${ }^{19}$ We refer to the share of employed persons in these occupations as the "share skilled" throughout the paper. Primeage employment is defined as the percentage of men ages 25-54 who are currently employed. The yearly wage is total wage earnings in the previous year for people who are currently wage-earning employees and employed. ${ }^{20}$

Other data. We digitized reports on the extent of labor shortages during WWII from the monthly Labor Market Reports compiled by the War Manpower Commission (1945). These reports included whether cities were experiencing labor shortages each month. We aggregate these to compute the percentage of months for each metro area during which there were severe labor shortages from 1942 to 1944. Metro areas experienced severe labor shortages during $20 \%$ of months on average. Data on employment in war related industries during WWII comes from ES-270 reports. We also use data on local education expenditures at the city level collected in County and City Data Books and available through the ICPSR. Public expenditures on education at the city level are available for years 1940 and 1947-48 for cities with population of at least 25,000. ${ }^{21}$ Finally, we use neighborhood segregation measures at the city level from Cutler et al. (1999). More details on the data sources are provided in the Appendix Section B.3.

\footnotetext{
${ }^{19}$ This corresponds to occupational codes 000-093, 200-690 under the 1950 IPUMS occupational coding scheme. Due to our focus on metro areas, our results are not sensitive to whether farm owners are defined as skilled.

${ }^{20}$ In 1940 individuals were only asked about wage income, so self-employed or business income is excluded. The majority of individuals excluded by the wage-earning employee restriction are farmers.

${ }^{21}$ These data are available through ICPSR: County and City Data Book [United States] Consolidated File: City Data, 1944-1977 (ICPSR 7735). Of the 147 metropolitan areas in our analysis sample, we have education data for approximately 83 percent of the sample residing in those metropolitan areas. The data include total expenditures for the city and do not distinguish between different schools within the city. We cannot, therefore, identify spending in schools attended predominantly by a specific race.
} 


\subsection{Understanding the determinants of WWII expenditures}

To investigate which areas received more war contracts based on 1940 characteristics, we regress expenditures per capita in each of the 147 metro areas on 1940 characteristics and predicted draft shares in those areas. To facilitate comparison, we standardize all variables to have mean zero and a standard deviation of one. The results in column 1 Table 1 show that, as expected, manufacturing is the main determinant of war expenditures. Both the share employed in manufacturing and the (log of) manufacturing output per capita in 1940 are positive and statistically significant predictors of war production expenditures.

Importantly other measures of economic activity, like the share unemployed or the share employed in skilled occupations, do not predict expenditures. And neither does the share of the population that is Black. However the predicted draft negatively and significantly predicts expenditures. ${ }^{22}$ Overall our findings are consistent with those reported previously in the literature.

\subsection{Empirical Approach}

We estimate the impact of war expenditures on the labor market outcomes of Black and white workers separately. We assess whether outcomes changed differentially between 1940 and 1950 in areas that received greater WWII expenditure (per capita) relative to those that received less, conditional on covariates. This strategy is a difference-in-difference approach where the treatment varies in intensity. Importantly, we measure outcomes in 1940 and 1950, five years after war production ceased. In so doing, we estimate the lasting impact of the war production effort on the employment and wages of workers. Specifically we estimate the following equation separately by race:

$$
Y_{r t}=\beta_{1} \text { WarExp }_{r} \times \text { Post }_{t}+\beta_{2} \text { Draft }_{r} \times \text { Post }_{t}+\text { Post }_{t}+\gamma_{r}+X_{r t} \rho+\varepsilon_{r t}
$$

where the outcome of interest for a given metro area $r$ in census year $t$ is one of three measures: the share of workers employed in skilled occupations, (log of) the average wage, and the prime-age employment rate. Regressions are weighted by the population of the relevant race. The standard errors are corrected for heteroskedasticity. ${ }^{23}$ The main independent variable of interest, WarExp $p_{r} \times$ Post $_{t}$, is the total cumulative war contract spending per capita in metro area $r($ WarExpr $)$ interacted with a post war indicator that

\footnotetext{
${ }^{22}$ As does the actual share. See Appendix Table A4.

${ }^{23}$ Our results are very similar if we cluster the standard errors at the metro level instead. Because we only have two time periods, one before and one after, adjusting for heteroskedasticity is appropriate according to Bertrand et al. (2004).
} 
equals one in $1950\left(\right.$ Post $\left._{t}\right)$. We also include metro fixed effects $\left(\gamma_{r}\right.$, which absorb the main effect of war expenditures), the post-war indicator ( Post $\left._{t}\right)$, and the time-varying metro area characteristics in $1940\left(X_{r t}\right)$ described below.

In some sense our approach is akin to a Bartik approach. WWII represents a large exogenous shock that differentially affects metropolitan areas based on the composition of their existing manufacturing base. We are essentially comparing places with similar manufacturing employment shares that differ based on how easily their manufacturing based can be converted into war production. The identification assumption is that conditional on manufacturing (and other baseline) covariates, the areas that received greater WWII expenditures would have been on the same trajectory as those receiving smaller amounts. This assumption would be violated if the pre-existing trends differ (if WWII expenditures went to places that were on different trajectories) or if areas that received higher expenditures were affected by the war by other factors that are correlated with expenditures.

We check the plausibility of these assumptions in three ways. First, we show that war expenditures are associated with employment changes during the war. Second, we check the robustness of the results to adding as controls the variables that predict expenditures interacted with post in $X_{r t}$. Most importantly, these include the share of manufacturing and predicted draft rate interacted with Post $_{t}$. We include the predicted draft rate since it is an exogenous shock that is correlated with war expenditures and could plausibly affect our outcomes of interest. We also control for a vector of other controls from the 1940 census (share of men employed in agriculture, share Black, and average years of education) interacted with Post $_{t} .{ }^{24}$ Finally, we assess whether war expenditures predict changes in outcomes prior to WWII. We also use the same identification strategy to investigate effects of expenditures during the war which we turn to now.

\section{Empirical results on wages, occupations, and employment}

\footnotetext{
${ }^{24}$ We do not assume that a given reported education implies an equivalent productivity across races. This would be problematic given that segregated schools provided Blacks with lower-quality education; see e.g. Boustan (2009) and Carruthers and Wanamaker (2017). Rather, we run the regressions separately by race, making no assumptions about equivalence in schooling across races. We also conduct robustness checks using a variety of other baseline controls interacted with post indicators, such as initial share of men in skilled occupations. See Figure 5.
} 


\subsection{Effects of expenditures on labor markets during WWII}

To investigate the effects of expenditures on the labor market during the war, we must rely on non-Census data on reported labor market shortages and war-related employment that were collected by the War Manpower Commission. Column 2 of Table 1 shows that metro areas with higher war expenditures also had more months of severe labor shortages. A standard deviation increase in expenditures is predicted to result in 0.457 standard deviations increase in months of severe labor shortages, conditional on the predicted draft, which is also independently associated with labor shortages. We find that greater expenditures and associated labor shortages increased the employment of Black and white workers in the defense industry during the war. ${ }^{25}$ These results show that expenditures led to labor shortages and to greater defense industry employment during the war, as expected. But importantly the employment of Black workers, as well as that of female workers, rose substantially with expenditures.

\subsection{Short-term effect of expenditures 1940-1950}

The large increase in expenditures that took place during the war decreased substantially and immediately upon the war's conclusion. In 1945 military expenditures amounted to 39 percent of GDP, falling to 20 percent in 1946, and by 1947, they were less than 10 percent. ${ }^{26}$ Thus, the direct impact of the war on employment ended prior to 1950 . We now investigate whether the spending had persistent impacts on the labor market outcomes of Black and white workers after the war.

Preliminary graphical evidence of the effects of war expenditures on changes in labor market outcomes over time for white and Black workers is presented in Figure 4. Changes in the share of skilled employment (Panel A) and the log of average wages (Panel B) are presented for Black men and white men separately. The blue diamonds indicate the 19401950 changes. Metro areas that received higher expenditures saw a larger, positive and statistically significant increase in the share of Black workers employed in skilled occupations. The same is not true of white workers; the share employed in skilled occupations grew at the same rate in areas with more and less war expenditures. We also show the changes prior to the war from 1930-1940 (in dark circles). War expenditures were not associated with increases in the share employed in skilled occupations, for either Black or

\footnotetext{
${ }^{25}$ See Appendix Table A5.

${ }^{26}$ There was another increase in expenditures associated with the Korean War, but expenditures at their highest only rose to 15 percent of GDP in 1953 and the Korean War began after the 1950 Census. See Appendix Figure A.3.
} 
white workers prior to the war. This provides preliminary evidence for the validity of our identifying assumptions.

Panel B shows that expenditures were also associated with large and statistically significant increases in wages among Black workers from 1940 to 1950. White workers also appeared to benefit from expenditures, though the association for them is weaker and statistically insignificant. There is no Census wage question prior to 1940 to examine wage pre-trends.

These preliminary results are confirmed in Table 2, where we present the results from estimating equation (1). Regression analysis allows us to control for census-region-specific time trends and weight by the relevant population of interest. We find positive and statistically significant effects of expenditures on the share employed in skilled occupations and on wages for Black workers. These results hold even when we control for baseline characteristics, including the predicted draft rate (column 2). The effects on white workers in the first column are statistically insignificant. ${ }^{27}$ Moreover we can reject (at the 5 percent level) the null hypothesis that the effects are the same for Black and white workers. Thus, war expenditures reduced the racial gap in wages and in the share of skilled occupational employment in metro areas with more expenditures. The last panel of the table shows that expenditures were not associated with significant changes in prime-age employment rates for either Black or white workers.

The magnitudes of these changes are economically meaningful. The share of Black workers in skilled occupations increased by 4.5 percentage points more in metro areas at the 90th percentile of expenditures compared with metro areas at the 10th percentile, representing a $13.6 \%$ percent increase relative to the mean in 1940. Similarly, the wage gains for Black workers were 9 log points, or 9.4 percent higher wages relative to the mean in 1940, which is higher than the estimated effects of an additional year of school at the time..$^{28}$

We conduct a series of robustness checks. Figure 5 presents the coefficient on WarExp $p_{r} \times$ Post $_{t}$ for a number of alternative specifications, separately for white and Black men. The coefficients are not very sensitive to the inclusion of various controls including censusdivision trends, basic controls, population, draft, and baseline outcomes. The choice of

\footnotetext{
${ }^{27}$ One interpretation is occupational segregation did not decrease and white men upgraded within the skilled category. We show in Appendix Table A8 that war expenditures decreased occupational segregation indexes - therefore occupational distributions did become more similar even at more granular levels. This result is consistent with limited wage increases for white men. Appendix Table A9 shows Black increases are concentrated in "Operatives" and "Craftsmen" occupational categories.

${ }^{28}$ OLS estimates of the returns to schooling at the time from for all men range from 5 percent (Goldin and Katz, 2000) to 8 percent (Clay et al., 2012). Returns to schooling were typically lower for Black men in this time period.
} 
weights does not affect the estimated coefficients, though the standard errors are larger if we do not use any weights. The results are not driven by the North or the South; they hold within region. As was the case in the figures, expenditures did not predict changes in outcomes from 1920 to 1930 or 1930 to 1940. And they did not affect women (the coefficients are positive but not precisely estimated). The results also hold within industry, with significantly larger effects within the defense industry. The conclusions with respect to the impact of war expenditures on the occupation and wages of Black and white workers are unchanged in these alternative specifications.

Our results cannot be solely explained by selective migration even though there was substantial white and Black migration during this period related to WWII expenditures ${ }^{29}$ see Appendix Section D.3. Columns 2 and 4 of Table 3 show that the results are very similar when we exclude potential interstate migrants. ${ }^{30}$ Thus the gains in wages and in the share in skilled occupations do not appear to be the result of the migration of higher skill Black workers to areas with higher war expenditures. We also show in Appendix Figure A.4 that war expenditures are not associated with changes in the share of prime-age men with high school degrees between 1940 and $1950 .{ }^{31}$

\subsection{Long-term effects of Expenditures 1920-1970}

We now investigate the effect of expenditures over the longer term. The effect of expenditures on wages and the share in skilled occupations are positive and statistically significant if we estimate long differences from 1940 to 1970 instead of 1940 to 1950 differences (Figure 5). Thus the effects of war expenditures persisted long after the war.

To see this more clearly we estimate the following regression, after stacking the data for all census years 1920 to 1970:

$$
Y_{r t}=\sum_{j \neq 1940} \beta_{j} \text { WarExpr } \times \mathbb{I}_{t=j}+\gamma_{r}+\alpha_{t}+X_{r t} \rho+\varepsilon_{r t}
$$

where $Y_{r t}$ is either the log of average wages or the share in skilled occupations, WarExp are total war expenditure per capita for metro $r$ and they are now interacted with a dummy for each decade other than 1940, which serves as the reference category. To ac-

\footnotetext{
${ }^{29}$ This result is consistent with Boustan (2009) and Derenoncourt (2019).

${ }^{30}$ We define a potential interstate migrant as any individual living in a different state than their state of birth and who is not living with a child born in their current residence state before April 1, 1942. The regression is at the individual level, clustered at metro-year level, with additional controls for age, marital status, and whether born in the South.

${ }^{31}$ Prime-age men is defined as men ages $25-54$ so most would not have been affected by the increase in high school graduation associated with war expenditures that we show later.
} 
count for changing metro definitions over time we use metro boundaries based on commuting zones in oder to maintain a uniform definition of labor market over time. ${ }^{32}$ All other controls are defined as before and interacted with Census year indicators.

The estimated coefficient for each decennial census year is presented in Figure 6. War expenditures were negatively correlated with the share of employment in skilled occupations among Black workers in 1920 and 1930 (though not statistically significantly so). However, the effect of war expenditures on this outcome becomes positive and significant in 1950 and 1960. It is still positive (though insignificant) in 1970 (Panel A). The effect on wages (Panel B) is also positive and significant from 1950 through 1970 (recall that the Census did not ask about wages before 1940). Expenditures have small and statistically insignificant effects for white workers.

In sum, the results suggest that war expenditures led to labor shortages during the war and increased employment of Black workers during the war. Black workers appear to have gained access to previously unavailable skilled occupations and their associated higher wages, and these positions and their associated higher wages remained available to Black workers for many decades after the war ended. These improvements for Black workers were not associated with declines in outcomes for white workers.

\subsection{Preliminary evidence on mechanisms}

There are several potential mechanisms that might generate persistent effects. First, Black men might have gained additional experience during the war. Second, the composition of workers might have changed due to education increases and/or selective migration. Third, expenditures could have shifted industry composition towards industries that already employed Black men in more highly skilled positions. Finally, the expenditures could have directly reduced employment discrimination.

We first investigate whether work experience could explain the results. To do so, we focus on the outcomes of workers who were too young to have gained significant experience during the war. When looking at changes from 1940 to 1950, we focus on comparing men ages 18-24 in 1940 to men ages 18-24 in 1950. When looking at changes from 19401960, the age range is 18-34. In both cases the point estimates in Table 4 are very similar to our main results, suggesting that our results cannot be explained only by additional experience gained during the war. Rather, Black workers without war experience were also able to access higher paying occupations after the war.

\footnotetext{
${ }^{32}$ For example, metro areas expanded due to "white flight" to suburban counties in the 1950s and 1960s. See Boustan (2010) for evidence on the effect of the Great Migration on "white flight".
} 
Evidence also suggests that compositional changes, either due to migration, education, or industry changes, cannot fully explain these results. We find similar results when we exclude migrants, condition on education, or look only within industry - see Figure 5. Occupational upgrading also occured across education levels and ages (see Appendix Figure A.5). Oaxaca-Blinder decompositions can also be informative about the extent to which changes in the distribution of workers across regions, occupations and industries affected the wage gap. These suggest that occupational upgrading-along with wage compression across education groups and occupations-are the main sources of relative wage increases for Black workers during this period. ${ }^{33}$

Having ruled out that our findings can be explained solely by changes in the experience or composition of the worker or local industry, we turn to an examination of the fourth explanation: declines in discrimination (either at the individual or institutional level). To do this we develop a model to quantify the contribution of declines in discrimination in generating our difference-in-difference empirical results while explicitly accounting for these compositional changes. We can also use the model to quantify the effect of war expenditures on aggregate patterns.

We need the model to measure these effects because our current difference-in-differences approach and Oaxaca decompositions above are not sufficient to separately quantify the contribution of each potential mechanisms. Our difference-in-differences results do link expenditures to outcomes, but they cannot separately identify the contribution of each potential mechanism. Oaxaca decompositions are descriptive and do not link the changes in the occupational distribution to the level of war expenditures. Moreover, difference-indifferences estimates net out various "common effects" and thus cannot speak to aggregate changes. Finally, in the presence of spillovers across space via trade and migration (explicitly incorporated in our theory), the DD estimates cannot be used directly to infer unbiased aggregate causal effects due to violations of the stable unit treatment value assumption (SUTVA). As shown in Appendix D.3, there was significant migration in the 1940s that was related to war expenditures. Hence, our DD results should be interpreted as identifying the differential effects on metro areas receiving more relative to less war expenditure, but not the aggregate effect of war expenditure on labor market outcomes. Therefore, for all of these reasons we need to develop a model for quantification.

\footnotetext{
${ }^{33}$ These are presented in Appendix C.3. The results are consistent with those reported in Margo (1995).
} 


\section{Quantification}

In this section, we use a general equilibrium model for three purposes. First, we quantify the importance of a particular mechanism - a reduction in discrimination-in generating our difference-in-difference empirical results above. Second, we quantify the total impact of government wartime spending on aggregate labor market outcomes for Black and white workers. Finally, we quantify the extent to which these aggregate effects of wartime spending are driven by reductions in discrimination.

\subsection{Model}

In this section, we provide a model in which the allocation of labor groups across regions, the allocation of labor groups within regions across industries and occupations, and the average wages of labor groups across regions is endogenous.

At time $t$ there is a continuum of workers indexed by $z \in \mathcal{Z}_{t}$, each of whom inelastically supplies one unit of labor. ${ }^{34}$ Workers are exogenously divided into a finite number of labor groups, indexed by $g$. The set of workers in group $g$ is given by $\mathcal{Z}_{g t} \subseteq \mathcal{Z}_{t}$, which has mass $N_{g t}$. Workers choose in which region (indexed by $r$ ) to live and in which industry (indexed by $i$ ) and occupation (indexed by $o$ ) to work in order to maximize utility. Labor is the only factor of production. All markets are perfectly competitive and all factors are freely mobile across occupations, industries, and regions. We index by $\mathcal{Z}_{\text {rgt }}$ and $\mathcal{Z}_{\text {riogt }}$ the endogenous sets of workers in group $g$ who choose to live in region $r$ and who choose to live in region $r$ and work in industry-occupation io at time $t$.

Production. Final good output is produced locally and is not traded, so that its consumption equals its production, both of which are denoted by $C_{r t}$. This final good is produced combining the services of industries according to a Cobb Douglas production function

$$
C_{r t}=\prod_{i} C_{r i t}^{\mu_{i}}
$$

where $C_{r i t} \geq 0$ is region $r^{\prime}$ s consumption of industry $i, \mu_{i} \geq 0$, and $\sum_{i} \mu_{i}=1$. $^{35}$ Consumption of industry $i$ in region $r$ is itself an aggregation across consumption of industry

\footnotetext{
${ }^{34}$ Given our reduced-form evidence showing no clear impact of wartime spending on employment shares, we abstract from endogenous labor supply. Incorporating endogenous labor supply will leave our baseline results largely unchanged given well-identified estimates of the labor-supply elasticity.

${ }^{35}$ During the war, most output of war industries is purchased by the government. We use the model to quantify the impact of government expenditures between 1940 and 1950, years in which government national defense expenditure shares were relatively low at $2.7 \%$ and 7.6\% of GDP in 1940 and 1950 respectively. Expenditures had peaked at 43.3\% of GDP in 1944.
} 
$i$ purchased from all regions and is given by

$$
C_{r i t}=\left(\sum_{j} \mu_{j i t}^{1 / \rho} C_{j r i t}^{(\rho-1) / \rho}\right)^{\rho /(\rho-1)}
$$

where $C_{j r i t}$ is consumption of industry $i$ in region $r$ purchased from region $j, \mu_{j i t} \geq 0$ is a demand shifter for industry $i$ output produced in region $j$, and $\rho \geq 0$ is the elasticity of substitution across regions (which is common across industries and time).

Output of industry $i$ in region $r$ is given by

$$
Y_{\text {rit }}=\left(\sum_{o} \mu_{\text {riot }}^{1 / \eta} Y_{\text {riot }}^{(\eta-1) / \eta}\right)^{\eta /(\eta-1)}
$$

where $Y_{\text {riot }}$ is the output of occupation $o$ used in the production of industry $i$ in region $r$ at time $t, \mu_{\text {riot }} \geq 0$ is a demand shifter for this occupation output, and $\eta \geq 0$ is the elasticity of substitution across occupations (which is common across industries and time). Occupation $o$ output supplied in industry $i$ is the sum of efficiency units, $L_{\text {riogt }}$, provided by all groups employed therein

$$
Y_{\text {riot }}=\sum_{g} L_{\text {riogt }} .
$$

A worker $z \in \mathcal{Z}_{\text {rgt }}$ supplies $T_{\text {riogt }} \mathcal{E}_{z i o t}$ efficiency units of labor if employed in industryoccupation pair io in region $r$ at time $t$, so that

$$
L_{\text {riogt }}=\int_{\mathcal{Z}_{\text {riogt }}} T_{\text {riogt }} \mathcal{E}_{\text {ziot }} d z,
$$

The parameter $T_{\text {riogt }}$ is the systematic component of productivity (combined with discrimination, as described in Section 5.2), common across all $z \in \mathcal{Z}_{\text {roigt }}$, whereas $\varepsilon_{z i o t}$ is the idiosyncratic component of productivity. Each worker is associated with a vector of $\varepsilon_{z i o t}$, one for each io pair, allowing workers within $\mathcal{Z}_{\text {rgt }}$ to vary in their relative productivities across io pairs. We assume that each $\varepsilon_{z i o t}$ is drawn independently from a Fréchet distribution with cumulative distribution function $G(\varepsilon)=\exp \left(-\varepsilon^{-\theta}\right)$, where a higher value of $\theta>1$ implies lower within-worker dispersion of efficiency units across io pairs.

Worker locations. We take as given the supply of worker types at the aggregate level and model their allocation across space. We let $\pi_{r g t}^{N}$ denote the share of workers in group $g$ living in $r$. We assume that the utility of a worker $z$ living in region $r$ is the product of amenities and the expected real wage from living there. Preferences for amenities from residing in region $r$ are themselves given by the product of a systematic component, $U_{r g t}$, 
and an idiosyncratic preference shock, $\varepsilon_{z r}^{U}$, which is distributed Fréchet with shape parameter $v>1$. We assume that each worker first draws her preference shocks across regions and chooses her region, and then draws her productivity shocks across industryoccupation pairs and chooses her industry-occupation.

Market clearing and trade. Goods markets, $Y_{\text {rit }}=\sum_{j} C_{j r i t}$, and labor markets, $N_{\text {rgt }}=$ $\sum_{i o}\left|\mathcal{Z}_{\text {riogt }}\right|$ and $N_{g t}=\sum_{r} N_{r g t}$, clear. We assume that occupation output and final goods are not traded. We assume that industrial output is traded freely across regions and that trade is balanced.

Mapping theory to data. We map industries in the model, $i$, to two aggregate industries in the data: defense and non-defense. Defense industries in the data are those that received substantial investment/purchases from the government during the wartime. They are not exclusively defense industries in non-war times, but rather manufacturing, mining, transportation, and government. They make up $42 \%$ and $49 \%$ percent of total metro employment in 1940 and 1950. We map occupations in the model, $o$, to two aggregate occupations in the data: skilled and unskilled. The skilled occupation in the model aggregates across the same set of disaggregated occupations as the skilled occupations in our empirical exercises. We map labor groups in the model, $g$, to four labor groups in the data defined by the intersection of two education levels (at least some high school and no high school) ${ }^{36}$ and two races (Black workers and those who are not Black, referred to as "whites"). We map regions in the model, $r$, to the 147 metropolitan areas used in our empirical exercises. We map time periods in the model, $t$, to the years 1940 and 1950.

Calibration. While we estimate the key novel aspects of our theory (the impact of government spending), we calibrate its four structural elasticities: $\theta, \rho, \eta$, and $v$. The parameter $\theta$ determines the elasticity of labor supply across io pairs within a region to changes in wages per efficiency unit. We set $\theta=2$, in line with estimates in Burstein et al. (2020), Galle et al. (2018), and Hsieh et al. (2019). ${ }^{37}$ The parameter $v$ determines the elasticity of population across regions to changes in real wages. We set $v=1.5$, in line with a large literature estimating geographic labor mobility; see e.g. the review in Fajgelbaum et al. (2019). The parameter $\rho$ determines the trade elasticity across regions. We set $\rho=5$, in line

\footnotetext{
${ }^{36}$ The majority of Black workers and many white workers did not have any high school education in 1940. We do not assume that a given reported education implies an equivalent productivity across races. This would be problematic given that segregated schools provided Blacks with lower-quality education; see e.g. Boustan (2009) and Carruthers and Wanamaker (2017).

${ }^{37}$ Burstein et al. (2020) and Galle et al. (2018) estimate the equivalent of our parameter $\theta$ leveraging exogenous variation in labor demand across occupations (Burstein et al., 2020) and industries (Galle et al., 2018) using exposure to computerization and the China shock, respectively. Hsieh et al. (2019) estimate the equivalent of our parameter $\theta$ to match the dispersion of wages.
} 
with a large literature both in international and intra-national trade; see e.g. the review in Head and Mayer (2014). Finally, the parameter $\eta$ determines the elasticity of substitution between the skilled and unskilled occupation within each industry. We set $\eta=1.7$, which allows us to match closely our difference-in-difference empirical results on wages and occupation upgrading by race in regions receiving more relative to less government spending when feeding in all estimated shocks; see Panel C in Table $6 .{ }^{38}$ Importantly, this approach to calibrating $\eta$ does not impose that the anti-discriminatory impact of spending is an important force in generating our difference-in-difference empirical results, since in the calibration of $\eta$ we feed in all estimated shocks.

\subsection{Estimation (of anti-discriminatory impacts)}

In this section we specify how government wartime spending may affect productivities, discrimination, and amenities after the spending itself has ended and describe our structural estimation of the anti-discriminatory impacts of government spending.

Government spending may potentially affect each region's productivity in each occupation within defense in a common way for both Black and white workers. For instance, a substantial share of government spending was allocated to investment in new and existing plants in the defense industry; such investment raises productivity not only during the war, but afterwards. While these shocks are common for Black and white workers, they can have differential effects across races because of the different initial compositions of Black and white workers across regions and across industries and occupations within regions. We refer to these impacts of government spending as compositional. ${ }^{39}$

Government spending may also have differential effects across races on the amenity values of regions (e.g., a region receiving more money may become relatively more attractive to Black individuals, conditional on the wages of Black and white workers, perhaps because discrimination has been reduced there) and on discrimination within each industry-occupation pair across regions (e.g., a region receiving more money may experience a reduction in discrimination in defense and a disproportionate reduction within the skilled occupation within defense). We refer to these impacts of government spending as anti-discriminatory. ${ }^{40}$

\footnotetext{
${ }^{38}$ For each value of $\eta$, we estimate all government spending shocks as a function of this choice. We iterate over values of $\eta$ until the model and data match well. See the Quantitative Appendix, Section E.3.2, for details.

${ }^{39}$ We describe our estimation of the compositional impacts in the Quantitative Appendix.

${ }^{40}$ Here, we do not attempt to explain why government spending may have been anti-discriminatory; but we discuss additional historical evidence on this issue in Section 7.
} 
Parameterization. As in Hsieh et al. (2019), we model the impact of labor-market discrimination on occupation allocations and wages as a "wedge" between wages and marginal products. This wedge reduces the perceived benefit to firms of employing Black workers; it is a reduced-form proxy consistent with a range of theoretical formulations of discrimination. Extending Hsieh et al. (2019) in order to leverage the exogenous variation at the heart of our difference-in-difference estimation in Sections 3 and 4, we allow this wedge to be specific to occupation, industry, and region.

Denote by $G_{r}$ government wartime expenditure per capita in region $r$. Focusing on the years 1940 and 1950, we express (without loss of generality) the structural productivity, net of the discriminatory wedge, of group $g$ in region $r$ and industry-occupation io at time $t$ as $^{41}$

$$
\ln T_{\text {riogt }}=\gamma_{\text {riog }}^{T}+\gamma_{\text {iogt }}^{T}+G_{r} \mathbb{I}_{t} \mathbb{I}_{i}\left[\beta_{1}^{T}+\beta_{2}^{T} \mathbb{I}_{o}+\beta_{3}^{T} \mathbb{I}_{g}+\beta_{4}^{T} \mathbb{I}_{o} \mathbb{I}_{g}\right]+\iota_{\text {riogt }}^{T}
$$

and the amenity value for group $g$ of living in region $r$ at time $t$ as

$$
\ln U_{r g t}=\gamma_{r g}^{U}+G_{r} \mathbb{I}_{t}\left[\beta_{1}^{U}+\beta_{2}^{U} \mathbb{I}_{g}\right]+\iota_{r g t}^{U}
$$

The sum of $\gamma_{\text {riog }}^{T} \gamma_{\text {iogt }}^{T}$, and $\iota_{\text {riogt }}^{T}$ in (8) represents the productivity level (net of discrimination) of group $g$ in region $r$ in industry-occupation io at time $t$ in the absence of government wartime spending; $\gamma_{\text {riog }}^{T}$ is a parameter that allows net productivity to be systematically higher in some riog's than others across time; and $\gamma_{\text {iogt }}^{T}$ is a parameter that allows for the net productivity of group $g$ in io to vary over time at the national level. The sum of $\gamma_{r g}^{U}$ and $\iota_{r g t}^{U}$ in (9) represent the amenity value of region $r$ for group $g$ at time $t$ in the absence of government wartime spending, where $\gamma_{r g}^{U}$ is a parameter that allows group-specific amenities to be systematically higher in some regions than others.

In (8) and (9), the variables $\mathbb{I}_{t}, \mathbb{I}_{i}, \mathbb{I}_{o}$, and $\mathbb{I}_{g}$ are, respectively, indicator functions that equal one if the year is $1950\left(\mathbb{I}_{t}\right)$, the industry is defense $\left(\mathbb{I}_{i}\right)$, the occupation is skilled $\left(\mathbb{I}_{o}\right)$, or the group (which is defined both by education and race) is Black $\left(\mathbb{I}_{g}\right)$. In (8), $\beta_{3}^{T}$ captures the (potentially) anti-discriminatory impact of $G_{r}$ on Black workers relative to white workers in the unskilled occupation within the defense industry. If $\beta_{3}^{T}>0$, then $G_{r}$ reduces racial discrimination in the unskilled occupation within the defense industry. ${ }^{42}$ $\beta_{3}^{T}+\beta_{4}^{T}$ captures the (potentially) anti-discriminatory impact of $G_{r}$ on Black workers rela-

\footnotetext{
${ }^{41} \mathrm{~A}$ high value of $T_{\text {riogt }}$ represents a combination of a high productivity and/or a low discriminatory wedge of group $g$ in region $r$ at time $t$ within industry-occupation io. In what follows, we often refer to $T_{\text {riogt }}$ as a "net productivity" for brevity.

${ }^{42}$ The parameter $\beta_{1}^{T}$ determines the impact of $G_{r}$ on the net productivity of whites in the unskilled occupation in the defense industry and $\beta_{1}^{T}+\beta_{3}^{T}$ determines the impact of $G_{r}$ on the productivity of Black workers in the unskilled occupation in the defense industry.
} 
tive to white workers in the skilled occupation within the defense industry. If $\beta_{3}^{T}+\beta_{4}^{T}>0$, then $G_{r}$ reduces racial discrimination in the skilled occupation within the defense industry; and if $\beta_{4}^{T}>0$, then $G_{r}$ reduces racial discrimination by more in the skilled occupation than in the unskilled occupation within the defense industry. ${ }^{43}$

In equation (9), $\beta_{2}^{U}$ captures the (potentially) anti-discriminatory impact of $G_{r}$ on Blacks relative to whites in amenity values. If $\beta_{2}^{U}>0$, then Black amenity values rise relative to white amenity values in regions receiving a higher value of $G_{r} \cdot{ }^{44}$ While changes in amenity values play little role in our quantitative analysis, in theory we want to allow for the possibility that Blacks would value reductions in discrimination over and above the wage implications of such reductions. In practice, this is what we find in our estimation.

In summary, $\beta_{3}^{T}, \beta_{4}^{T}$, and $\beta_{2}^{U}$ parameterize the (potentially) anti-discriminatory effects of government wartime spending per capita. We next turn to identifying these parameters. We describe the identification of the compositional effects of government wartime spending (the parameters $\beta_{1}^{T}, \beta_{2}^{T}$, and $\beta_{1}^{U}$ ) in the Quantitative Appendix.

Identification. In equilibrium, we obtain a simple relationship between government wartime spending per capita, $G_{r}$, and the share of group $g^{\prime}$ s labor in industry-occupation io within region $r$ at time $t$, denoted by $\pi_{\text {riogt }}^{L}$; see the Quantitative Appendix for all derivations. Together with our parametrization above, group $g^{\prime}$ s allocation across io pairs within region $r$ at time $t$ can be expressed as

$$
\ln \pi_{\text {riogt }}^{L}=\gamma_{\text {rgt }}+\gamma_{\text {riot }}+\gamma_{\text {riog }}+\gamma_{\text {iogt }}+\beta_{3} G_{r} \mathbb{I}_{t} \mathbb{I}_{i} \mathbb{I}_{g}+\beta_{4} G_{r} \mathbb{I}_{t} \mathbb{I}_{i} \mathbb{I}_{g} \mathbb{I}_{o}+\iota_{\text {riogt }}
$$

where the $\gamma$ terms are fixed effects and the reduced-form parameters map to structural parameters as follows: $\beta_{3} \equiv \theta \beta_{3}^{T}, \beta_{4} \equiv \theta \beta_{4}^{T}$, and $\iota_{\text {riogt }} \equiv \theta c_{\text {riogt }}^{T}$ (recall that $\theta$ is the parameter governing the distribution of worker productivity across industry-occupation pairs, which in equilibrium determines the labor supply elasticity across io pairs within a region). To understand the logic behind identification, it is useful to re-express the fixed effect regression in equation (10) in differences. Consider two labor groups (one Black, $g^{\prime}$, and one white, $g$ ) and two regions (one receiving more wartime spending, $r^{\prime}$, than an-

\footnotetext{
${ }^{43}$ The sum $\beta_{1}^{T}+\beta_{2}^{T}$ determines the impact of $G_{r}$ on the productivity of whites in the skilled occupation in the defense industry and $\beta_{1}^{T}+\beta_{2}^{T}+\beta_{3}^{T}+\beta_{4}^{T}$ determines the impact of $G_{r}$ on the net productivity of Blacks in the skilled occupation in the defense industry.

${ }^{44}$ The parameter $\beta_{1}^{U}$ determines the impact of $G_{r}$ on the amenity value of living in region $r$ for whites and $\beta_{1}^{U}+\beta_{2}^{U}$ determines the impact of $G_{r}$ on the amenity value of living in region $r$ for Blacks.
} 
other, $r$ ). Focusing on the defense industry, $i$, and the unskilled occupation, $o,(10)$ implies

$$
\begin{aligned}
\ln \left(\frac{\pi_{r^{\prime} i o g^{\prime} t^{\prime}}^{L}}{\pi_{r^{\prime} i o g^{\prime} t}^{L}} / \frac{\pi_{\text {riog } t^{\prime} t^{\prime}}^{L}}{\pi_{\text {riog }}^{L}}\right)-\ln \left(\frac{\pi_{r^{\prime} \text { iogt }}^{L}}{\pi_{r^{\prime} \text { iogt }}^{L}} / \frac{\pi_{\text {riogt }}^{L}}{\pi_{\text {riogt }}^{L}}\right)=\beta_{3}\left(G_{r^{\prime}}-G_{r}\right)+ \\
\left(\iota_{r^{\prime} \text { iog } t^{\prime} t^{\prime}}-\iota_{r^{\prime} \text { iog } g^{\prime} t}\right)-\left(\iota_{\text {riog }} t^{\prime}-\iota_{\text {riog }}\right)-\left[\left(\iota_{r^{\prime} \text { iogt }}-\iota_{r^{\prime} \text { iogt }}\right)-\left(\iota_{\text {riogt }}-\iota_{\text {riogt }}\right)\right]
\end{aligned}
$$

Accordingly, if we observe greater Black-compared-to-white reallocation between 1940 and 1950 towards the unskilled occupation in the defense industry precisely in regions receiving more wartime spending (a positive left-hand-side of the previous expression), we will identify a positive $\beta_{3}$ (under an identification assumption described below). Identification of $\beta_{4}$ follows similar logic: within the skilled occupation, $o^{\prime}$, the right-hand-side of the previous expression would include $\left(\beta_{3}+\beta_{4}\right)\left(G_{r^{\prime}}-G_{r}\right)$.

Hence, differential changes between 1940 and 1950 in allocations of Black and white workers across io pairs across regions receiving different amounts of government wartime spending per capita identify $\beta_{3}$ and $\beta_{4}$. In the model, the assumption allowing us to identify $\beta_{3}$ and $\beta_{4}$ estimating (10) using OLS is that, conditional on region-group, regionindustry-occupation-time, and industry-occupation-labor-group-time fixed effects, changes in productivities of Black workers relative to white workers in region-industry-occupation triplets that would have occurred in the absence of government spending are uncorrelated with government spending. We interpret these parameters as reductions in discrimination-as opposed to changes in relative productivities-by assuming that government spending does not raise the primitive productivities of Black workers relative to white workers in industry-occupation pairs in regions receiving more government spending.

One threat to identification that is not captured by the model would be if the unobserved characteristics of Black workers improved relative to white workers in regions receiving more spending. However, we observe no similar pattern of Black occupational upgrading in non-defense industries, which suggests that migration did not affect the relative abilities (conditional on education) of Black and white workers across regions. Moreover, we show that the same pattern of reallocation of Black workers towards skilled occupations occurs within non-migrants in Figure 5 and Table 3, which suggests that selective migration is not driving our results. Third, Appendix Figure A.4 shows that the average share of prime-age men who have a high school degree did not change between 1940 and 1950 as a result of government spending, which provides direct evidence that an important dimension of unobservable characteristics (in the model) did not change.

Similarly, in equilibrium we obtain a simple relationship between government wartime spending per capita, $G_{r}$, and the share of group $g$ living in region $r$ at time $t$, denoted by 
$\pi_{r g t}^{N}$. Together with our parametrization above, the allocation of group $g$ to region $r$ at time $t$ can be expressed as

$$
\frac{1}{v} \ln \pi_{r g t}^{N}-\ln \text { Wage }_{r g t}=\gamma_{r g}+\gamma_{g t}+\gamma_{r t}+\beta_{2}^{U} G_{r} \mathbb{I}_{t} \mathbb{I}_{g}+\iota_{r g t}^{U}
$$

where Wage rgt is the average wage of workers in group $g$ in region $r$ at time $t$ and $v$ is the elasticity of migration to real wages. The right-hand-side of (11) represents the amenity value for group $g$ of living in region $r$ at time $t$ (plus a constant across regions), which must be high in region $r$ at time $t$ if the share of group $g$ living in region $r$ at time $t$ is high relative to the wage the group receives there, conditional on the labor supply elasticity across regions, $v$, which is the left-hand-side of (11). For instance, we would interpret an increase in the share of more-educated Blacks living in region $r$ between 1940 and 1950 (relative to what would be predicted by the change in their wages) as an increase in the amenity value of this group living in region $r$ over time.

Similarly, differential changes between 1940 and 1950 in allocations of Black and white workers across regions receiving different amounts of government wartime spending (relative to that predicted by the observed changes in wages) identify the anti-discriminatory effects of government spending on amenities. The identification assumption-estimating (11) using OLS-is that, conditional on region-labor group and labor group-time fixed effects, the differential changes in amenities of Blacks relative to whites in regions receiving more relative to less government wartime spending per capita that would have occurred in the absence of government spending (the change across time in $\iota_{r g t}^{U}$ for Black workers minus its value for white workers in a given region) are uncorrelated with government spending.

Estimation results. Table 5 presents results of estimating (10) in columns 1 and 2, where column 1 uses employment and column 2 uses labor payments to measure labor allocations within a region, $\pi_{\text {riogt }}^{L}$. Column 1 serves as our baseline, although results are largely unchanged across columns. In column 1 , we find no evidence that greater government expenditure per capita decreases discrimination in the unskilled occupation in the defense industry: the coefficient $\beta_{3}=0.023$ is not significantly different from zero. The point estimate-together with $\theta=2$-yields the value of the structural parameter of interest $\beta_{3}^{T}=\beta_{3} / \theta \approx 0.012$. This point estimate implies that a metropolitan area, $r^{\prime}$, at the 90th percentile of government expenditure per capita $\left(G_{r^{\prime}} \approx 3.155\right)$ experiences an increase of approximately 3.5 percent $(\approx 100 \times 0.012 \times(3.155-0.198))$ in the net productivity of Black workers relative to white workers in the unskilled occupation within the defense industry, relative to a metropolitan area, $r$, at the 10th percentile $\left(G_{r}=0.198\right)$. 
On the other hand, we find statistically significant evidence that greater government expenditure per capita reduces racial discrimination within the skilled occupation in the defense industry. This increase is economically large. The point estimate of coefficient $\beta_{4}$-together with $\theta=2$-yields $\beta_{4}^{T}=\beta_{4} / \theta \approx 0.064$. This point estimate implies that a metropolitan area at the 90th percentile of government expenditure per capita experiences an increase of approximately 22.4 percent $(\approx 100 \times 0.064 \times(3.155-0.198)+3.5)$ in the net productivity of Blacks relative to whites within the skilled occupation in the defense industry (compared to within the unskilled occupation), relative to a metropolitan area at the 10th percentile.

Column 7 presents the results of estimating (11), which is estimated under our baseline assumption that $v=1.5$. We find statistically significant evidence that greater wartime expenditure raises the amenity value of a metropolitan area relatively more for Black than white workers. The coefficient $\beta_{2}^{U} \approx 0.07$ implies that a metropolitan area at the 90th percentile of exposure experiences an increase in its amenity value for Blacks relative to whites of approximately 21 percent $(\approx 100 \times 0.07 \times(3.155-0.198))$. Translating this into a more readily understandable metric, this induces the same change in allocations across these two metropolitan areas that would be induced by an increase in Black wages of 21 percent in the more exposed metropolitan area.

In summary, we find that government spending during World War II had substantial anti-discriminatory effects. Regions receiving greater government expenditure per capita experience a substantial reduction in racial discrimination in the labor market, although only narrowly in skilled occupations within defense industries. Similarly, regions receiving greater government expenditure per capita become more attractive places for Blacks workers to live in (relative to white workers), conditional on the wages that Black and white workers receive. ${ }^{45}$

\subsection{Discrimination and our difference-in-difference results}

To what extent can these reductions in discrimination explain our difference-in-difference results? Our theoretical model allows us to disentangle the quantitative effects of the reduction in discrimination induced by government spending. To do so, we calibrate our model to match the 1940 data; see the Quantitative Appendix for details on the initial model calibration. We then feed into this model only the anti-discriminatory shocks identified in Section 5.2.

\footnotetext{
${ }^{45}$ The additional columns of Table 5 present estimation results for the compositional impacts of government spending.
} 
Specifically, starting from the 1940 calibration; we raise the log net productivity of Blacks in region $r$, with government wartime spending per capita of $G_{r}$, by $\beta_{3}^{T} G_{r}$ in the unskilled occupation within the defense industry and by $\left(\beta_{3}^{T}+\beta_{4}^{T}\right) G_{r}$ in the skilled occupation in the defense industry. We also increase the amenity value of Black workers by $\beta_{2}^{U} G_{r} ;$ and we hold all other parameters fixed. ${ }^{46}$

Then we solve for the new equilibrium of the model, which entails allowing all prices and wages to respond endogenously, and allowing all agents to reallocate optimally across metropolitan areas and within metropolitan areas across industry-occupation pairs. ${ }^{47}$ We then estimate regressions of the form in (1) in Section 3.3 using actual data and, separately, using model-generated data. The comparison between the two set of results determines the extent to which changes in discrimination alone explain the original differencein-difference results.

Table 6 displays our results. The outcomes of interest are the share in skilled occupations (the skilled occupation in the model) and the ln average wage of each race in each metropolitan area. As in Table 2, we report the coefficient on war expenditure per capita times a 1950 indicator variable, which in the notation of the model above is the coefficient on $G_{r} \mathbb{I}_{t}$. Panel A reports the results in the actual data using the more demanding specifications in Table 2. Panel B reports the counterfactual impact in model-generated data of the anti-discriminatory effects of government spending.

According to column 1 of Panels A and B, the anti-discriminatory effects of government spending fully account for the greater increase in the share of Black workers allocated to skilled occupations within regions receiving more wartime spending (comparing 0.018 in Panel B to 0.015 in Panel A). According to column 3, the anti-discriminatory effects of government spending account for about half (0.015 in Panel B and 0.031 in Panel A) of the greater percent increase in the average wage of Black workers within regions receiving more wartime spending. ${ }^{48}$

We finally turn to differential outcomes across metropolitan areas for whites. Accord-

\footnotetext{
${ }^{46}$ Whereas we identified net productivity and amenity changes for Black workers relative to white workers, when we only feed in the anti-discriminatory impacts of wartime spending we hold white productivity and amenity values fixed.

${ }^{47}$ Details of the equations that determine the new equilibrium are provided in the Quantitative Appendix.

${ }^{48}$ As previously stated, our estimation and calibration do not impose that these anti-discriminatory shocks alone explain any (let alone all) of the impact of government spending across metropolitan areas. The result on wages follows from the full general equilibrium of the model, as observed wage changes are not targeted in our calibration or estimation. The result on occupation upgrading follows from the fact that in the data all occupation upgrading for Black workers in more exposed metros occurred within defense industries and from the result in the model that changes in industry and occupation productivity do not generate substantial occupation upgrading for either white or Black workers (a result that is not hardwired into the calibration or estimation).
} 
ing to column 2 of Panels A and B, both in the data and the model we see no economically significant effects of government spending on the share of whites in skilled occupations within a region receiving more wartime spending. According to column 4 of Panels A and $\mathrm{B}$, we see no economically or statistically significant change in white wages in more relative to less exposed metropolitan areas.

In summary, these results lead us to conclude that the anti-discriminatory effects of wartime spending are the primary channel through which wartime spending shapes differential Black outcomes across metropolitan areas in the 1940s. This mechanism is not an important driver of differential white outcomes across metropolitan areas (and, as we show below, in the aggregate). That is, reducing racial discrimination does not appear to reduce white real wages. Given a reasonable labor demand system, an increase in the productivity of one labor group need not reduce the real wage of another. Our results suggest that, on average, white and Black workers were complements in production in spite of being perfect substitutes within each job. ${ }^{49}$

\subsection{Aggregate results}

In this section we use the model to quantify the total impact of government wartime spending on aggregate patterns showing Black workers catching up to white workersin terms of wages and the share of employment in skilled occupations-and the extent to which these aggregate effects of wartime spending are driven by reductions in discrimination. To do this we calibrate our model to match 1940 data and feed into our model the relevant changes in net productivities and amenities. When quantifying the aggregate effects of wartime spending, we feed into our model both compositional and anti-discriminatory changes; when quantifying the extent to which these aggregate effects are driven by a reduction in discrimination caused by wartime spending, we instead feed in only the components of these changes that are anti-discriminatory.

Upon feeding in these shocks, we solve the model for the 1950 equilibrium, holding all other parameters at their 1940 levels. Given the 1950 equilibrium, we then aggregate results across all metropolitan areas to construct the aggregate effects of wartime spending (and, separately, the aggregate effects of the anti-discriminatory impacts of wartime spending) on the allocations to skilled occupations and the wages of Black and white workers.

Table 7 reports our results. The first column of Table 7 reports the change in the share

\footnotetext{
${ }^{49}$ These results are well known in the context of Ricardian models of international trade-see e.g. Dornbusch et al. (1977) and Wilson (1980)—which are mathematically equivalent to Roy models of the labor market.
} 
of Blacks relative to whites in skilled occupations and the percent $(\ln )$ change in the wage of Blacks relative to whites in the actual data between 1940 and 1950 aggregated across the 147 metropolitan areas. The second column reports the changes in these outcomes caused by wartime expenditure according to the model. Wartime spending causes a 2.1 percentage point decline in the difference between the share of whites and Blacks employed in skilled jobs between 1940 and 1950, which is about a quarter (reported in column 3) of the total decline of 8.1 percentage points in the data. Wartime spending causes a $2.9 \%$ decline in the relative wage of whites to Blacks between 1940 and 1950, which is about a seventh (reported in column 3 ) of the total decline of $21.7 \%$ in the data. The third column reports the changes in these outcomes caused by the anti-discriminatory impacts of wartime expenditure. Almost all of the aggregate effects of wartime spending on the Black-white wage and skilled-employment gaps are caused by the anti-discriminatory effects of wartime spending.

\section{Intergenerational effects on human capital}

\subsection{Effects of war expenditures on school attendance, high school com- pletion}

One might expect that persistent improvements in the labor market for Black workers, due in part to decreases in discrimination, might also affect the human capital of the next generation for a number of reasons. First, the incomes of Black families in affected metropolitan areas rose. Second, more Black workers accessed skilled occupations, which possibly increased the returns to schooling. Third, higher wages could increase the opportunity cost of schooling. Fourth, given that discrimination declined there might have been broader changes in attitudes towards Black families in the cities that received more war funds, resulting in declines in residential segregation which would affect access to schooling. Finally, greater incomes could have led to greater investments in public schooling in Black neighborhoods.

To investigate whether WWII expenditures affected the educational attainment of the next generation, we first estimate the effects of war expenditures on school enrollment among 16-18 year olds across metropolitan areas between 1940 and 1950. We estimate our main DD equation (1), but with school attendance as the outcome of interest and at the individual level (with errors clustered at the metro-year level). We focus on 16-18 year old children because almost all children in metropolitan areas, including Black children, report being enrolled in school at age 15 in 1940. 
We find that the school attendance of Black boys increased more in areas with greater war contract expenditures (Table 7), as evidenced by the positive and statistically significant coefficient on WarExp $p_{m} \times$ Post $_{t}$ for Black boys. The results are positive for Black girls though about half the size and not statistically significant. The results also hold if we exclude the South (Panel B) which we do because of existing evidence showing significant improvements in the quality of schools serving Black children (Card and Krueger, 1992) during this period. There is no effect on white boys or girls in any specification. ${ }^{50}$

However, this analysis suffers two limitations. The first is that they pertain to only the few cohorts included and the second is that we are limited by the small sample in 1950 since only sample-line persons were asked about schooling. Thus, we present results from an alternative approach that uses completed schooling reported in the 1960 census, where we have a $5 \%$ sample in which all individuals were asked about years of education. We then estimate the following equation,

$Y_{\text {irgc }}=\sum_{j \neq 1938} \beta_{j} \operatorname{WarExp}_{r} \times \mathbb{I}_{c=j} \times \mathbb{I}_{g=\text { Black }}+\sum_{j \neq 1938} \gamma_{j}$ WarExp $p_{r} \times \mathbb{I}_{c=j}+\gamma_{r g}+\gamma_{t g}+X_{\text {irgc }} \rho+\varepsilon_{\text {irgc }}$

where $Y_{i r g c}$ is a dummy equal to one if individual $i$ of race $g$ and graduation cohort $c$ living in metropolitan area $r$ graduated from high school. ${ }^{51}$ WWII expenditures are interacted with a dummy for Black race and with cohort dummies. A cohort is defined as a three year group, based on expected high school graduation year. Individuals graduating high school during 1938-1940 serve as the excluded baseline category. We restrict the sample to non-Southern metropolitan areas and drop individuals who have moved between states in the previous five years. We estimate this regression separately by gender and plot the estimated coefficients in Figure 7. Note that the coefficients for WarExp $p_{r} \times \mathbb{I}_{c=j} \times \mathbb{I}_{g=\text { Black }}$ identifies the impact of war expenditures on Black children relative to white children. There seems to be a clear increase in the share of Black boys graduating high school and a similar increase for Black girls, albeit noisier. ${ }^{52}$

We conclude that war expenditures are associated with increases in the high school

\footnotetext{
${ }^{50}$ In Appendix Table A13 we repeat this exercise for 1940 to 1960 and also find positive impacts on the school attendence of Black boys. As a falsification exercise, we repeat the analysis for 1930 to 1940 and find no effects (as expected) in Appendix Table A14.

${ }^{51}$ The main concern with these estimates is migration. There are two concerns: first, individuals who migrated to a metropolitan area after completing school might be counted as more (or less) treated than they actually were, which would attenuate estimates. Secondly, war expenditures could have differentially attracted more educated migrants for younger cohorts. We include a dummy for whether an individual was born in the South and interact with race dummies as well as a full set of cohort indicators.

${ }^{52}$ Appendix Figure A.7 uses the 1940 Census to look at pre-trends across cohorts prior to WWII and finds little evidence of pre-trends for Black boys though again finds noisier results for Black girls.
} 
graduate rates of Black children relative to white children. The magnitude of the coefficients suggests the effects are not trivial with the mean coefficient on the interaction term for boys (girls) being 2.1\% (1.6\%). The high school graduation rate for Black boys (girls) in metropolitan areas at the 90th percentile of expenditures is $6.3(4.8)$ percentage points higher than in metropolitan areas at the 10th percentile of expenditures.

Importantly, the results show that war expenditures were not associated with greater high school graduation rates for the Black or white cohorts that graduated before 1940, as expected. The effects we find are only for cohorts graduating after 1941. In contrast to the estimated effects for Black boys, higher war expenditures are associated with lower high school graduation rates during WWII for white boys. ${ }^{53}$ The estimates for white boys remain negative but become statistically insignificant after 1947. The results for Black and white girls (shown in Panel B) are similar.

\subsection{Mechanisms for increases in schooling}

We now investigate why WWII expenditures led to increases in schooling among Black children. First, we investigate whether war expenditures affected the returns to school. We estimate standard Mincerian wage equations where we interact whether an individual completed at least some high school with WarExp $m \times$ Post $_{t} .{ }^{54}$ Table 9 shows this triple difference is statistically insignificant. Interestingly, we find similar results for the effect on returns to education in our model data. It appears war expenditures did not increase returns to schooling. This is consistent with the fact that returns to school declined during the "Great Compression" period (Goldin and Katz, 1992) and not because of changing selection into schooling (Bishop, 1989). But this means that higher returns to school cannot explain increased investment in school.

Next, we look at school expenditures. The fact that white children are not positively affected suggested there were no major changes in education policy or expenditures in cities with greater expenditures. We verify this by estimating equation (1), but replacing the outcome with the log of education expenses per capita. The results in Table 10

\footnotetext{
${ }^{53}$ We verified that high school enrollment and graduation rates decreased nationally during WWII using data provided by Claudia Goldin which comes from the Biennial Reports of the Commissioner of Education.

${ }^{54}$ Specifically we estimate the following equation:

$Y_{i r t}=\beta_{1} E_{i r t}+\beta_{3} E_{i r t} \times$ Post $_{t}+\beta_{2} \operatorname{Exp}_{r} \times$ Post $_{t}+\beta_{4} E_{i r t} \times \operatorname{Exp}_{r}+\beta_{5} E_{i r t} \times \operatorname{Exp}_{r} \times$ Post $_{t}+$ Post $_{t}+\gamma_{r}+X_{i r t} \rho+\varepsilon_{i r t}$

where $E_{i r t}$ is an indicator for whether the individual completed at least some high school. We use whether the individual completed at least some high school so we can directly compare with model predictions. Appendix Table A15 repeats this analysis using years of education and finds similar results.
} 
show there were no significant increases in education expenditures in cities with more war expenditures. ${ }^{55}$

To investigate if there were changes in residential segregation, we look at whether war expenditues affected two indices of segregation: the dissimilarity index and the isolation index from Cutler et al. (1999). ${ }^{56}$ We observe no declines in residential segregation associated with war expenditures using either one, as shown in Table 10.

Overall, the most plausible mechanism appears to be the change in family income. Previous work has shown that parental income remains the most important predictor of children's educational achievement, even more so than parental education (Reardon, 2011). Recent analysis of the the strong association between racial segregation and racial achievement gaps concludes that the gap is completely accounted for by racial differences in school poverty (Reardon et al., 2019). This is true even after years of increasing public expenditures on schools that serve lower income students (Lafotune et al., 2018).

Given this, it should not be surprising that declines in workplace discrimination that led to substantial increases in the earned income of Black families would result in increases in the educational achievement of their children. A move from the 10th to the 90th percentile of war expenditures is associated with an absolute (not relative to whites) increase in wages of $9.4 \%$ and an absolute (not relative to whites) increase in the share of Black boys graduating high school of $3.6 \% .{ }^{57}$ If we assume all of the increases in schooling are due to greater incomes then this implies an elasticity of 1.0 (for Black girls 0.5). This is broadly consistent with analysis based on more contemporary data of an outsized role of parental income in explaining educational outcomes of children. ${ }^{58}$

\footnotetext{
${ }^{55}$ Unfortunately there is no data at the sub-city level that would allow us to investigate whether expenditures or quality of school increase in Black neighborhoods relative to white.

${ }^{56}$ The index of dissimilarity is defined for metropolitan area $r$ as Dissim $_{r t}=\frac{1}{2} \sum_{i=1}^{N} \mid$ Black $_{\text {Blrt }}-\frac{\text { White }_{\text {irt }}}{\text { White }_{r t}} \mid$

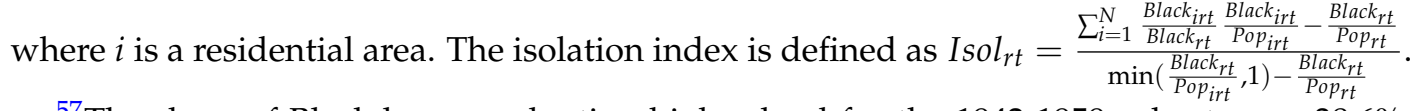

${ }^{57}$ The share of Black boys graduating high school for the 1942-1959 cohorts was 38.6\%, excluding the South. For Black girls it is $44.8 \%$.

${ }^{58}$ Existing work based on more recent data has generated estimates of parental income elasticities with respect to years of completed schooling of their children (not high school completion) that range from 3 to 80 percent (Taubman, 1989). Our estimates are on the higher end which may be due to (1) the extremely low levels of schooling at this time among Black families, (2) the different definition of the outcome (high school completion) or (3) because the effect of aggregate income shocks might differ from family-specific income shocks (for example, by generating peer effects).
} 


\section{Why did discrimination decline?}

In this paper we document that WWII expenditures account for substantial and persistent improvements in the absolute and relative labor market outcomes of Black workers during the 1940s and further show that these expenditures also led to increases in the human capital formation of the next generation of Black workers. Our results point strongly to the importance of declines in discrimination. This is consistent with the changing perceptions of Black men during this period. Data from a 1943 survey of Black soldiers reveals increasing optimism regarding the probability they would be able to find a high quality job and be treated better by white people compared to before the war. ${ }^{59}$

Why did discrimination decline? The fact that the effect was limited in non-defense industries and persisted after the war suggests two likely mechanisms. First, employers were incorrectly statistically discriminating against Black workers but they updated their expectations after observing Black workers in skilled occupations during the war. Because productivity is occupation- and industry-specific, expectations and behaviors changed only in affected industries but not elsewhere. Second, it is also possible that "institutional discrimination" declined in affected industries; see e.g. Small and Pager (2020). It is likely the war affected the broad set of practices that firms adopted, which would mostly result in changes in how they promoted workers into skilled occupations. Of course these two explanations are not mutually exclusive. Note that continued government intervention cannot explain the persistent effects because most facilities were re-converted to consumer goods production and the FEPC was disolved after WWII.

Both mechanisms can cause persistent changes. Once incorrect beliefs are correctly updated then they can be self-maintaining. Once investments are made in reducing "institutional discrimination" then these changes can also persist. For example, once a union is fully integrated then it might be costly to revert. Another example of instititutional practices that can result in disciminatory outcomes is the widespread use of referral-based hiring (Small and Pager, 2020). Racially homogenous organizations relying on referralbased hiring will continue hiring racially homogenous workers since social networks exhibit homophily. If a shock changes the racial composition of the firm then this can alter future hiring patterns.

This labor market "hysteresis" due to changes in discrimination is consistent with other research. Whatley (1990) finds that Cincinnati manufacturing firms during WWI

\footnotetext{
${ }^{59}$ These survey results are from a March 1943 survey of soldiers "Attitudes of Negro Soldiers" (1943). And it is also consistent with declines in discriminatory opinions about the intelligence of Black people. In nationally representative surveys, the share of whites who believe that Blacks are just as intelligent as whites if given the same education increased from $42 \%$ in early 1942 to 53\% in 1946.
} 
exhibited state dependence - once they hire a Black worker they are more likely to hire Black workers in the future. Saez et al. (2019) finds that subsidies for youth employment increased youth employment even after ending the policy due to a permanent decline in discriminatory job postings. Miller and Segal (2012) show that the effect of affirmative action quotas on police hiring persists even after the quotas are no longer mandatory. Miller (2017) shows similar evidence for private employers after they are no longer subject to federal contracting affirmative action policies.

Why would war expenditure have caused firms update incorrect beliefs and discriminatory institutional practices? While the Executive Order barring discrimination likely mattered, we do not think it was the main driver behind the positive effect of war expenditures on skill upgrading and wages of Black workers. ${ }^{60}$ We say this for two reasons. First, we find similar effects when looking only within the South where the Executive Order enforcement was ineffective. Second, we present evidence that severe labor shortages were likely responsible for forcing firms to invest in changing discriminatory practices. Table 11 interacts war expenditures with whether a metropolitan area experienced more months of severe labor shortages than the median metropolitan area during 1942-1944. The interaction term is strongly positive while the war expenditure term becomes statistically insignificant. As one historian of this period concludes "The greatest force for change was the general expansion of industry and the shortage of labor as more men and women entered the armed forces. These manpower shortages gradually forced white employers and workers to forget their prejudices, if only temporarily, and accept Black employees. By the end of the war the quantity and quality of jobs open to Afro-Americans had increased dramatically." (Wynn, 1976). This conclusion is also consistent with the findings of Ferrara (2020), who documents that deaths of semi-skilled white workers during WWII resulted in occupational upgrading for Black men in the South.

Because discrimination declines were limited to specific industries and returns to schooling did not increase, the effects of WWII expenditures on the accumulation of human capital of the next generation cannot be easily explained directly by declines in discrimination. The data also show that places with more funds did not see general decreases in residential segregation consistent with narrow rather than broad changes in attitudes towards Blacks. Instead, our findings suggest that the increase in wages caused in part by reductions in discrimination enabled parents to invest more in their children. Substantial attention has been devoted to lowering racial gaps in education. Recent work has documented the strong correlation between state racial disparities in test scores and state racial

\footnotetext{
${ }^{60}$ This does not mean the government efforts were not important - for the direct effect of the FEPC on Black employment see (Collins, 2001).
} 
socioeconomic disparities (Reardon, 2015). Our results are consistent with these more recent findings and suggest that improving the economic opportunities of Black families would be an effective policy for reducing racial gaps in educational outcomes, and that educational policies alone may not be sufficient.

\section{References}

Aaronson, Daniel and Bhashkar Mazumder, "The effect of Rosenwald schools on black achievement," Journal of Political Economy, 2011, 119 (5), 821-888.

Acemoglu, Daron, David Autor, and David Lyle, "Women, war and wages: The effect of female labor supply on the wage structure at mid-century," Journal of Political Economy, 2004, 112 (3), 497-551.

Bayer, Patrick and Kerwin Kofi Charles, "Divergent Paths: A new perspective on earnings differences between black and white men since 1940," The Quarterly Journal of Economics, 2018, 133 (3), 1459-1501.

Bertrand, Marianne, Esther Duflo, and Sendhil Mullainathan, "How much should we trust differences-in-differences estimates?," The Quarterly Journal of Economics, 2004, 119 (1), 249-275.

Bianchi, Nicola and Michela Giorcelli, "Not all management training is created equal: Evidence from the Training Within Industry program," Working Paper 2020.

Billips, Robert S., "Hourly entrance rates of common laborers in 20 industries, July 1936," Monthly Labor Review, 1936, 44 (4), 938-952.

Bishop, John, "Why the apathy in American high schools," Educational Researcher, 1989, $18(1), 6-10$.

Boustan, Leah Platt, "Competition in the promised land: Black migration and racial wage convergence in the North, 1940-1970," Journal of Economic History, 2009, 69 (3), 755-782.

_, "Was postwar suburbanization 'White Flight'? Evidence from the black migration," Quarterly Journal of Economics, 2010, 125 (1), 417-443.

Brunet, Gillian, "Stimulus on the home front: The state-level effects of WWII spending," Working Paper 2018. 
Burstein, Ariel, Gordon Hanson, Lin Tian, and Jonathan Vogel, "Tradability and the labor-market impact of immigration: Theory and evidence from the United States," Econometrica, 2020, 88 (3), 1071-1112.

Card, David and Alan Krueger, "School quality and black-white relative earnings: A direct assessment," The Quarterly Journal of Economics, 1992, 107 (1), 151-200.

Carrington, William J. and Kenneth R. Troske, "On measuring segregation in samples with small units," Journal of Business and Economic Statistics, 1997, 15 (4), 402-409.

Carruthers, Celeste K. and Marianne H. Wanamaker, "Separate and unequal in the labor market: Human capital and the Jim Crow wage gap," Journal of Labor Economics, 2017, 35 (3), 655-692.

Clay, Karen, Jeff Lingwall, and Melvin Stephens, "Do schooling laws matter? Evidence from the introduction of compulsory attendance laws in the United States," Working Paper 184772012.

Collins, William, "African-American economic mobility in the 1940s: A portrait from the Palmer Survey," Journal of Economic History, 2000, 60 (3), 756-781.

_ , "Race, Roosevelt, and wartime production: Fair employment in World War II labor markets," The American Economic Review, 2001, 91 (1), 272-286.

Collins, William J., "The Great Migration of black Americans from the US South: A guide and interpretation," Working Paper 272682020.

- and Marianne H. Wanamaker, "Selection and income gains in the Great Migration of African Americans," American Economic Journal: Applied, 2014, 6 (1), 220-252.

- and Robert A. Margo, "Historical perspectives on racial differences in schooling in the United States," Working Paper 97702003.

Commission, U.S. Government War Manpower, The Labor Market, Reports and Analysis Service, 1945.

Cutler, David M., Edward L. Glaeser, and Jacob L. Vigdor, "The rise and decline of the American ghetto," Journal of Political Economy, 1999, 107 (3), 455-506.

Derenoncourt, Ellora, "Can you move to opportunity? Evidence from the Great Migration," Working Paper 2019. 
_ and Claire Montialoux, "Minimum wages and racial inequality," Working Paper 2019.

Dewey, Donald, "Negro employment in Southern industry," Journal of Political Economy, 1952, 60, 279-293.

Donohue, John J. and James Heckman, "Continuous versus episodic change: The impact of civil rights policy on the economic status of blacks," Journal of Economic Literature, 1991, 29 (4), 1603-1643.

Dornbusch, Rudiger, Stanley Fischer, and Paul A. Samuelson, "Comparative Advantage, Trade, and Payments in a Ricardian Model with a Continuum of Goods," The American Economic Review, December 1977, 67 (5), 823-839.

Duncan, Greg J. and Katherine Magnuson, "Socioeconomic status and cognitive functioning: Moving from correlation to causation," Wiley Interdisciplinary Review: Cognitive Science, 2012, 3 (3), 377-386.

Duncan, Otis and Beverly Duncan, "A methodological analysis of segregation indexes," American Sociological Review, 1955, 20 (2), 210-217.

Eckert, Fabian, Adres Gvirtz, and Michael Peters, "A consistent county-level crosswalk for US spatial data since 1790," Working Paper 2018.

Fajgelbaum, Pablo D., Eduardo Morales, Juan Carlos Suarez Serrato, and Owen Zidar, "State taxes and spatial misallocation," The Review of Economic Studies, 2019, 86 (1), 333376.

Ferrara, Andreas, “World War II and black economic progress," Working Paper 2020.

Fishback, Price and Joseph A. Cullen, "Second World War spending and local economic activity in US counties, 1939-58," The Economic History Review, 2013, 66 (4), 975-992.

Fishback, Price V., "Segregation in job hierarchies: West Virginia Coal Mining, 19061932," Journal of Economic History, 1984, 44 (3), 755-774.

- and Valentina Kachanovskaya, "The multiplier for federal spending in the states during the Great Depression," The Journal of Economic History, 2015, 75 (1), 125-162.

Foote, Christopher, Warren Whatley, and Gavin Wright, "Arbitraging a discriminatory labor market: Black workers at the Ford Motor co., 1918-1947," Journal of Labor Economics, 2003, 21 (3), 493-532. 
Frazier, Edward K. and Jacob Perlman, "Entrance rates of common laborers, July 1939," Monthly Labor Review, 1939, 46 (12), 1450-1465.

Galle, Simon, Andres Rodriguez-Clare, and Moises Yi, "Slicing the pie: Quantifying the aggregate and distributional effects of trade," Working Paper 2018.

Garin, Andy, "Public investment and the spread of 'good-paying' manufacturing jobs: Evidence from World War II's big plants," Working Paper 2019.

Goldin, Claudia, "The role of World War II in the rise of women's employment," American Economic Review, 1991, 81 (4), 741-756.

- and Lawrence Katz, "The Great Compression: The wage structure in the United States at mid-century," The Quarterly Journal of Economics, 1992, 107 (1), 1-34.

_ and _ , "Education and income in the early 20th century: Evidence from the Prairies," The Journal of Economic History, 2000, 60 (3), 782-818.

Haines, Michael R. and ICPSR, "Historical, Demographic, Economic, and Social Data: The United States, 1790-2002," 2010.

Head, Keith and Thierry Mayer, "Gravity equations: Workhorse, toolkit, and cookbook," in G. Gopinath, E. Helpman, and K. Rogoff, eds., Handbook of International Economics, Vol. 4, Elsevier, 2014, chapter 3, pp. 131-195.

Hsieh, Chang-Tai, Erik Hurst, Charles I. Jones, and Peter J. Klenow, "The allocation of talent and U.S. economic growth," Econometrica, 2019, 87 (5), 1439-1474.

Jaworski, Taylor, "World War II and the industrialization of the American South," The Journal of Economic History, 2017, 77 (4), 1048-1082.

Lafotune, Julien, Jesse Rothstein, and Diane W. Schanzenbach, "School finance reform and the distribution of student achievement," American Economic Journal: Applied Economics, 2018, 10 (2), 1-26.

Lang, Kevin and Ariella Kahn-Lang Spitzer, "Race discrimination: An economic perspective," Journal of Economic Perspectives, 2020, 34 (2), 68-89.

- and Jee-Yeon K. Lehmann, "Racial discrimination in the labor market: Theory and empirics," Journal of Economic Literature, 2012, 50 (4), 959-1006. 
Maloney, Thomas, "Wage compression and wage inequality between black and white males in the United States, 1940-1960," The Jounral of Economic History, 1994, 54 (2), 358-381.

Margo, Robert, "Explaining black-white wage convergence, 1940-1950," ILR Review, 1995, 48 (3), 470-481.

Margo, Robert A., "Explaining black-white wage convergence 1940-1950: The role of the Great Compression," Working Paper 441993.

Miller, Amalia R. and Carmit Segal, "Does temporary affirmative action produce persistent effects? A study of black and female employment in law enforcement," The Review of Economics and Statistics, 2012, 94 (4), 1107-1125.

Miller, Conrad, "The persistent effect of temporary affirmative action," American Economic Journal: Applie Economics, 2017, 9 (3), 152-190.

Reardon, Sean F., "The widening academic achievement gap between the rich and the poor: New evidence and possible explanations," in Greg J. Duncan and Richard J. Murnane, eds., Whither opportunity? Rising Inequality, Schools and Children's Life Chances, Russell Sage Foundation, 2011, chapter 5, pp. 91-116.

_ , "Education," in Charles Varner David Grusky and Marybeth Mattingly, eds., State of the States: The Poverty and Inequality Report, Stanford Center for Poverty and Inequality, 2015, chapter 7, pp. 43-48.

_, Ericka S. Weathers, Erin M. Fahle, Heewon Jang, and Demetra Kalogrides, "Is separate still unequal? New evidence on school secregation and racial academic achievement gaps," Working Paper 19-06 2019.

Rhode, Paul W., James M. Snyder Jr., and Koleman Stumpf, "The arsenal of democracy: Production and politics during WWII," Journal of Public Economics, 2018, 166, 145-161.

Rose, Evan, "The rise and fall of female labor force participation during World War II in the United States," The Journal of Economic History, 2018, 78 (3), 1-39.

Ruggles, Steven, Sarah Flood, Ronald Goeken, Josiah Grover, Erin Meyer, Jose Pacas, and Matthew Sobek, “IPUMS USA: Version 10.0 [dataset]," 2020.

Saez, Emmanuel, Benjamin Schoefer, and David Seim, "Hysteresis from employer subsidies," Working Paper 263912019. 
Schindler, David and Mark Westcott, "Shocking racial attitudes: Black GIs in Europe," Working Paper 67232017.

Sitkoff, Harvard, "Racial militancy and interracial violence in the Second World War," The Journal of American History, 1971, 58 (3), 661-681.

Small, Mario L. and Devah Pager, "Sociological perspectives on racial discrimination," Journal of Economic Perspectives, 2020, 34 (2), 49-67.

Smith, James and Finis Welch, "Black economic progress after Myrdal," Journal of Economic Literature, 1989, 27 (2), 519-564.

Sundstrom, William A., "The color line: Racial norms and discrimination in urban labor markets, 1910-1950," The Journal of Economic History, 1994, 54 (2), 382-396.

System, U.S. Selective Service, Special Monographs of the Selective Service System, Washington, D.C.: Government Printing Office, 1956.

Taubman, Paul, "Role of Parental Income in Educational Attainment," The American Economic Review, 1989, 79 (2), 57-61.

Turner, Sarah E. and John Bound, "Closing the gap or widening the divide: The effects of the G.I. Bill and World War II on the educational outcomes of black americans," Journal of Economic History, 2003, 63 (1), 145-177.

Whatley, Warren, "Getting a foot in the door: Learning, state dependence, and the racial integration of firms," The Journal of Economic History, 1990, 50 (1), 43-66.

Wilson, Charles A, "On the General Structure of Ricardian Models with a Continuum of Goods: Applications to Growth, Tariff Theory, and Technical Change," Econometrica, November 1980, 48 (7), 1675-1702.

Wright, Gavin, Old South New South: Revolutions in the Southern economy since the Civil War, Basic Books, 1986.

Wynn, Neil A., The Afro American and the Second World War, Holmes and Meier Publishers, 1976. 
Figure 1: Long-term trends in Black-White gaps

Panel A: Share in skilled occupations

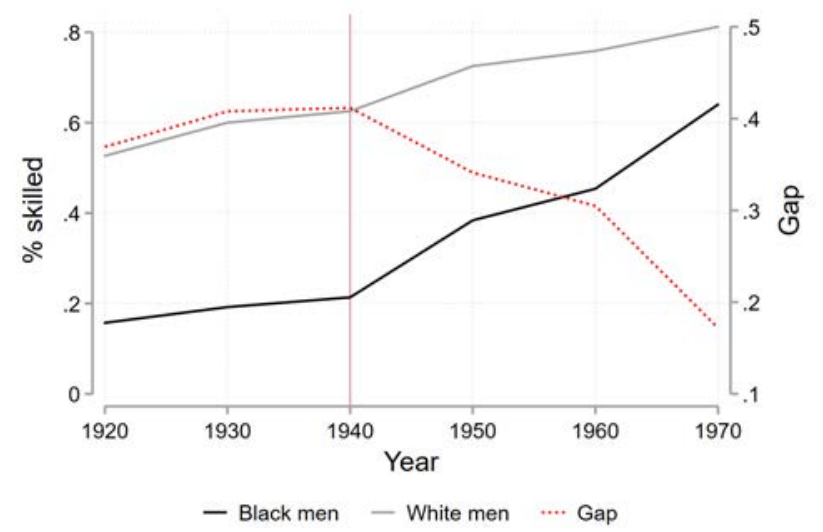

Panel B: Average (log of) wages

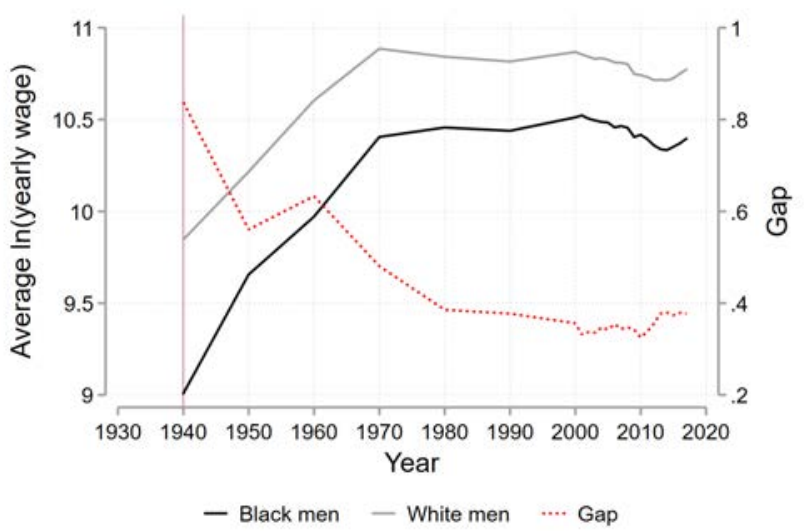

Panel C: Share graduating HS

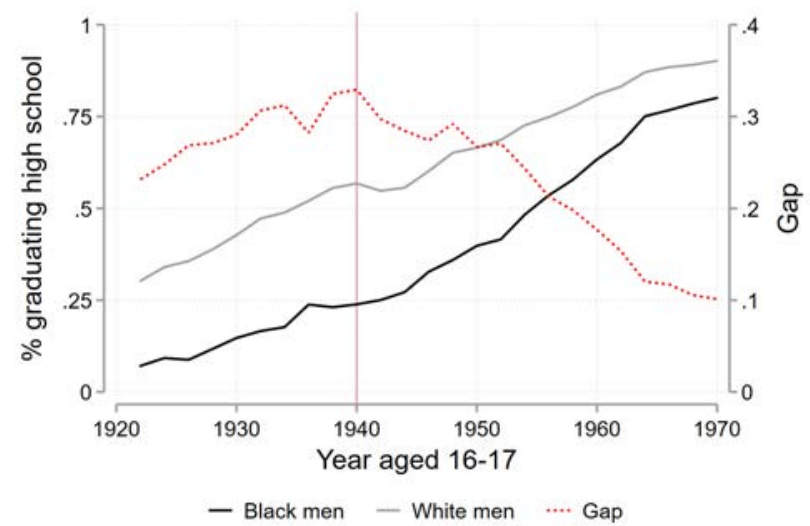

Note: Share skilled is the share of employed men who are not farmers, laborers, or service workers. Wages are total wage earnings (2017 dollars) in the previous year for men ages 25-54 who are currently employees. Share graduating high school is based on share completing at least twelve years of school by age 35. Data from Census and ACS samples for 1920-2017 accessed from IPUMS (Ruggles et al. 2020). 
Figure 2: WWII expenditures per capita $(\$ 1000 s, 1940)$

Panel A: By metro

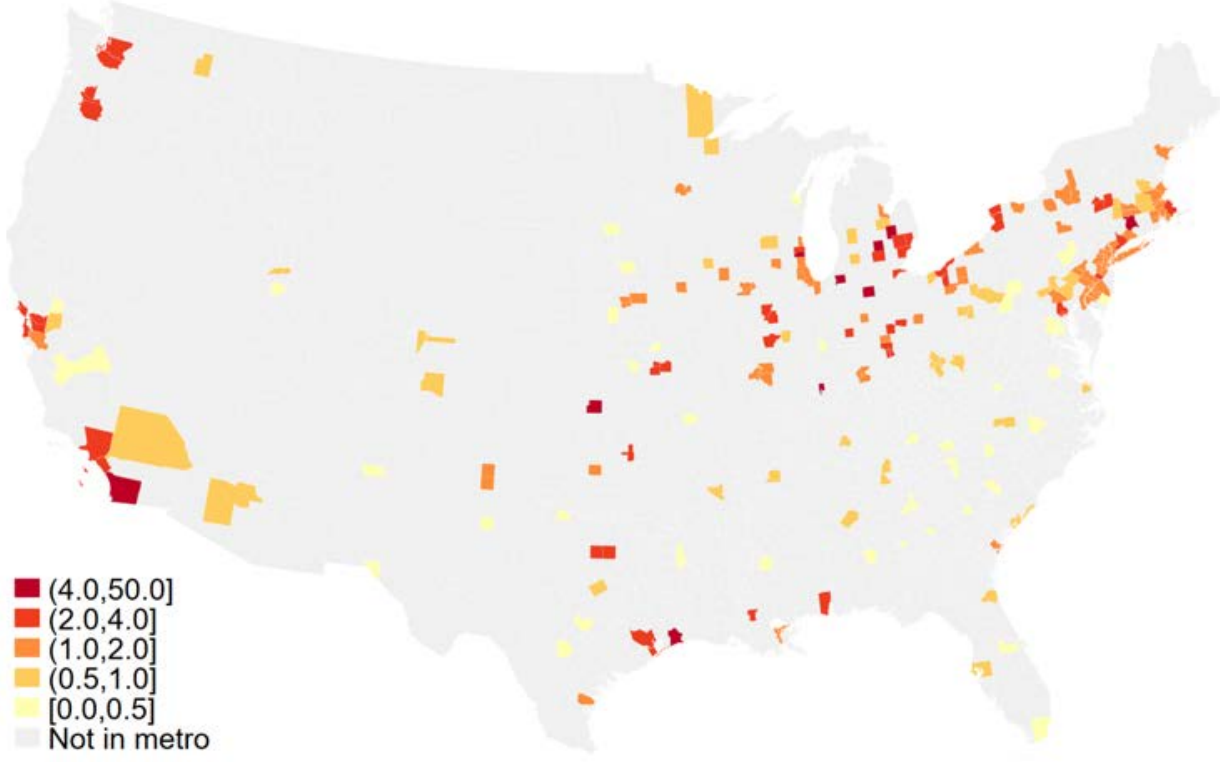

Panel B: By county

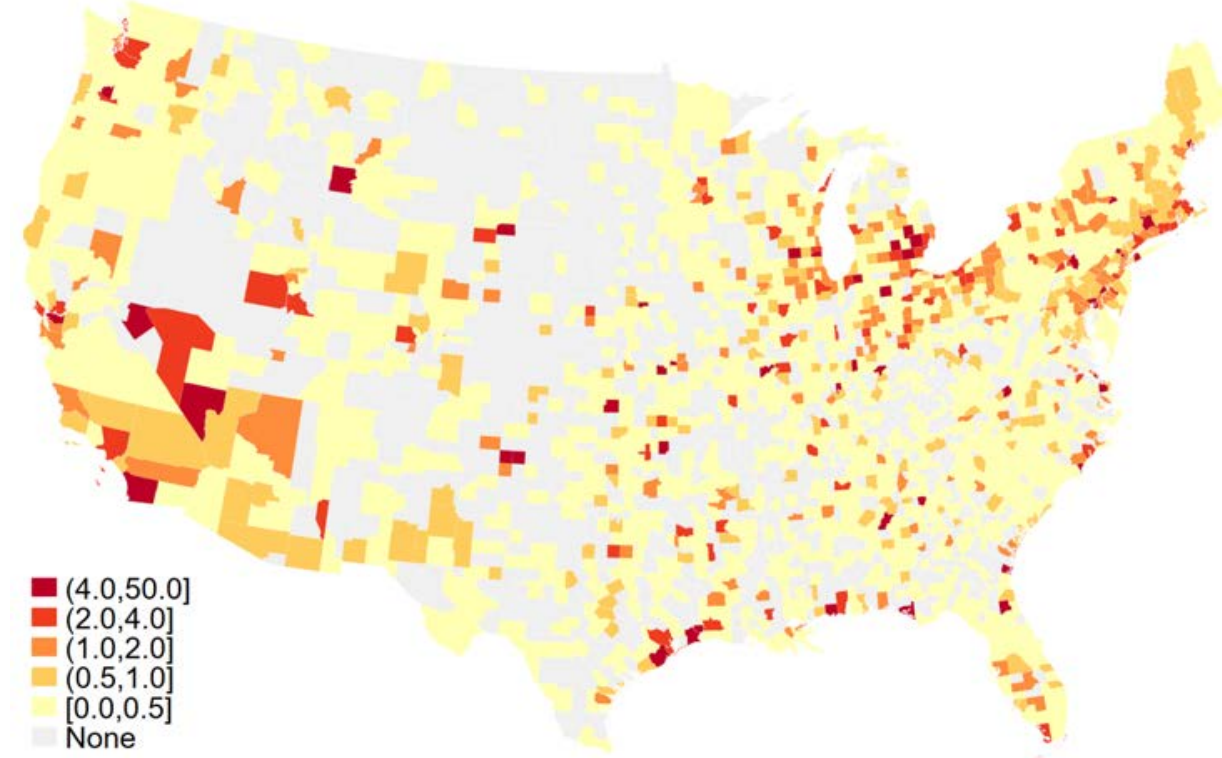

Note: Includes 147 metropolitan areas areas which are county groupings based on 1950 Census definitions. The primary qualification is containing a city with population above 50,000 . $55 \%$ of the population live in metropolitan areas in 1950. War expenditures per capita are total war expenditures divided by the 1940 population. Total war expenditures comes from the 1947 County Data Book. The mean war expenditure across metropolitan areas is $\$ 1,457$ with standard deviation of $\$ 1,371$ (1940 dollars). 
Figure 3: Distribution of WWII expenditures per capita by metropolitan area $(\$ 1000$ s, 1940)

Panel A: Raw distribution

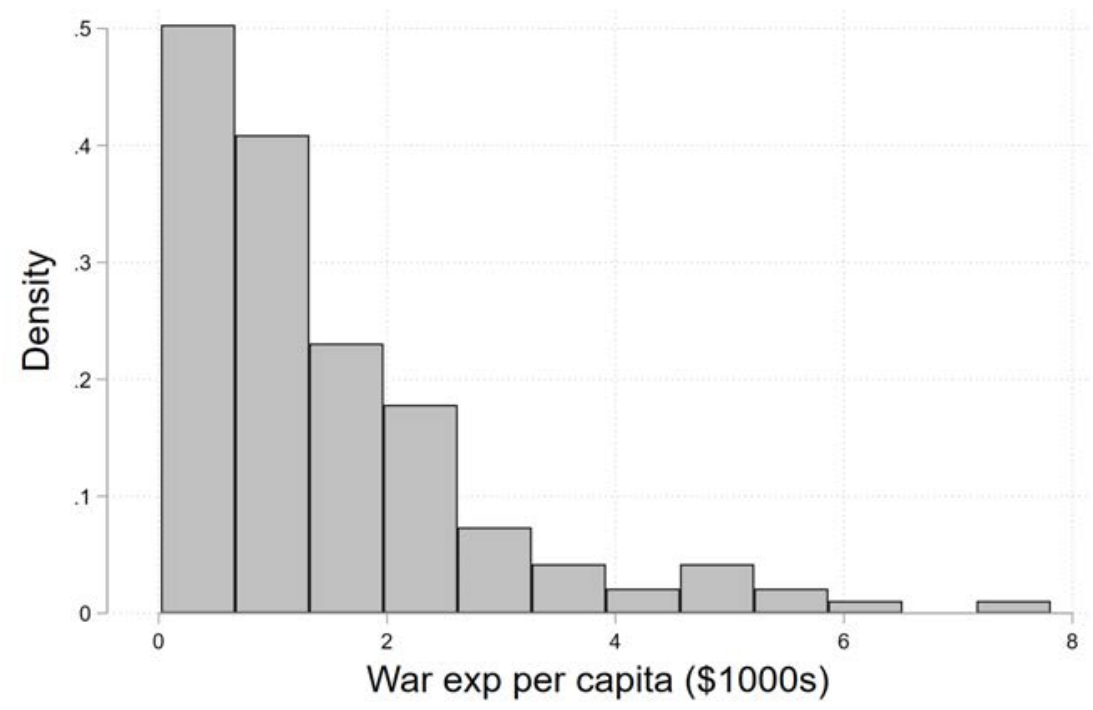

Panel B: Residualized

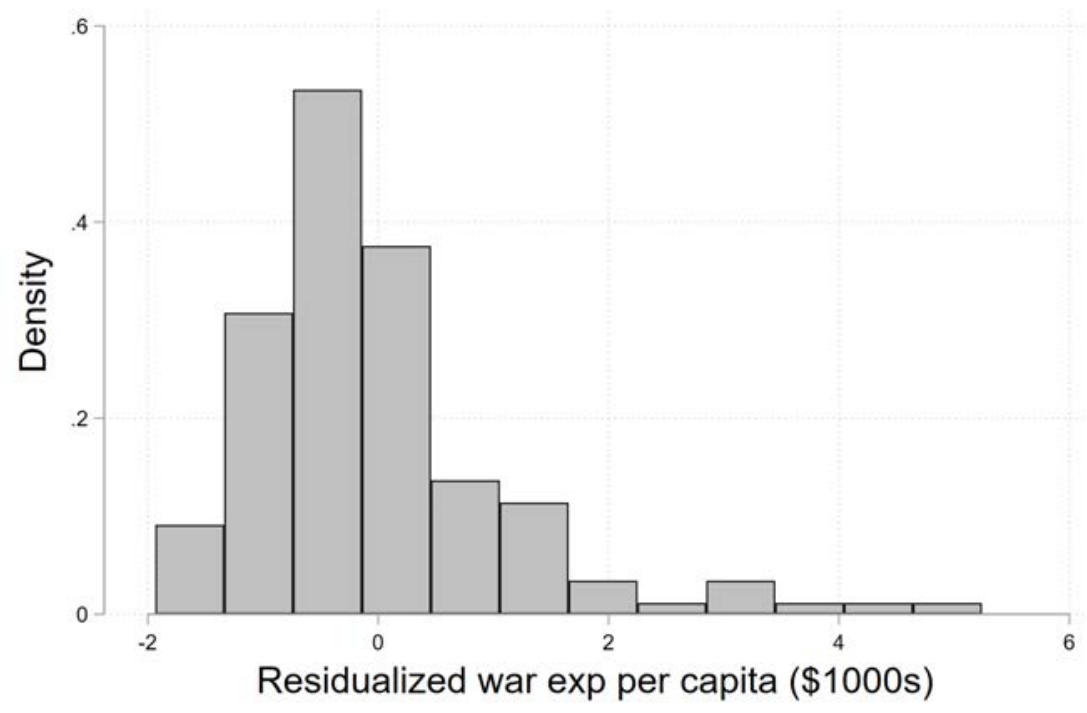

Note: Includes 147 metropolitan areas which are county groupings based on 1950 Census definitions. War expenditures per capita are total war expenditures divided by the 1940 population. Controls include region fixed effects, share of employed men in manufacturing, in agriculture, share Black, and predicted draft rate based on demographics. Total war expenditures comes from the 1947 County Data Book. The mean war expenditure across metropolitan areas is $\$ 1,457$ with standard deviation of $\$ 1,371$ (1940 dollars). 
Figure 4: Raw changes in outcomes by metro area

Panel A: Share in skilled occupations
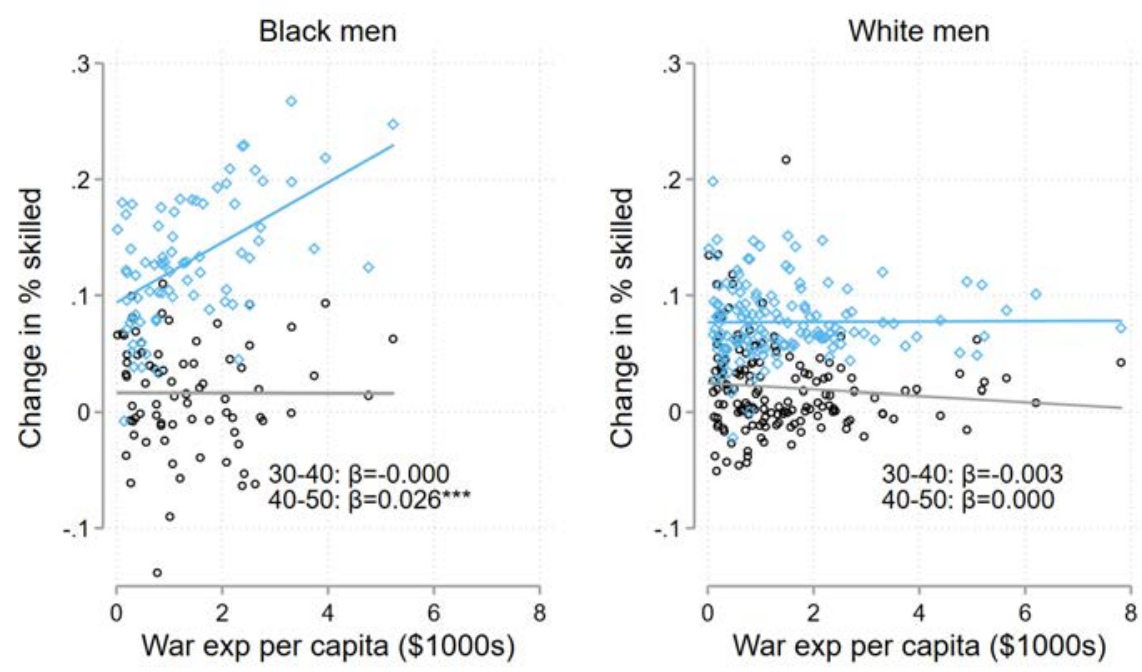

- Change 1930-40 $\diamond$ Change 1940-1950

Panel B: $\ln ($ Average yearly wage)
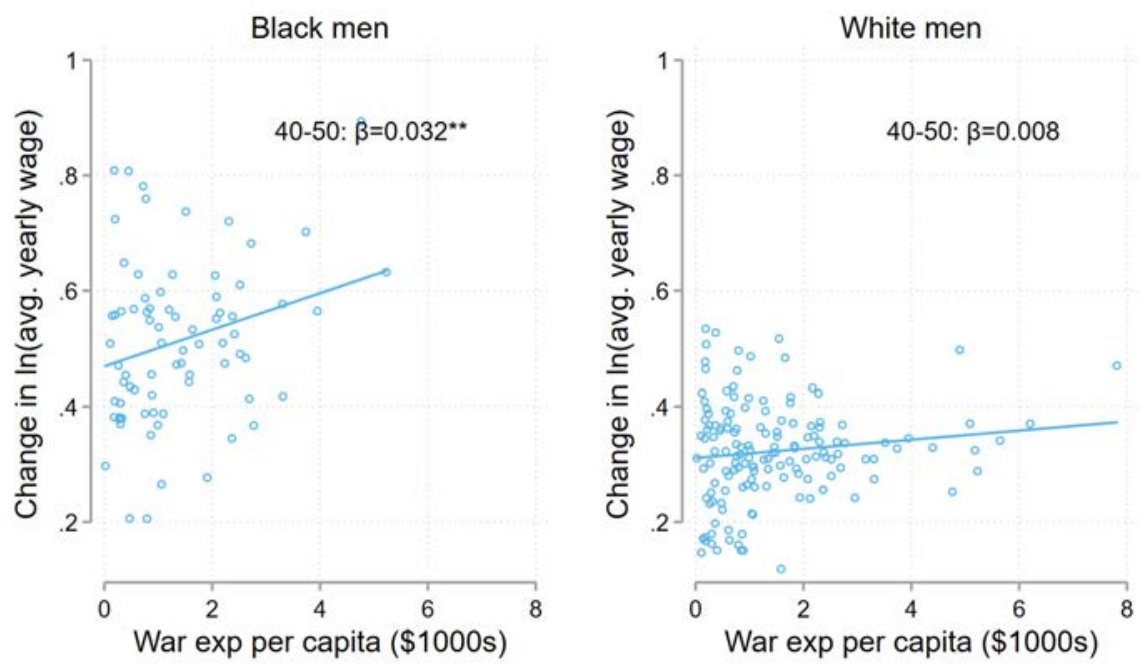

- Change 1940-1950

Note: Each point represents a metropolitan area. We restrict focus to metropolitan areas with a relevant population in all years of at least 2500 (equivalent to at least 25 observations in the $1 \%$ Census sample) which leaves 147 metropolitan areas for white men and 76 metropolitan areas for Black men. Regressions do not include any controls or weights. Results are qualitatively similar if population weights are used on the full sample. Share skilled is the share of employed men who are not farmers, laborers, or service workers. Average yearly wage is the average wage earnings (1940 dollars) in the previous year for men who are currently employees. There is no wage data in the 1930 Census. Data is from 1930 Census (5\%), 1940 Census (100\%) and 1950 Census (1\%) samples. Significance levels based on robust standard errors. ${ }^{*} \mathrm{p}<.1$; ${ }^{* *} \mathrm{p}<.05 ;{ }^{* * *} \mathrm{p}<.01$ 


\section{Figure 5: Robustness of effects of war expenditures on main outcomes}

Panel A: Share in skilled occupations

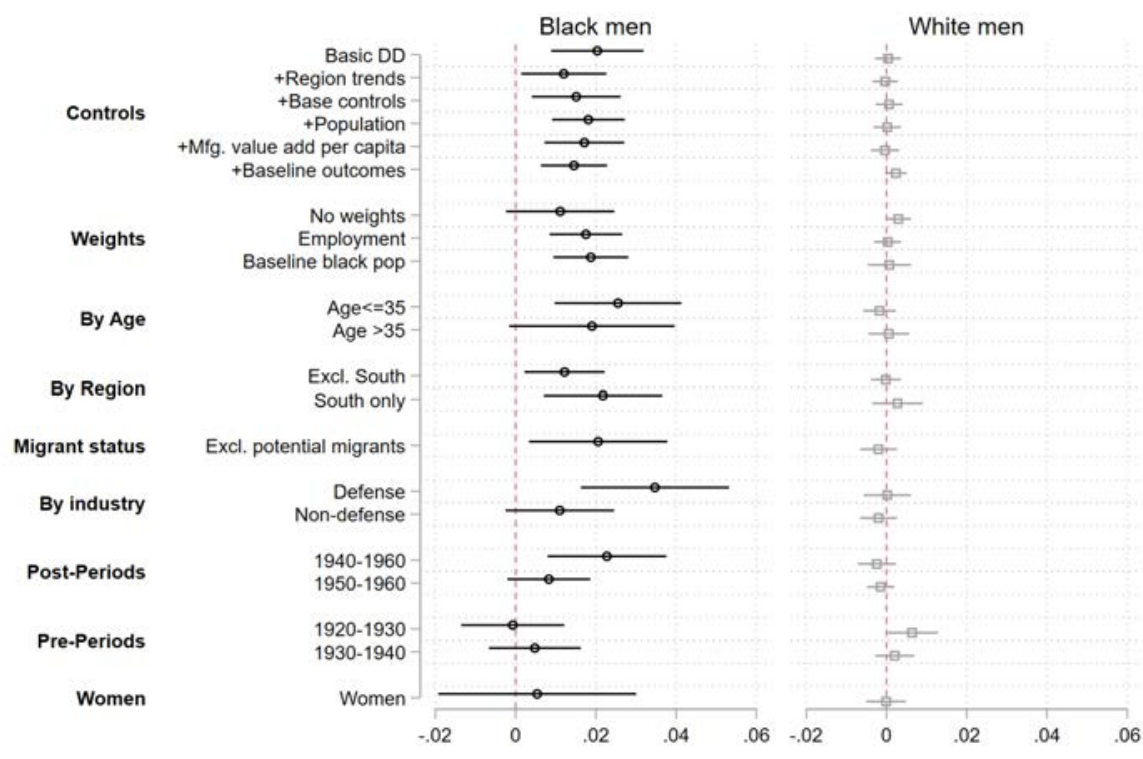

Panel B: $\ln ($ Average yearly wage)

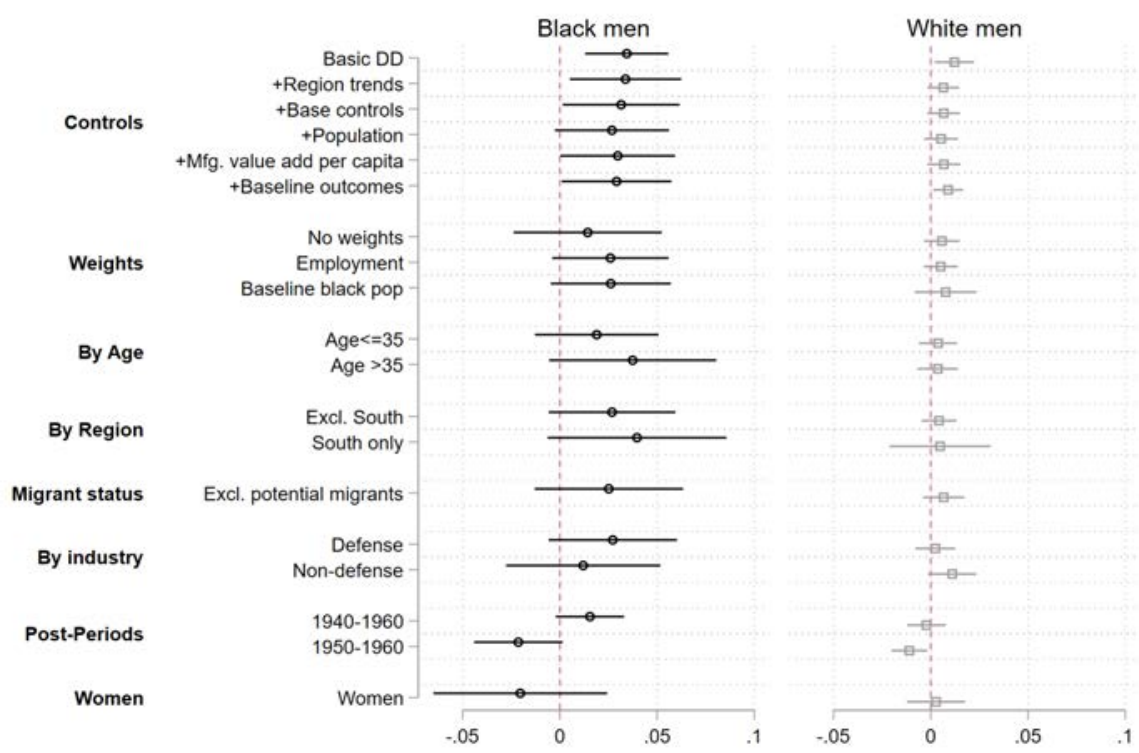

Note: See equation 1 for the basic specification. Intervals are 95\% confidence intervals. All controls are interacted with an indicator for post. "+Base controls" is our standard specification with controls for region, average years of education, share in manufacturing, share in agriculture, share Black, and predicted draft rate. "+Population" adds controls for the (log of) total population and Black popuation in 1940. "+Baseline outcomes" adds controls for 1940 share employed, share skilled, and (log of) average yearly wage. "Excl. potential migrants" means excluding individuals in 1950 who were not born in their current state of residence and is not living with a child eight years or older born in the current state of residence. There are 147 metropolitan areas and data comes from the 1920-1960 Census samples. 
Figure 6: Long-term impacts of war expenditures (1920-1970)

Panel A: Share in skilled occupations

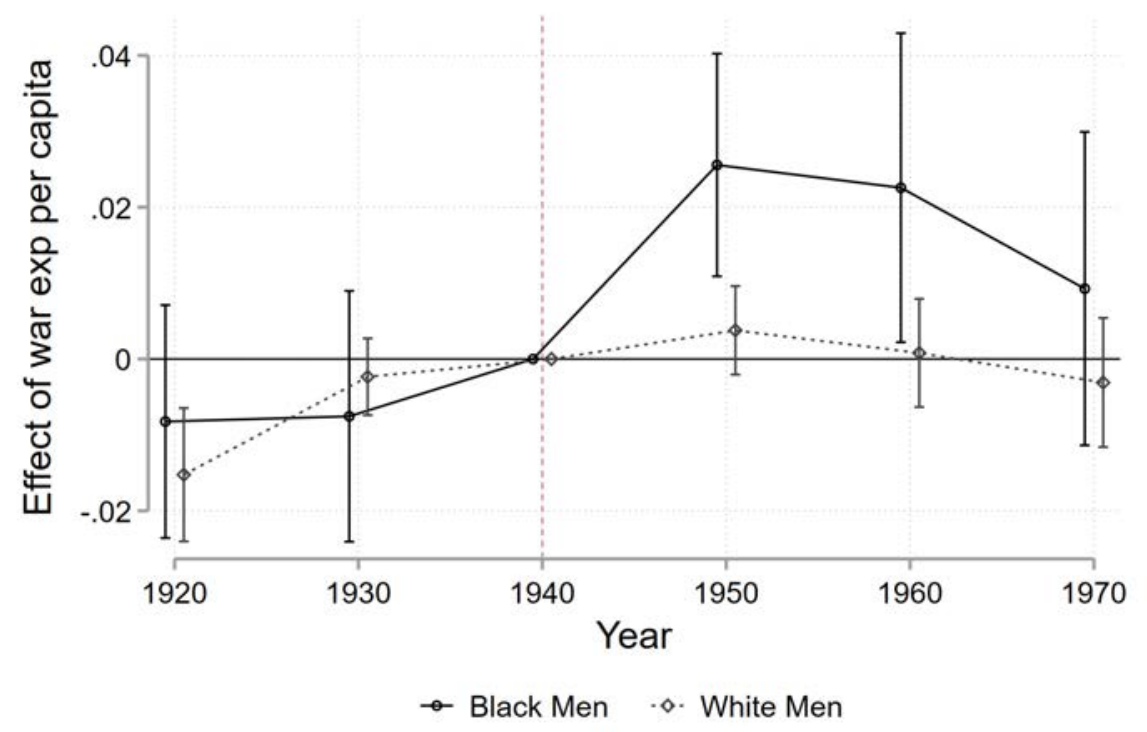

Panel B: $\ln ($ Average yearly wage)

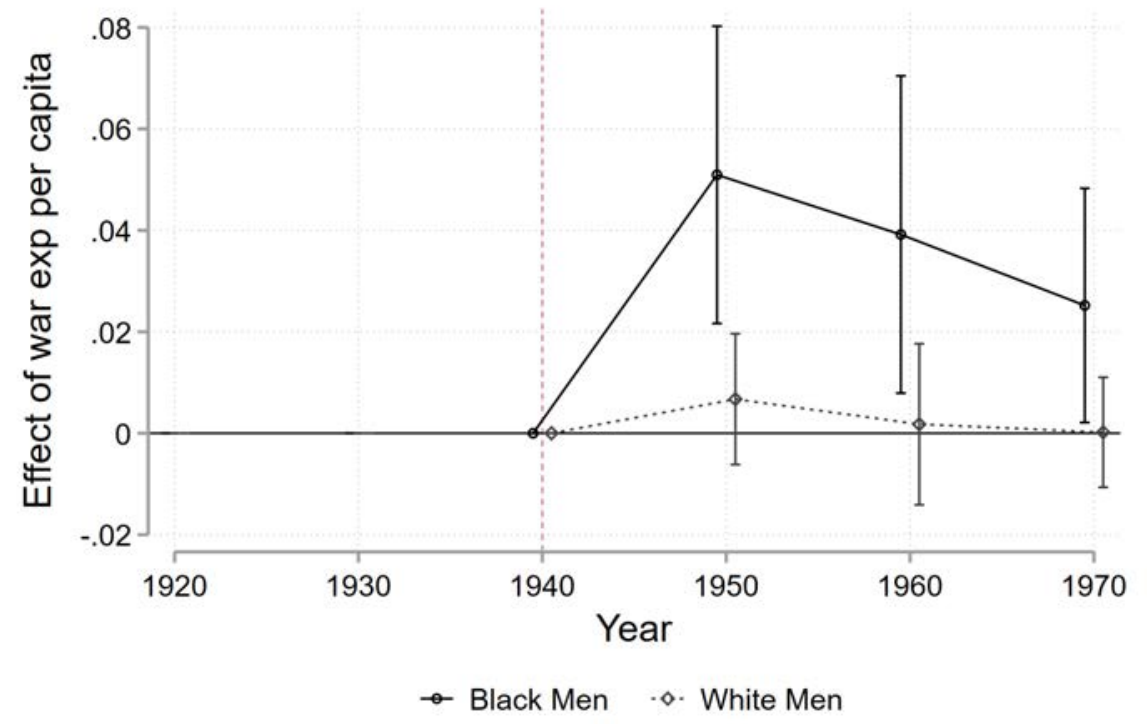

Note: See equation 2 for the basic specification; regressions are run separately for Black and white men but the coefficients are plotted on the same graph. Controls include aggregate Census division, share employed in manufacturing, share employed in agriculture, share Black, years of education in the first available year; each is interacted with a full set of year indicators; omitting the base year (1940). Commuting zone boundaries for metropolitan areas are used instead of 1940 and 1950 metropolitan area definitions due to changing metropolitan area boundaries over time. This results in some metropolitan areas being combined or dropped leaving 135 commuting zones. Data comes from the 1920-1970 Census samples. 
Figure 7: Effects of war expenditures on high school graduation rates Panel A: Boys

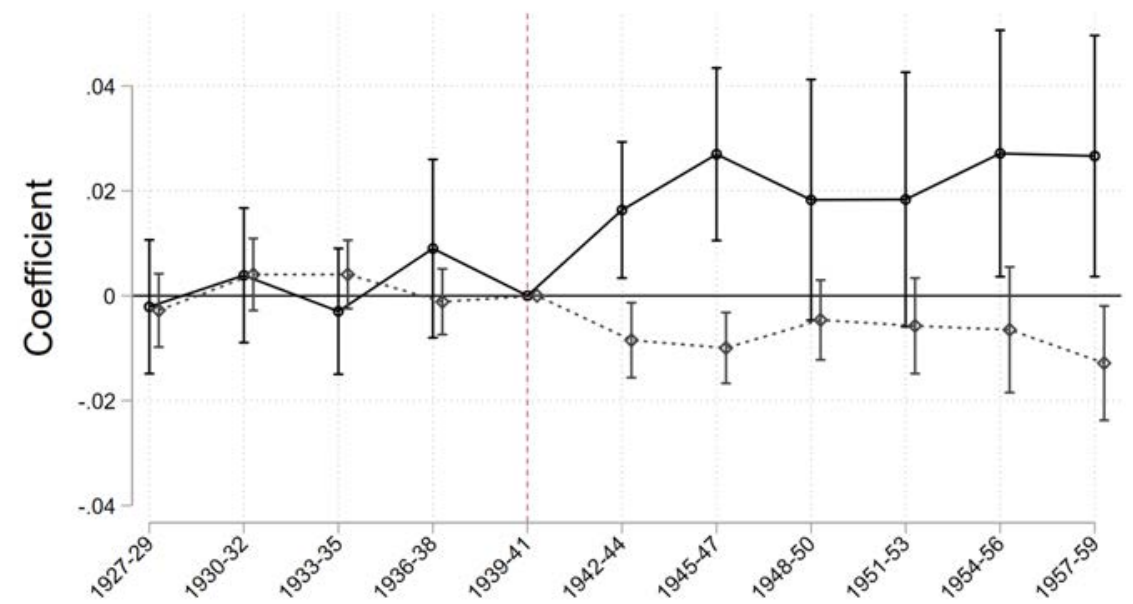

High school graduation year

๑- War exp * Black ๑. War exp

Panel B: Girls

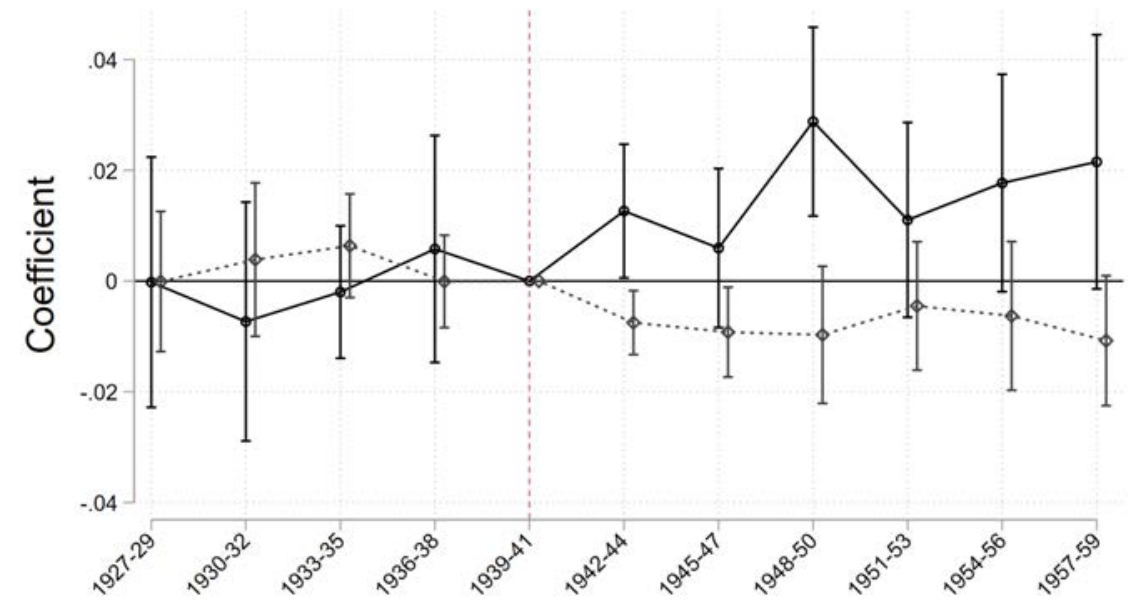

High school graduation year

- War exp*Black ๑. War exp

Note: See equation 12 for the estimating equation. Intervals are $95 \%$ confidence intervals. Cohorts grouped by expected graduation year and excludes the South and individuals not living in metropolitan areas or who have moved to a state other than their birth state in the previous five years. Graduating high school is defined as having completed 12 years of schooling in 1960. Fixed effects include metro-race FE and cohort-race FE. Other controls interacted with race include indicators for whether born in the South interacted with race and cohort indicators. Results are similar if controls for veteran status are included. Data comes from the 1960 Census (5\% sample). 
Table 1: Predictors of per capita war expenditure

\begin{tabular}{|c|c|c|}
\hline & $\begin{array}{c}(1) \\
\text { War exp } \\
\text { per capita }\end{array}$ & $\begin{array}{c}(2) \\
\text { Months of labor shortages } \\
1942-44 \\
\end{array}$ \\
\hline War exp per capita & & $\begin{array}{c}0.457^{* * *} \\
(0.103)\end{array}$ \\
\hline Predicted draft rate & $\begin{array}{c}-0.167^{* *} \\
(0.066)\end{array}$ & $\begin{array}{c}0.175^{*} \\
(0.090)\end{array}$ \\
\hline $\ln ($ Avg yearly wage $)$ & $\begin{array}{c}0.046 \\
(0.141)\end{array}$ & $\begin{array}{l}-0.145 \\
(0.134)\end{array}$ \\
\hline$\%$ Agriculture & $\begin{array}{c}0.016 \\
(0.149)\end{array}$ & $\begin{array}{c}-0.215 \\
(0.140)\end{array}$ \\
\hline$\%$ Government & $\begin{array}{c}0.096 \\
(0.156)\end{array}$ & $\begin{array}{c}0.247^{* * *} \\
(0.079)\end{array}$ \\
\hline$\%$ Manufacturing & $\begin{array}{l}0.388^{* *} \\
(0.152)\end{array}$ & $\begin{array}{c}0.130 \\
(0.112)\end{array}$ \\
\hline $\ln$ (Mfg. value added per capita) & $\begin{array}{l}0.153^{*} \\
(0.083)\end{array}$ & $\begin{array}{c}0.087 \\
(0.099)\end{array}$ \\
\hline \% Skilled & $\begin{array}{c}0.139 \\
(0.183)\end{array}$ & $\begin{array}{l}-0.017 \\
(0.156)\end{array}$ \\
\hline \% Unemployed & $\begin{array}{l}-0.029 \\
(0.102)\end{array}$ & $\begin{array}{l}-0.148^{*} \\
(0.082)\end{array}$ \\
\hline$\%$ Black & $\begin{array}{c}0.033 \\
(0.073)\end{array}$ & $\begin{array}{c}0.164 \\
(0.115)\end{array}$ \\
\hline $\ln$ (Population) & $\begin{array}{l}-0.029 \\
(0.077)\end{array}$ & $\begin{array}{c}0.047 \\
(0.091)\end{array}$ \\
\hline Northeast & $\begin{array}{c}0.018 \\
(0.103)\end{array}$ & $\begin{array}{c}0.011 \\
(0.106)\end{array}$ \\
\hline Midwest & $\begin{array}{c}0.029 \\
(0.154)\end{array}$ & $\begin{array}{c}0.073 \\
(0.113)\end{array}$ \\
\hline West & $\begin{array}{c}0.110 \\
(0.100)\end{array}$ & $\begin{array}{c}0.372^{* * *} \\
(0.105)\end{array}$ \\
\hline Observations & 147 & 132 \\
\hline R-squared & 0.33 & 0.45 \\
\hline
\end{tabular}

Note: An observation is a metro area and all variables are as of 1940 and have been standardized to have $\mu=0$ and $\sigma^{2}=1$. Percentages are shares of employed men except for \% unemployed which is the share of men in the labor force. Omitted aggregate Census division category is the South. War expenditure per capita in 1940 dollars. Months of labor shortages are percentage of months 1942-1944 with acute labor shortages according to Labor Market Reports. Only 132 of the 147 metro areas are identified in these reports. Robust standard errors in parentheses. ${ }^{*} \mathrm{p}<.1 ;{ }^{* *} \mathrm{p}<.05 ;{ }^{* * *} \mathrm{p}<.01$ 
Table 2: Effect of war expenditures (1940-1950)

\begin{tabular}{|c|c|c|c|c|}
\hline & (1) & (2) & (3) & (4) \\
\hline & \multicolumn{2}{|c|}{ Black Men } & \multicolumn{2}{|c|}{ White Men } \\
\hline & Basic & Controls & Basic & Controls \\
\hline \multicolumn{5}{|l|}{ Panel A: Share skilled } \\
\hline \multirow[t]{2}{*}{ War exp per capita * Post } & $0.012^{* *}$ & $0.015^{* * *}$ & -0.000 & 0.001 \\
\hline & $(0.005)$ & $(0.006)$ & $(0.002)$ & $(0.002)$ \\
\hline Mean Y - 1940 & 0.33 & 0.33 & 0.77 & 0.77 \\
\hline Mean Y - 1950 & 0.48 & 0.48 & 0.83 & 0.83 \\
\hline \multicolumn{5}{|c|}{ Panel B: $\ln ($ Average yearly wage) } \\
\hline \multirow[t]{2}{*}{ War exp per capita * Post } & $0.035^{* *}$ & $0.031^{* *}$ & 0.006 & 0.007 \\
\hline & $(0.015)$ & $(0.015)$ & $(0.004)$ & $(0.004)$ \\
\hline Mean Y - 1940 & 6.55 & 6.55 & 7.26 & 7.26 \\
\hline Mean Y - 1950 & 7.06 & 7.06 & 7.56 & 7.56 \\
\hline \multicolumn{5}{|c|}{ Panel C: Prime-age employment rate } \\
\hline \multirow[t]{2}{*}{ War exp per capita * Post } & -0.005 & -0.006 & $-0.004^{* *}$ & $-0.003^{*}$ \\
\hline & $(0.005)$ & $(0.006)$ & $(0.002)$ & $(0.002)$ \\
\hline Mean Y - 1940 & 0.80 & 0.80 & 0.88 & 0.88 \\
\hline Mean Y - 1950 & 0.84 & 0.84 & 0.92 & 0.92 \\
\hline Metro areas & 147 & 147 & 147 & 147 \\
\hline Mean war exp per capita & 1.46 & 1.46 & 1.46 & 1.46 \\
\hline Metro FE & $X$ & $\mathrm{X}$ & $X$ & $\mathrm{X}$ \\
\hline Division-Year FE & $X$ & $X$ & $X$ & $X$ \\
\hline Baseline controls & - & $X$ & - & $X$ \\
\hline Draft control & - & $X$ & - & $X$ \\
\hline
\end{tabular}

Note: Sample is 147 metro areas. See equation 1 for the basic specification. War expenditure is $\$ 1000$ s per capita. Share skilled is the share of employed men who are not farmers, laborers, or service workers. Wages are total wage earnings in the previous year for men who are currently employees. Prime-age employment is the share of men ages 25-54 who are employed. Baseline controls are 1940 variables interacted with a post indicator: average years of education, share employed in manufacturing, share employed in agriculture, and share Black. Draft control is predicted draft rate based on 1940 demographics. Primary data sources are 1940 (100\%; 5\% sub-sample for whites) and 1950 (1\%) Census samples. Metro area definitions are based on 1940 and 1950 Census Bureau definitions. All values are in 1940 dollars. Regressions are weighted by relevant population. Robust standard errors in parentheses. ${ }^{*} \mathrm{p}<.1 ;{ }^{* *} \mathrm{p}<.05 ;{ }^{* * *} \mathrm{p}<.01$ 
Table 3: Effect of war expenditures excluding potential interstate migrants (19401950)

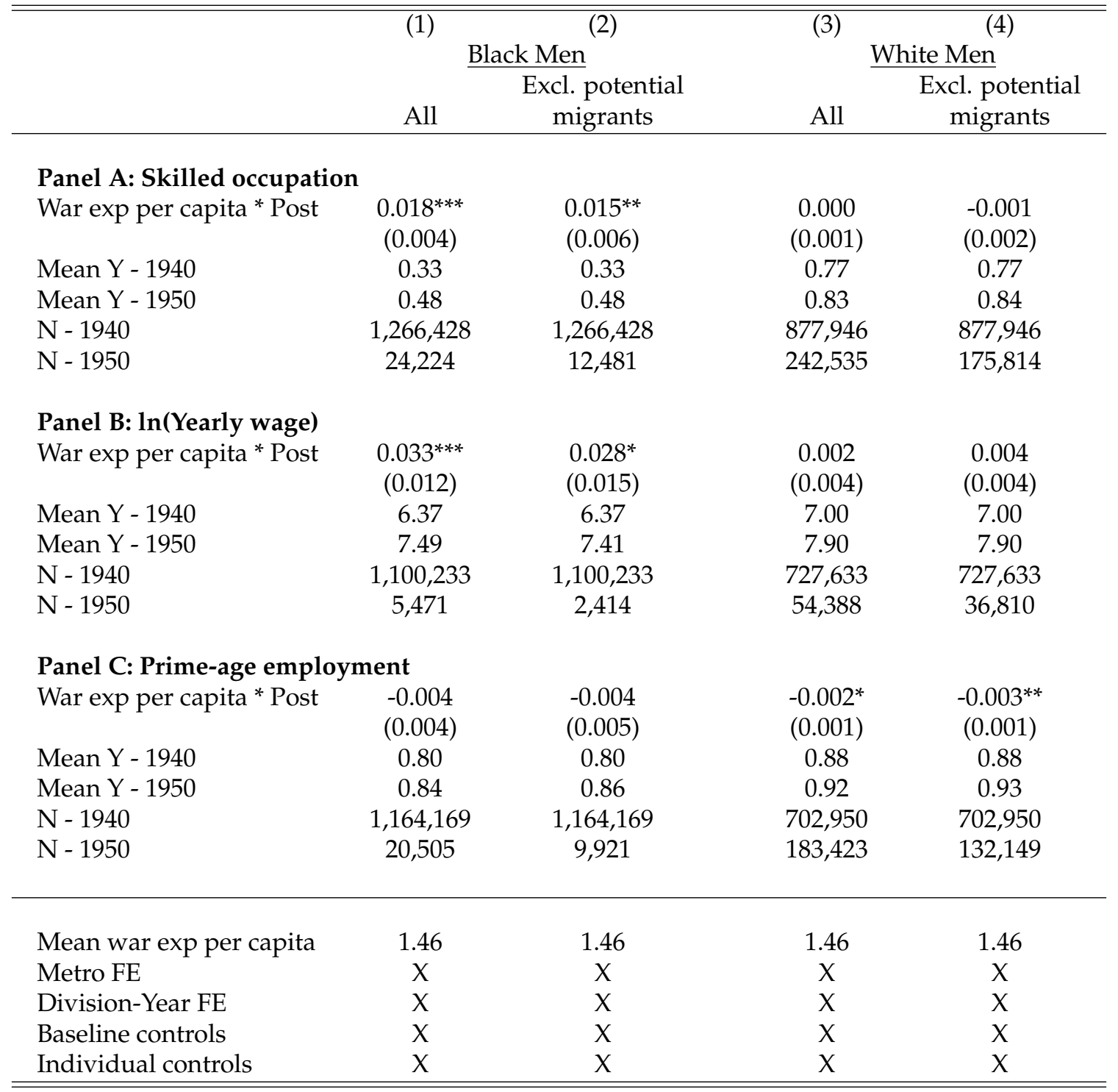

Note: Regression at the individual level and only includes men living in one of 147 metro areas. See equation 1 for the basic specification. War expenditure is $\$ 1000$ s per capita. Excluding potential interstate migrants means excluding individuals in 1950 who were not born in their current state of residence and is not living with a child eight years or older born in the current state of residence. For employed men, a skilled occupation is defined as all occupations except farmers, laborers, or service workers. Wages are total wage earnings (1940 dollars) in the previous year for men who are currently employees. Prime-age employment is whether men ages 25-54 are employed. Baseline controls are 1940 variables interacted with a post indicator: average years of education, share employed in manufacturing, share employed in agriculture, and share Black. Individual controls include a cubic in age, whether born in the South, and whether married. Primary data sources are 1940 (100\%; 5\% sub-sample for whites) and 1950 (1\%) Census samples. All values are in 1940 dollars. Regressions weighted by sampling weights. Standard errors clustered at the metro-year level. ${ }^{*} \mathrm{p}<.1{ }^{* *} \mathrm{p}<.05 ;{ }^{* * *} \mathrm{p}<.01$ 


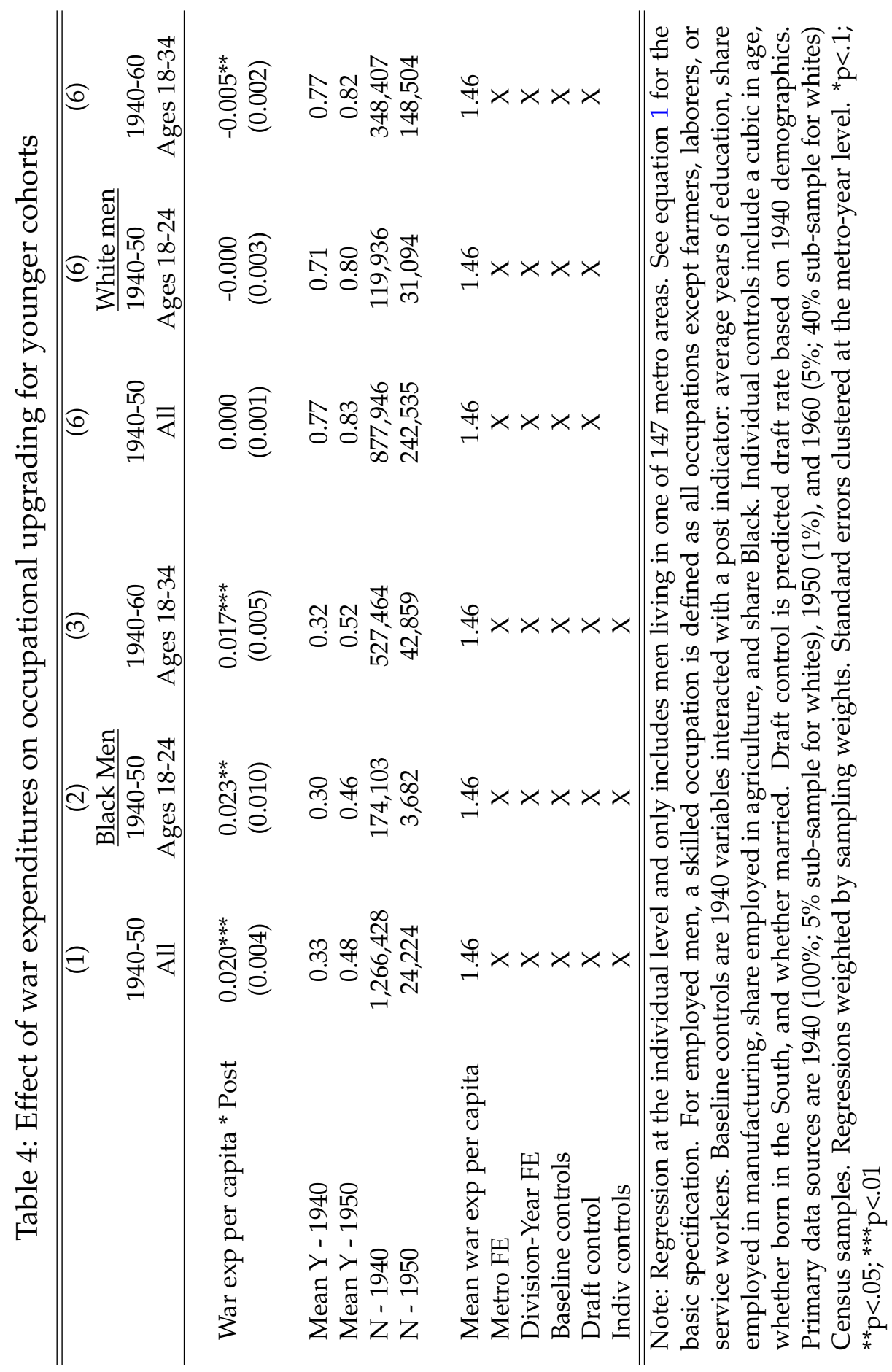


Table 5: Estimation of model shocks

\begin{tabular}{|c|c|c|c|c|c|c|c|c|c|}
\hline & (1) & (2) & (3) & (4) & (5) & \multirow{2}{*}{$e^{(6)}$} & \multicolumn{3}{|c|}{$\begin{array}{lll}(7) & (8) & (9)\end{array}$} \\
\hline & \multicolumn{2}{|c|}{ Labor allocation - io } & \multicolumn{3}{|c|}{$\underline{\text { Adjusted labor income }}$} & & \multirow{2}{*}{\multicolumn{3}{|c|}{$\frac{\text { Labor allocation - } \mathrm{r}}{\frac{1}{v} \ln \pi_{r g t}^{N}-\ln \text { Wage }_{\text {rgt }}}$}} \\
\hline & $\ln \pi_{\text {riogt }}^{L, e m p l}$ & $\ln \pi_{\text {riogt }}^{L, \text { wage }}$ & riot & riot & rit & rit & & & \\
\hline$\beta_{1}$ & & & & & $\begin{array}{c}-\mathbf{0 . 0 1 7} \\
(0.018)\end{array}$ & $\begin{array}{l}-0.006 \\
(0.117)\end{array}$ & & & \\
\hline$\beta_{2}$ & & & $\begin{array}{c}\mathbf{0 . 0 5 2} \\
(0.120)\end{array}$ & $\begin{array}{c}0.033 \\
(0.123)\end{array}$ & & $\begin{array}{c}0.042 \\
(0.123)\end{array}$ & & & \\
\hline$\beta_{3}$ & $\begin{array}{c}\mathbf{0 . 0 2 3} \\
(0.038)\end{array}$ & $\begin{array}{c}0.029 \\
(0.037)\end{array}$ & & $\begin{array}{l}-0.104 \\
(0.090)\end{array}$ & & $\begin{array}{l}-0.054 \\
(0.095)\end{array}$ & & & \\
\hline$\beta_{4}$ & $\begin{array}{c}\mathbf{0 . 1 2 7}^{* * * *} \\
(0.045)\end{array}$ & $\begin{array}{l}0.123^{* * *} \\
(0.051)\end{array}$ & & $\begin{array}{l}0.223^{* *} \\
(0.089)\end{array}$ & & $\begin{array}{l}0.207^{* *} \\
(0.089)\end{array}$ & & & \\
\hline$\beta_{1}^{U}$ & & & & & & & & $\begin{array}{c}-\mathbf{0 . 0 1 1} \\
(0.008)\end{array}$ & $\begin{array}{l}-0.010 \\
(0.008)\end{array}$ \\
\hline$\beta_{2}^{U}$ & & & & & & & $\begin{array}{c}\mathbf{0 . 0 7 0}^{* * *} \\
(0.025)\end{array}$ & & $\begin{array}{l}0.054^{* *} \\
(0.024)\end{array}$ \\
\hline Observations & 3,630 & 3,514 & 3,728 & 3,728 & 3,728 & 3,728 & 1,070 & 1,070 & 1,070 \\
\hline R-squared & 0.991 & 0.991 & 0.999 & 0.999 & 0.994 & 0.994 & 0.998 & 0.996 & 0.996 \\
\hline$\gamma_{\text {riog }}$ & $x$ & $x$ & $x$ & X & $X$ & $x$ & - & - & - \\
\hline$\gamma_{\text {iogt }}$ & $x$ & $X$ & $X$ & $x$ & $x$ & $x$ & - & - & - \\
\hline$\gamma_{\text {riot }}$ & $x$ & $X$ & - & - & - & - & - & - & - \\
\hline$\gamma_{r g t}$ & 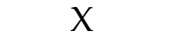 & $X$ & - & - & - & - & - & - & - \\
\hline$\gamma_{\text {rit }}$ & - & - & $X$ & $x$ & - & - & - & - & - \\
\hline$\gamma_{r g}$ & - & - & - & - & - & - & $x$ & $x$ & $X$ \\
\hline$\gamma_{g t}$ & - & - & - & - & - & - & X & $x$ & $X$ \\
\hline$\gamma_{r t}$ & - & - & - & - & - & - & $X$ & - & - \\
\hline Draft control & - & - & - & - & - & - & - & $\mathrm{X}$ & $\mathrm{X}$ \\
\hline
\end{tabular}

Note: Baseline parameter values are bolded. An observation is an $r, i, o, t, g$ cell and only includes individuals living in metro areas. Columns 1 and 2 estimate (10) using employment (1) and income (2) to measure allocations across io within $r$. Columns 3 and 4 estimate (48) and (47); the column heading riot refers to the dependent variable being an adjusted measure of labor income at the riot level. Columns 5 and 6 estimate (51) and (50); the column heading rit refers to the dependent variable being an adjusted measure of labor income at the rit level. Column 7 estimates (11), column 8 estimates (45), and column 9 estimates (44). Predicted draft rate is based on 1940 demographics. Primary data sources are 1940 (100\%) and $1950(1 \%)$ Census samples. Regressions weighted by cell population. Standard errors clustered at the metro-year level. ${ }^{*} \mathrm{p}<.1 ;{ }^{* *} \mathrm{p}<.05 ;{ }^{* * *} \mathrm{p}<.01{ }^{*} \mathrm{p}<.1 ;{ }^{* *} \mathrm{p}<.05 ;{ }^{* * *} \mathrm{p}<.01$ 
Table 6: Evaluating actual estimated changes versus model data

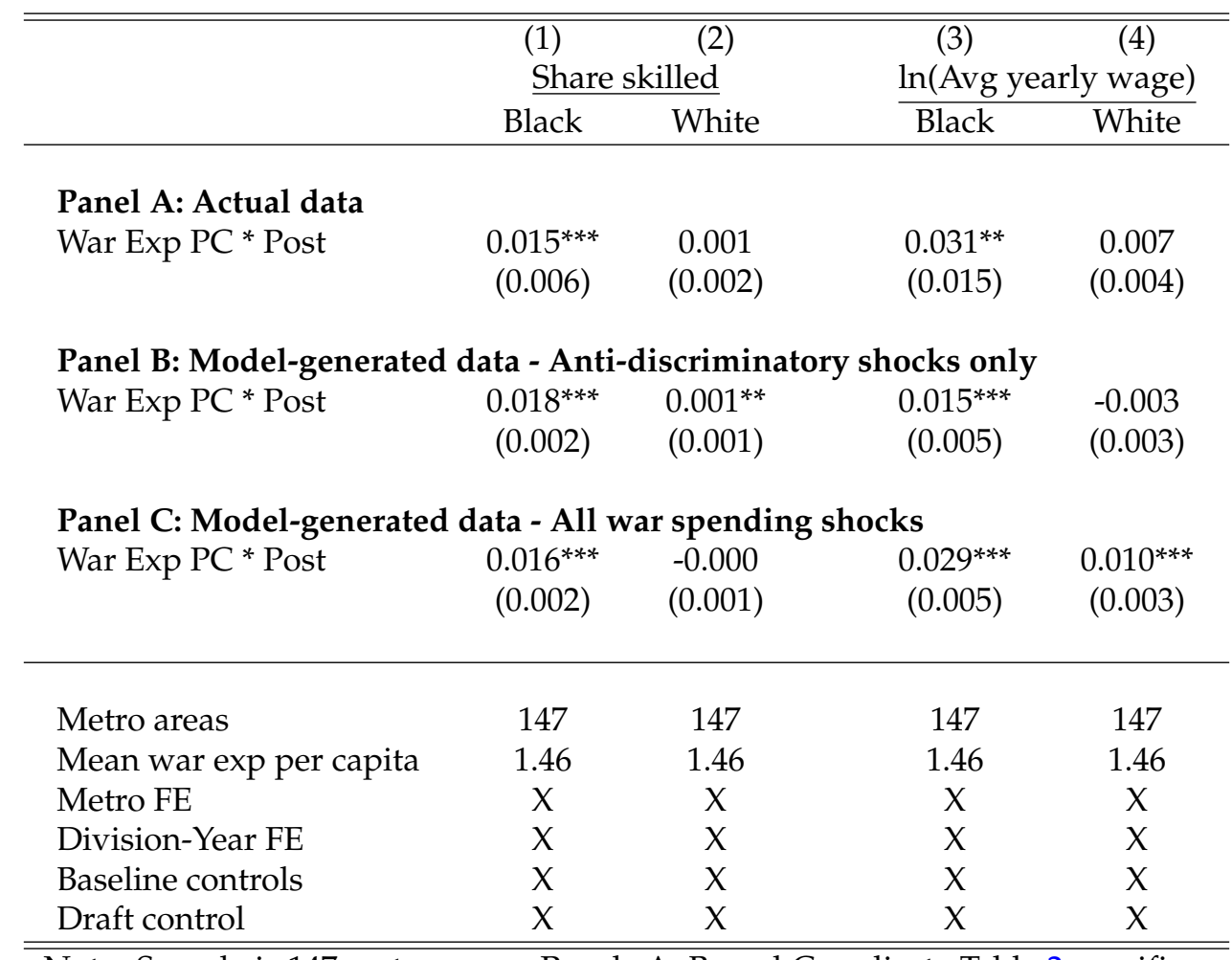

Note: Sample is 147 metro areas. Panels A, B, and C replicate Table 2 specifications with all controls. Panel A uses actual data and Panels $B$ and $C$ use data generated by the model. We feed in only the anti-discriminatory shocks in Panel B and all war-spending related shocks in Panel C. Panel B is used to determine the importance of anti-discriminatory mechanisms for our DiD empirical estimates while Panel $C$ is used to calibrate the value of $\eta$. Share skilled is the share of employed men who are not farmers, laborers, or service workers. Wages are total wage earnings in the previous year for men who are currently employees. Baseline controls are 1940 variables interacted with a post indicator: average years of education, share employed in manufacturing, share employed in agriculture, and share Black. Draft control is predicted draft rate based on 1940 demographics. Primary data sources are $1940(100 \%)$ and 1950 (1\%) Census samples. Metro area definitions based on 1940 and 1950 Census Bureau definitions. Regressions are weighted by relevant population. Robust standard errors in parentheses. ${ }^{*} \mathrm{p}<.1 ;{ }^{* *} \mathrm{p}<.05 ;{ }^{* * *} \mathrm{p}<.01$ 
Table 7: Ability of war expenditure shocks to explain aggregate changes in race gaps

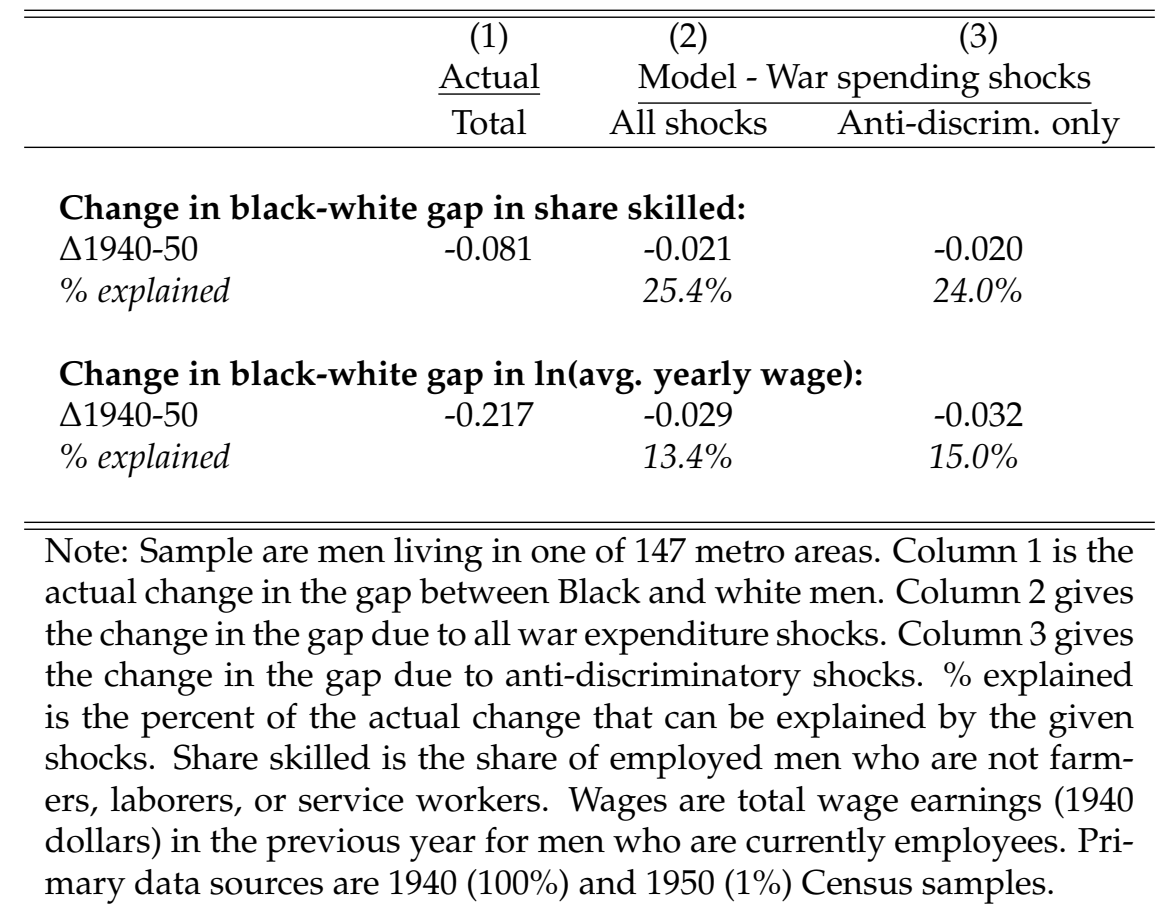


Table 8: Effect of war expenditures on school attendance (1940-1950)

\begin{tabular}{|c|c|c|c|c|}
\hline & \multirow{2}{*}{\multicolumn{2}{|c|}{$\begin{array}{l}(1) \\
\text { Black Children }\end{array}$}} & \multirow{2}{*}{\multicolumn{2}{|c|}{$\begin{array}{l}\text { (3) } \\
\text { White Children }\end{array}$}} \\
\hline & & & & \\
\hline & Boys, $\overline{16-18}$ & Girls, $16-18$ & Boys, $\overline{16-18}$ & Girls, $16-18$ \\
\hline \multicolumn{5}{|l|}{ Panel A: All metros } \\
\hline \multirow{2}{*}{ War exp per capita * Post } & $0.037^{* *}$ & 0.019 & 0.002 & 0.002 \\
\hline & $(0.017)$ & $(0.017)$ & $(0.004)$ & $(0.004)$ \\
\hline N - Pre & 127,085 & 144,710 & 81,738 & 81,738 \\
\hline N - Post & 488 & 521 & 4,256 & 4,256 \\
\hline \multicolumn{5}{|l|}{ Panel B: Excluding South } \\
\hline \multirow[t]{2}{*}{ War exp per capita * Post } & $0.055^{* *}$ & $0.022^{*}$ & 0.002 & 0.002 \\
\hline & $(0.021)$ & $(0.013)$ & $(0.005)$ & $(0.005)$ \\
\hline N - Pre & 56,707 & 62,974 & 69,176 & 69,176 \\
\hline N - Post & 254 & 272 & 3,446 & 3,446 \\
\hline Mean Y - Pre & 0.50 & 0.50 & 0.65 & 0.61 \\
\hline Mean Y - Post & 0.54 & 0.58 & 0.69 & 0.64 \\
\hline Mean war exp per capita & 1.46 & 1.46 & 1.46 & 1.46 \\
\hline Metro-Age FE & $X$ & $x$ & $X$ & $X$ \\
\hline Division-Year-Age FE & $X$ & $X$ & $X$ & $X$ \\
\hline Draft control & $x$ & $x$ & $x$ & $x$ \\
\hline
\end{tabular}

Note: Regression at the individual level and only includes children living in one of 147 metro areas. See equation 1 for the basic specification. School attendance is an indicator whether the child attended any school in the past month (1940) or two months (1950). Draft control is predicted draft rate based on 1940 demographics. Primary data sources are 1940 (100\%; 5\% sub-sample for whites) and 1950 (1\%) Census samples. Regressions weighted by sample line weights. Standard errors clustered at the metro-year level. ${ }^{*} \mathrm{p}<.1 ;{ }^{* *} \mathrm{p}<.05 ;{ }^{* * *} \mathrm{p}<.01$ 


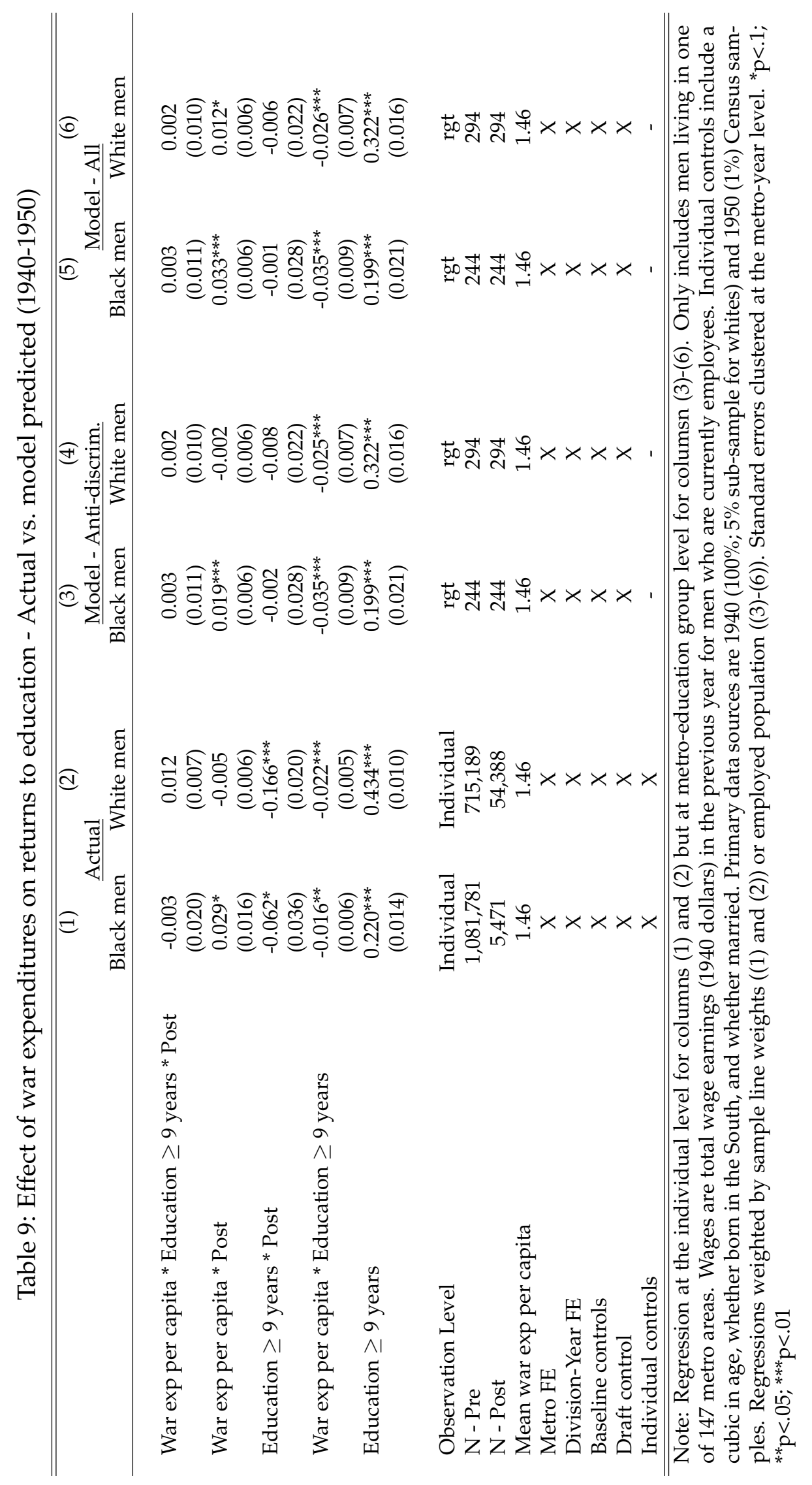


Table 10: Effect of war expenditures on school expenditures and residential segregation (1940-1950)

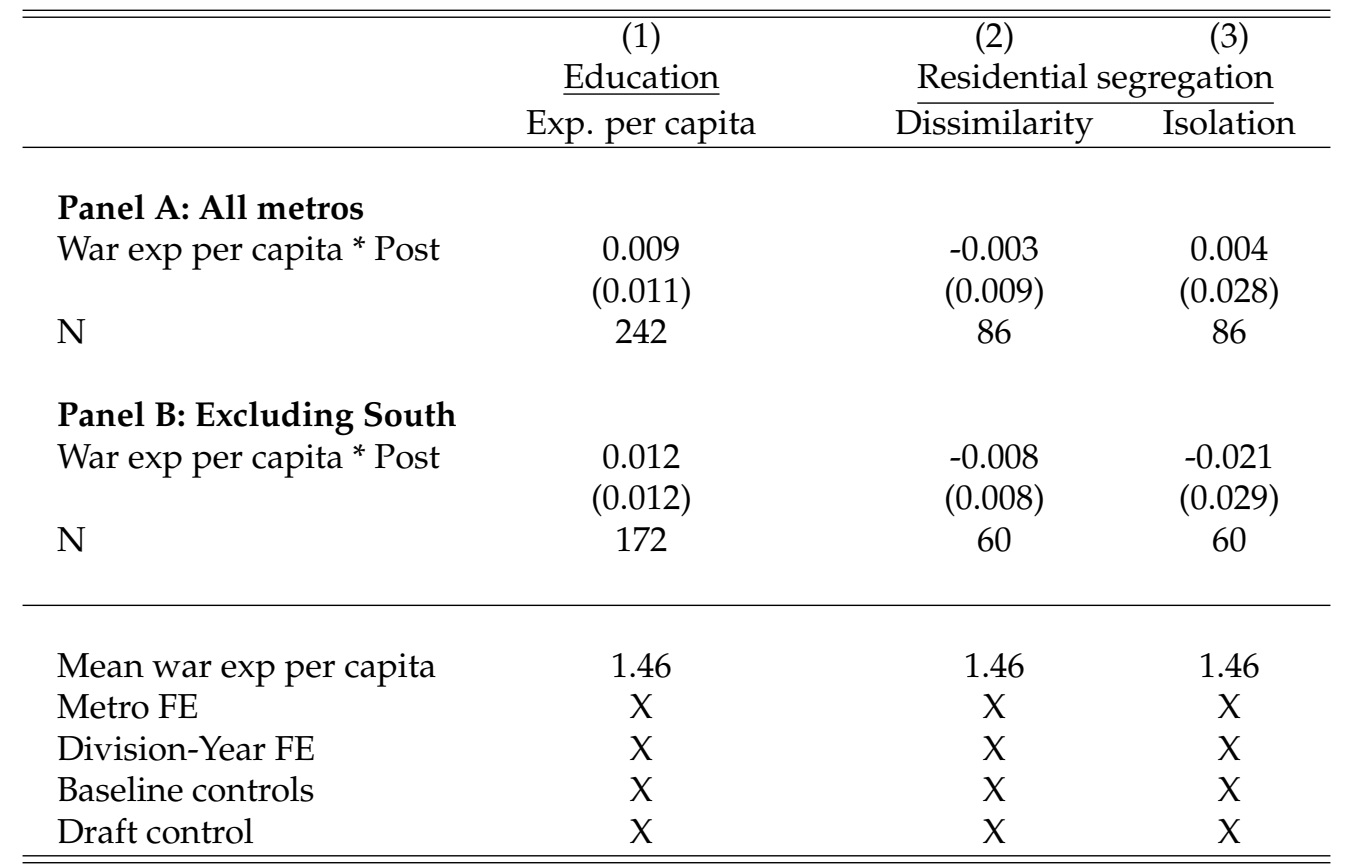

Note: Full sample is 147 metro areas; educational expenditures is available for only 121 metro areas. See equation 1 for the basic specification. Residential segregation indices are from Cutler et al. (1999) and are only available for 43 of our metro areas. Baseline controls are 1940 variables interacted with a post indicator: average years of education, share employed in manufacturing, share employed in agriculture, and share Black. Draft control is predicted draft rate based on 1940 demographics. Regressions weighted by Black population; results are similar if unweighted estimates are used. Robust standard errors in parentheses. ${ }^{*} \mathrm{p}<.1 ;{ }^{* *} \mathrm{p}<.05 ;{ }^{* * *} \mathrm{p}<.01$ 
Table 11: Role of labor shortages on effect of war expenditures (1940-1950)

\begin{tabular}{|c|c|c|c|c|c|c|}
\hline & \multicolumn{3}{|c|}{ Black men } & \multicolumn{3}{|c|}{ White men } \\
\hline War exp per capita * Post & $\begin{array}{l}0.015^{* *} \\
(0.006)\end{array}$ & & $\begin{array}{c}-0.002 \\
(0.010)\end{array}$ & $\begin{array}{c}0.001 \\
(0.002)\end{array}$ & & $\begin{array}{l}0.005^{* *} \\
(0.002)\end{array}$ \\
\hline Labor shortage $\%$ * Post & \multicolumn{3}{|c|}{$\begin{array}{c}0.061^{* * *} \\
(0.012)\end{array}$} & \multicolumn{3}{|c|}{$\begin{array}{l}-0.005 \\
(0.006)\end{array}$} \\
\hline War exp per capita * Labor shortage $\%$ * Post & & & $\begin{array}{l}0.020^{* *} \\
(0.010)\end{array}$ & & & $\begin{array}{c}-0.005^{* *} \\
(0.002)\end{array}$ \\
\hline Observations & 258 & 258 & 258 & 264 & 264 & 264 \\
\hline Mean war exp per capita & 1.55 & 1.55 & 1.55 & 1.55 & 1.55 & 1.55 \\
\hline$\%$ of months with labor shortage & 0.21 & 0.21 & 0.21 & 0.21 & 0.21 & 0.21 \\
\hline Metro FE & $X$ & $X$ & $X$ & $X$ & $X$ & $X$ \\
\hline Division-Year FE & $X$ & $x$ & $X$ & $x$ & $x$ & $X$ \\
\hline Baseline controls & $x$ & $x$ & $x$ & $x$ & $x$ & $x$ \\
\hline Draft control & $x$ & $x$ & $X$ & $x$ & $x$ & $X$ \\
\hline $\begin{array}{l}\text { Note: Sample is } 132 \text { metro areas with data on la } \\
1944 \text { with acute labor shortages according to La } \\
\text { the share of employed men who are not farmer } \\
\text { acted with a post indicator: average years of edy } \\
\text { and share Black. Draft control is predicted draf } \\
5 \% \text { sub-sample for whites) and } 1950 \text { (1\%) Censt } \\
\text { definitions. All values are in } 1940 \text { dollars. Reg } \\
\text { parentheses. }{ }^{*} \mathrm{p}<.1{ }^{* *} \mathrm{p}<.05 ;{ }^{* *} \mathrm{p}<.01\end{array}$ & $\begin{array}{l}\text { or shorta } \\
\text { or Market } \\
\text { laborers, } \\
\text { cation, sha } \\
\text { rate basec } \\
\text { samples. } \\
\text { essions ar }\end{array}$ & $\begin{array}{l}\text { es. Months } \\
\text { Reports. War } \\
\text { or service w } \\
\text { e employed } \\
\text { on } 1940 \text { dem } \\
\text { Metro area d } \\
\text { weighted by }\end{array}$ & $\begin{array}{l}\text { labor sh } \\
\text { expendit } \\
\text { rkers. Ba } \\
\text { manufa } \\
\text { graphics } \\
\text { finitions } \\
\text { relevant }\end{array}$ & $\begin{array}{l}\text { are perc } \\
1000 \text { s per } \\
\text { controls a } \\
\text {, share er } \\
\text { ary data } \\
\text { n } 1940 \text { a } \\
\text { tion. Ro }\end{array}$ & $\begin{array}{l}\text { atage of mo } \\
\text { capita. Shar } \\
\text { e } 1940 \text { vari } \\
\text { ployed in a } \\
\text { urces are } 1 \\
\text { d } 1950 \text { Cen } \\
\text { ust standar }\end{array}$ & $\begin{array}{l}\text { ths } 1942- \\
\text { skilled is } \\
\text { les inter- } \\
\text { riculture, } \\
40(100 \% \text {; } \\
\text { as Bureau } \\
\text { errors in }\end{array}$ \\
\hline
\end{tabular}




\section{A Appendix Tables and Figures}

Figure A.1: Black vs. white men occupational dissimilarity index by metro area (1940)

\section{Panel A: Unadjusted}

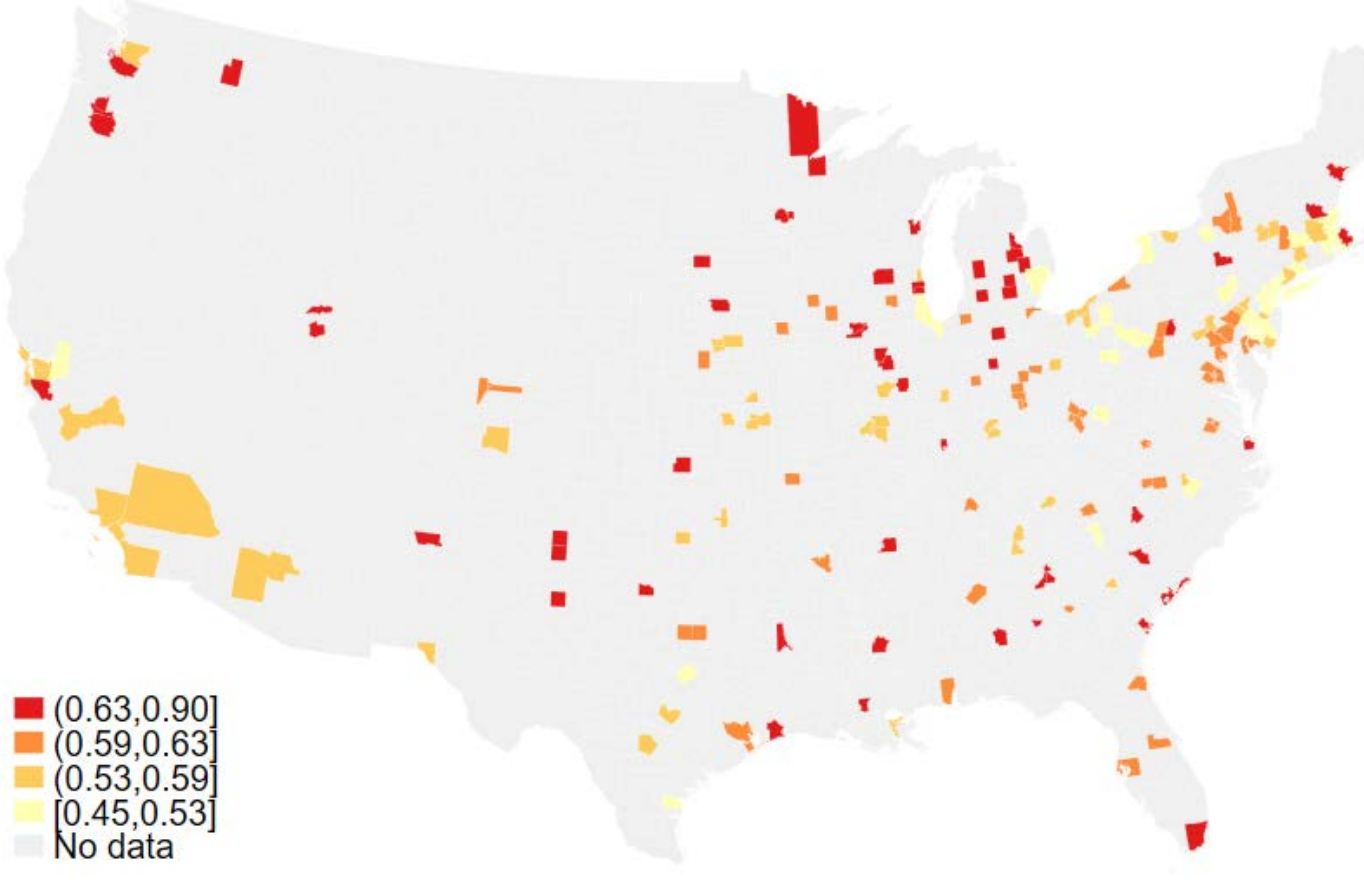

Panel B: Adjusted for randomness and education

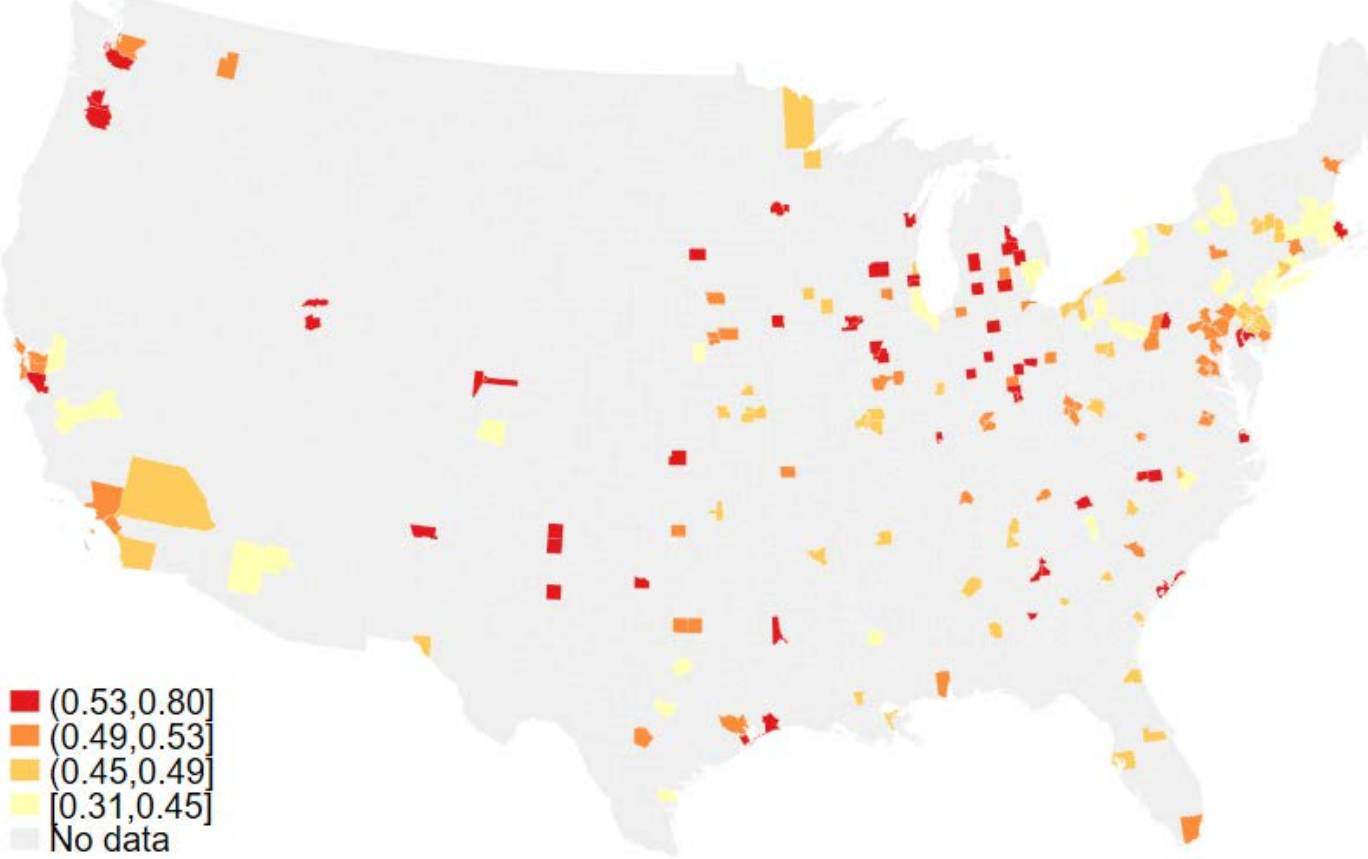

Note: For 147 metro areas, as defined by the Census Bureau in 1940 and 1950. Panel A presents unadjusted occupational dissimilarity indices while Panel B adjusts for education (5 groups) and randomness. For more details on the creation of these measures, please see Appendix Section C.2. 
Figure A.2: Average yearly wage and years of education by occupation for white men (1940)

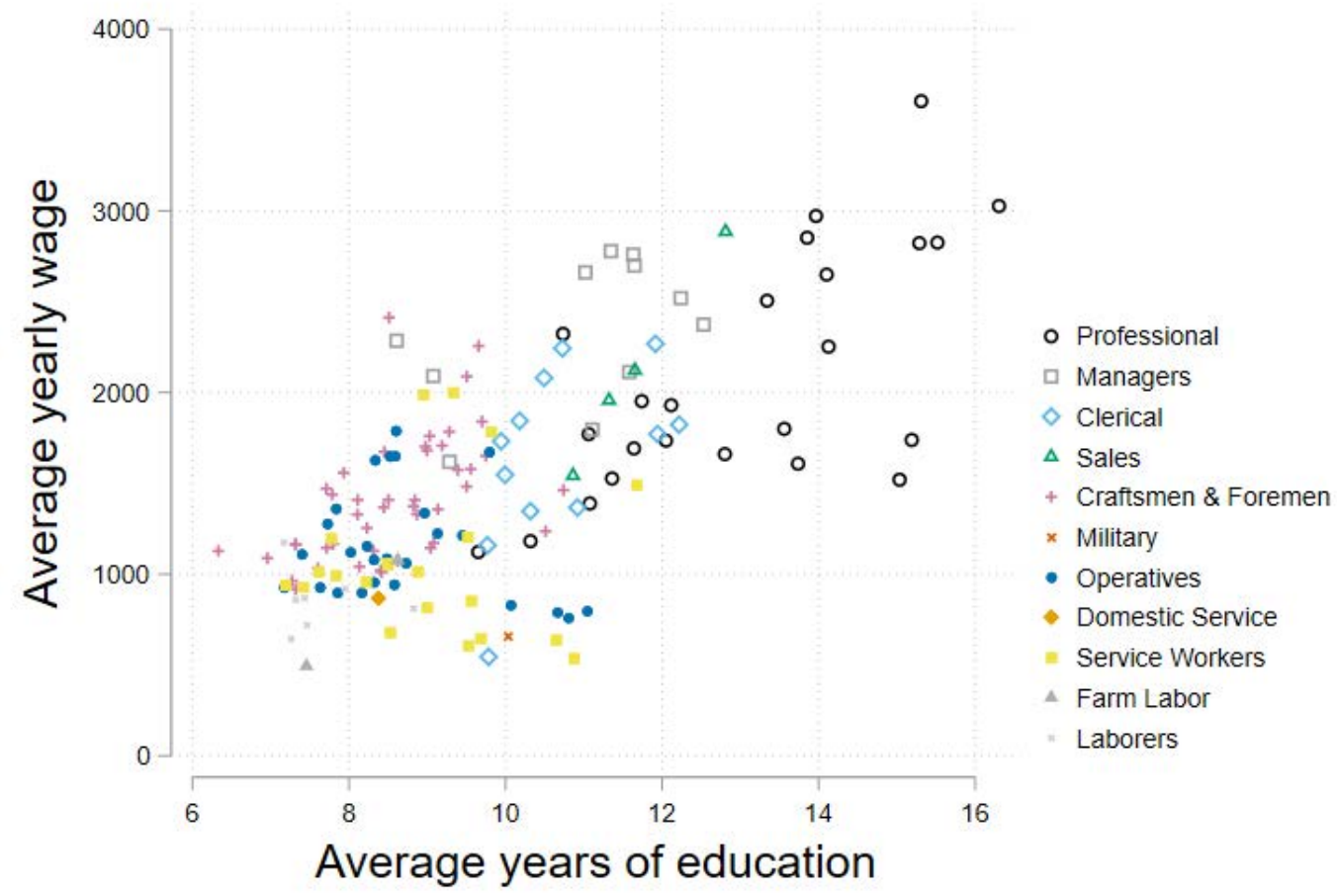

Note: Each point is an occupation from the 1950 Census occupational coding scheme with at least 10,000 employed white men. Average yearly wage is average total wage earnings within the occupational group (1940 dollars) in the previous year for men who are currently employees. 
Figure A.3: Defense expenditures as a share of GDP

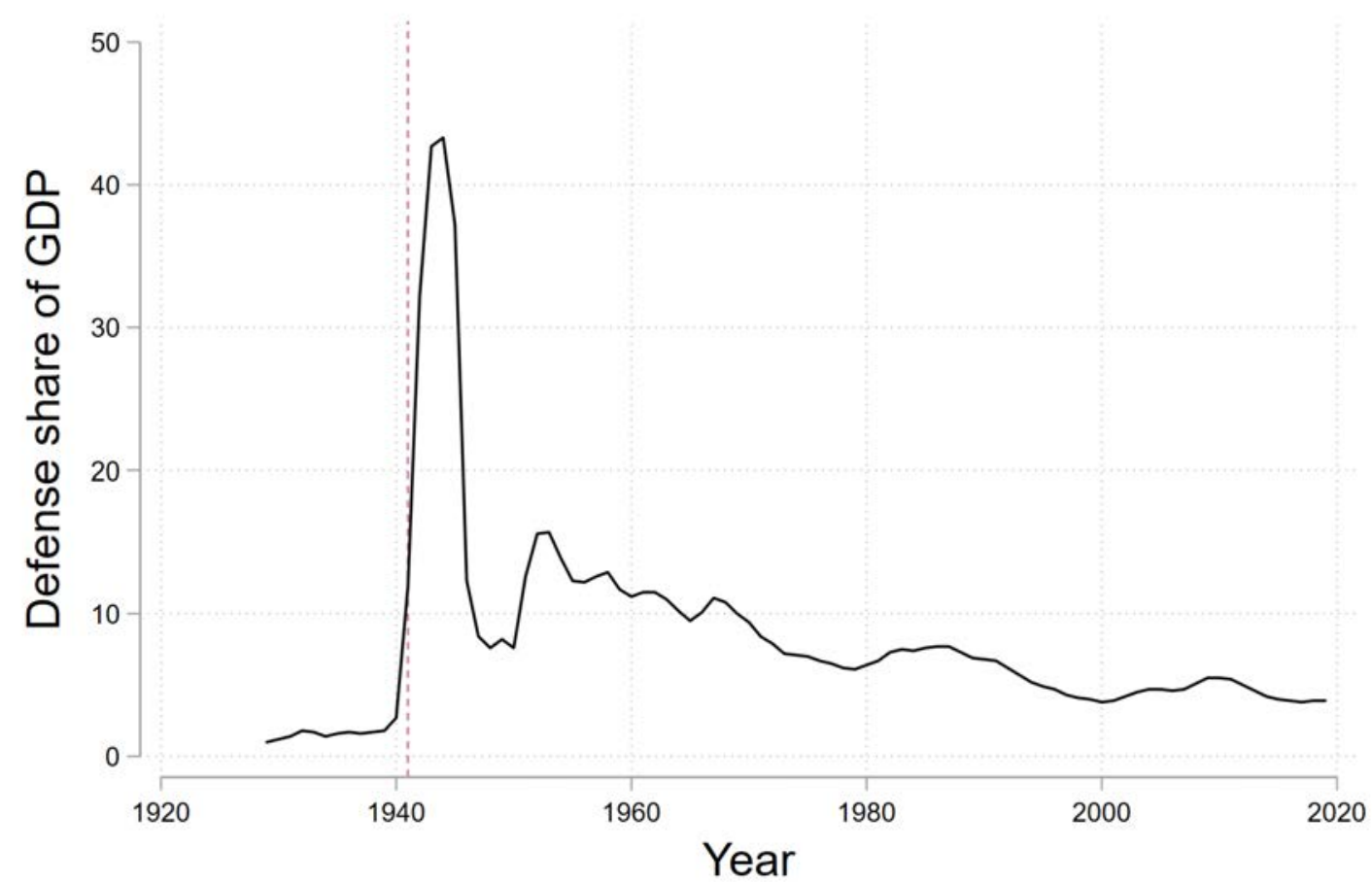

Note: Data is from U.S. Bureau of Economic Analysis series "Shares of gross domestic product: Government consumption expenditures and gross investment: Federal: National defense [A824RE1A156NBEA]", retrieved from FRED. 
Figure A.4: Effect of war expenditures on share of prime-age men who completed high school

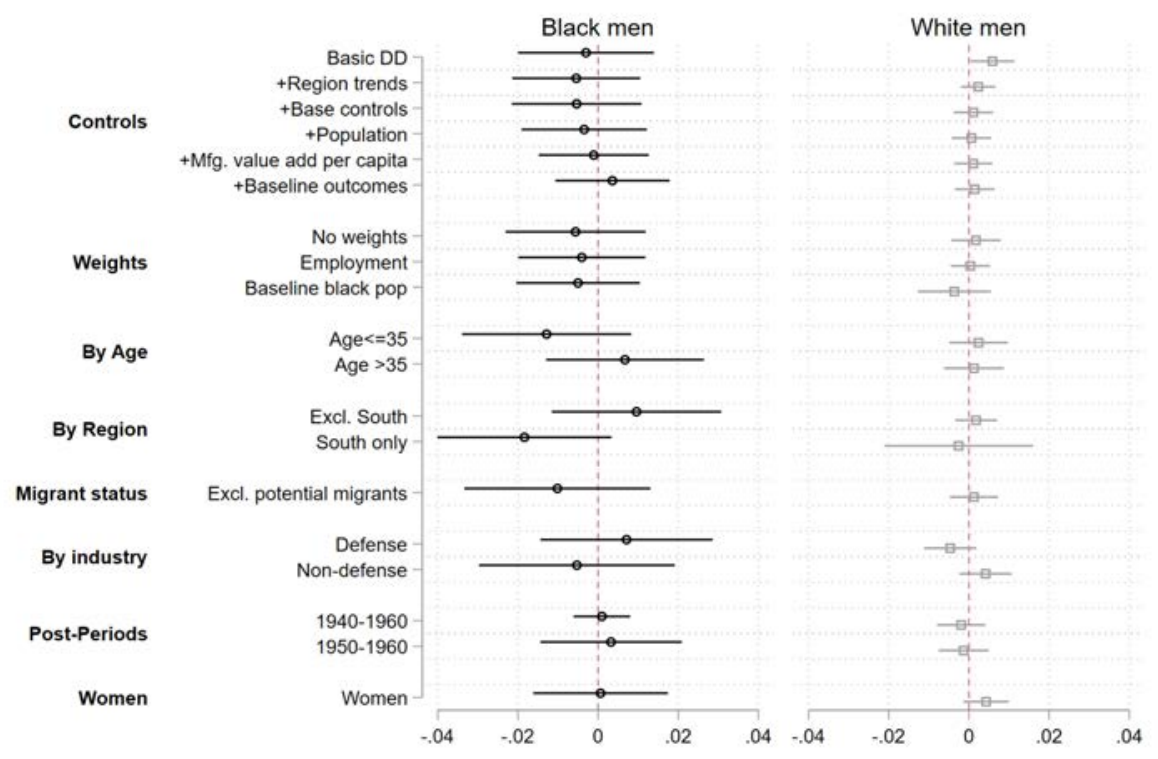

Note: See equation 1 for the basic specification. Intervals are $95 \%$ confidence intervals. All controls are interacted with an indicator for post. "+Base controls" is our standard specification with controls for region, average years of education, share in manufacturing, share in agriculture, share Black, and predicted draft rate. "+Population" adds controls for the (log of) total population and Black popuation in 1940. "+Baseline outcomes" adds controls for 1940 share employed, share skilled, and (log of) average yearly wage. "Excl. potential migrants" means excluding individuals in 1950 who were not born in their current state of residence and is not living with a child eight years or older born in the current state of residence. There are 147 metro areas and data comes from the 1940-1960 Census samples. 
Figure A.5: Black occupational upgrading by age and education Panel A: By age

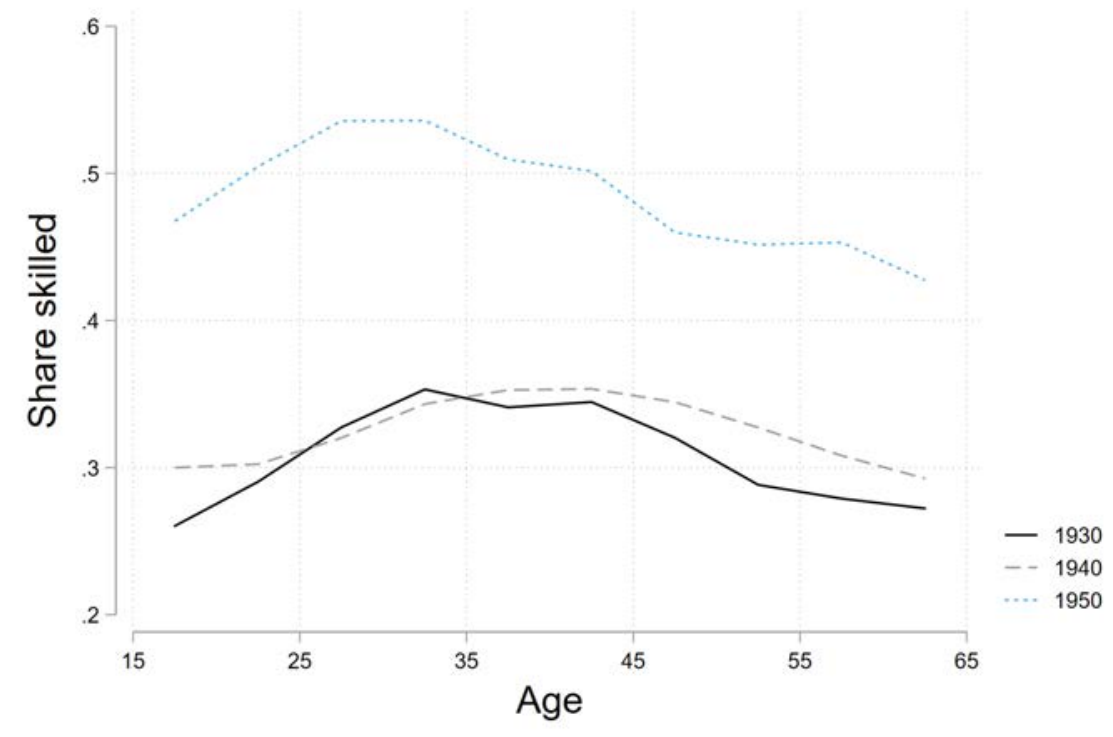

Panel B: By education

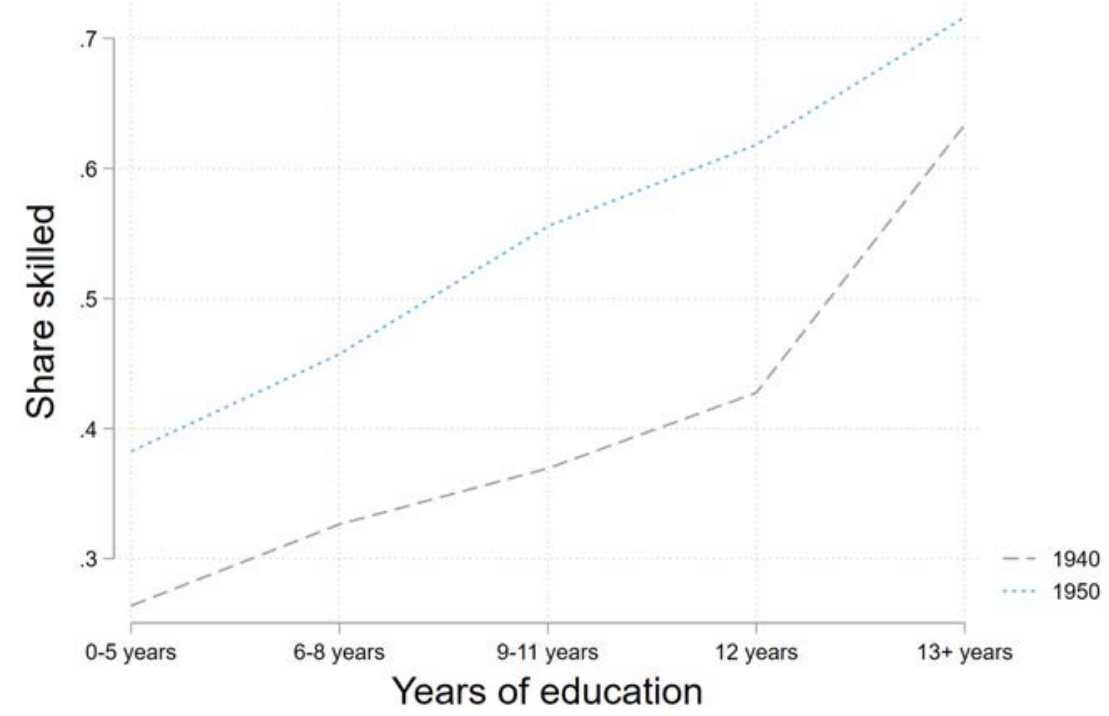

Note: Sample is employed men living in metro areas. Data comes from the $1930(5 \%)$, 1940 Census $(100 \%)$, and $1950(1 \%)$ samples. 
Figure A.6: Relationship between war expenditure per capita and (log of) population
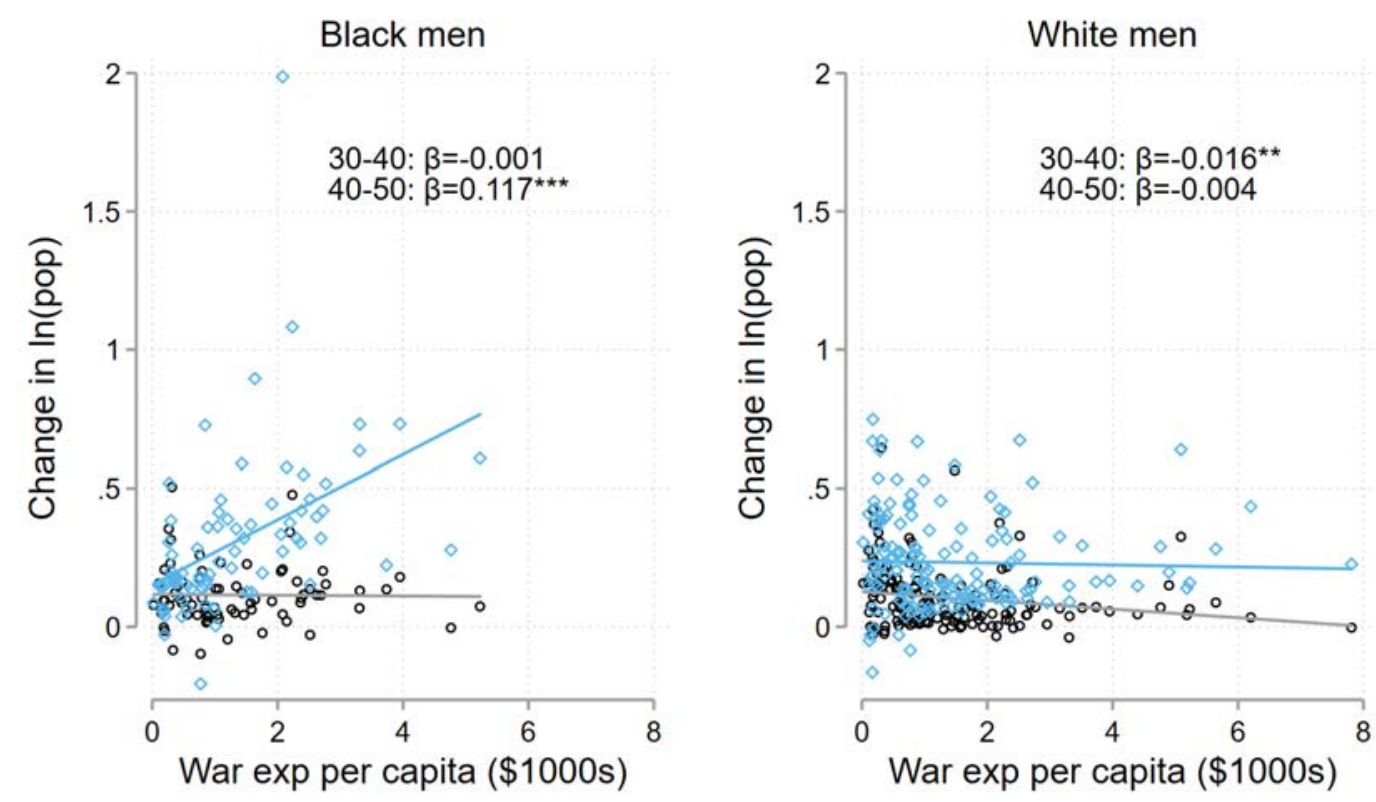

- Change 1930-40

$\diamond$ Change 1940-1950

Note: Each point represents a metro area. We restrict focus to metropolitan areas with a relevant population in all years of at least 2500 which leaves 147 metropolitan areas for white men and 76 metropolitan areas for Black men. Regressions do not include any controls or weights. Results are qualitatively similar if population weights are used on the full sample. Data is from County Data Books. Significance levels based on robust standard errors. ${ }^{*} \mathrm{p}<.1 ;{ }^{* *} \mathrm{p}<.05 ;{ }^{* * *} \mathrm{p}<.01$ 
Figure A.7: Pre-trends in high school graduation rates (1940 Census) Panel A: Boys

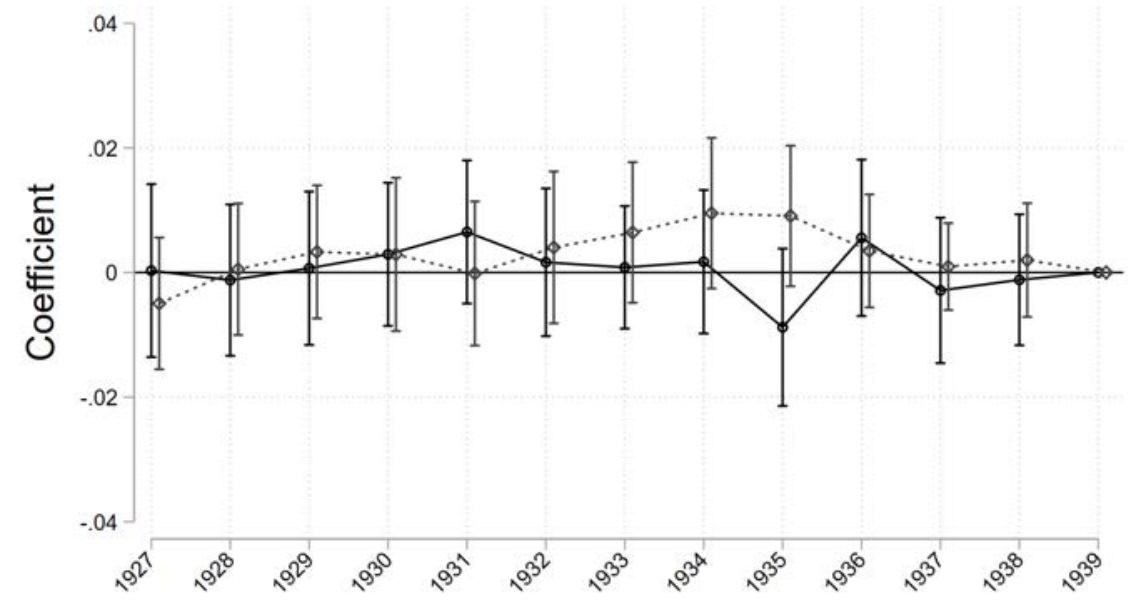

High school graduation year

๑- War exp * Black ๑. War exp

Panel B: Girls

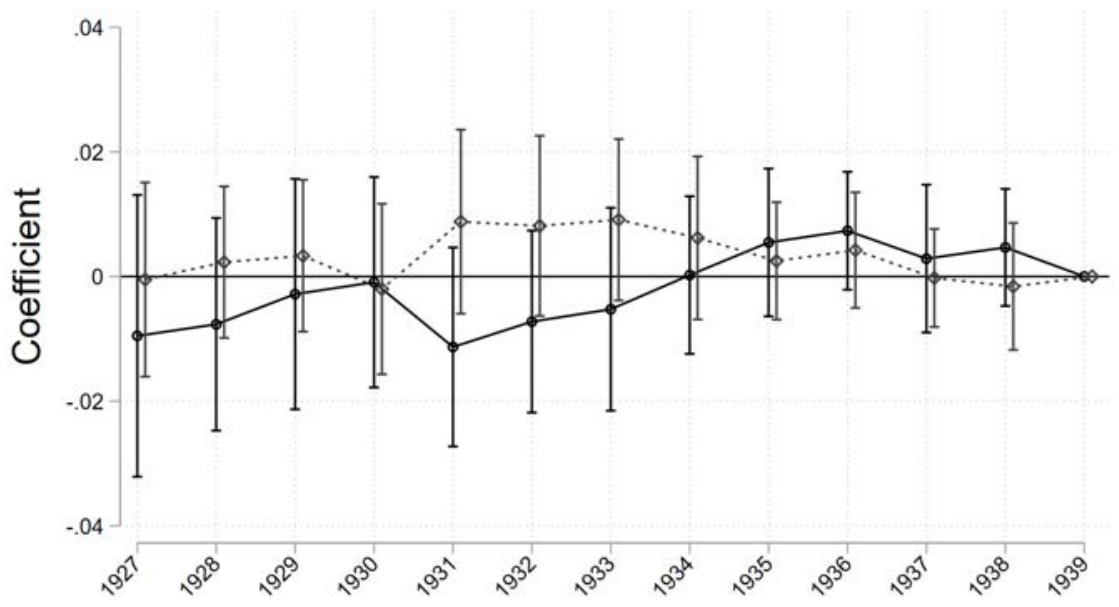

High school graduation year

$\rightarrow$ War exp*Black ๑. War exp

Note: See equation 12 for the estimating equation. Intervals are $95 \%$ confidence intervals. Cohorts grouped by expected graduation year and excludes the South. Graduating high school is defined as having completed 12 years of schooling in 1960. Fixed effects include metro-race FE and cohort-race FE. Other controls interacted with race include include whether born in the South interacted with cohort indicators. Results are similar if controls for veteran status are included. Data comes from the 1940 Census ( $100 \%$ sample; $5 \%$ sub-sample for whites). 
Table A1: Occupational distribution for Black and white men in 1940 and 1950

\begin{tabular}{lcccc}
\hline \hline & \multicolumn{3}{c}{ Black men } & \multicolumn{2}{c}{ White men } \\
& 1940 & 1950 & 1940 & 1950 \\
\hline Professional & 1.9 & 1.9 & 5.8 & 7.4 \\
Farmers & 19.6 & 13.0 & 13.5 & 10.2 \\
Managers & 1.4 & 2.0 & 9.9 & 11.1 \\
Clerical & 1.1 & 2.7 & 6.9 & 6.5 \\
Sales & 0.6 & 1.0 & 6.2 & 6.5 \\
Craftsmen \& Foremen & 4.3 & 7.6 & 15.6 & 19.2 \\
Military & 0.2 & 2.6 & 0.7 & 2.4 \\
Operatives & 12.0 & 20.8 & 17.9 & 19.7 \\
Domestic Service & 2.9 & 0.8 & 0.3 & 0.1 \\
Service Workers & 11.7 & 13.1 & 5.8 & 5.8 \\
Farm Laborer & 18.5 & 10.8 & 7.0 & 4.4 \\
Laborers & 25.8 & 23.6 & 10.6 & 6.8 \\
\hline \hline & Note: Occupational distribution is for employed men in 1940 \\
and is not limited to men in metro areas. & Data is from the \\
1940 Census (100\%). & \multicolumn{4}{l}{. }
\end{tabular}


Table A2: Example unions policies towards Black workers during the Great Depression

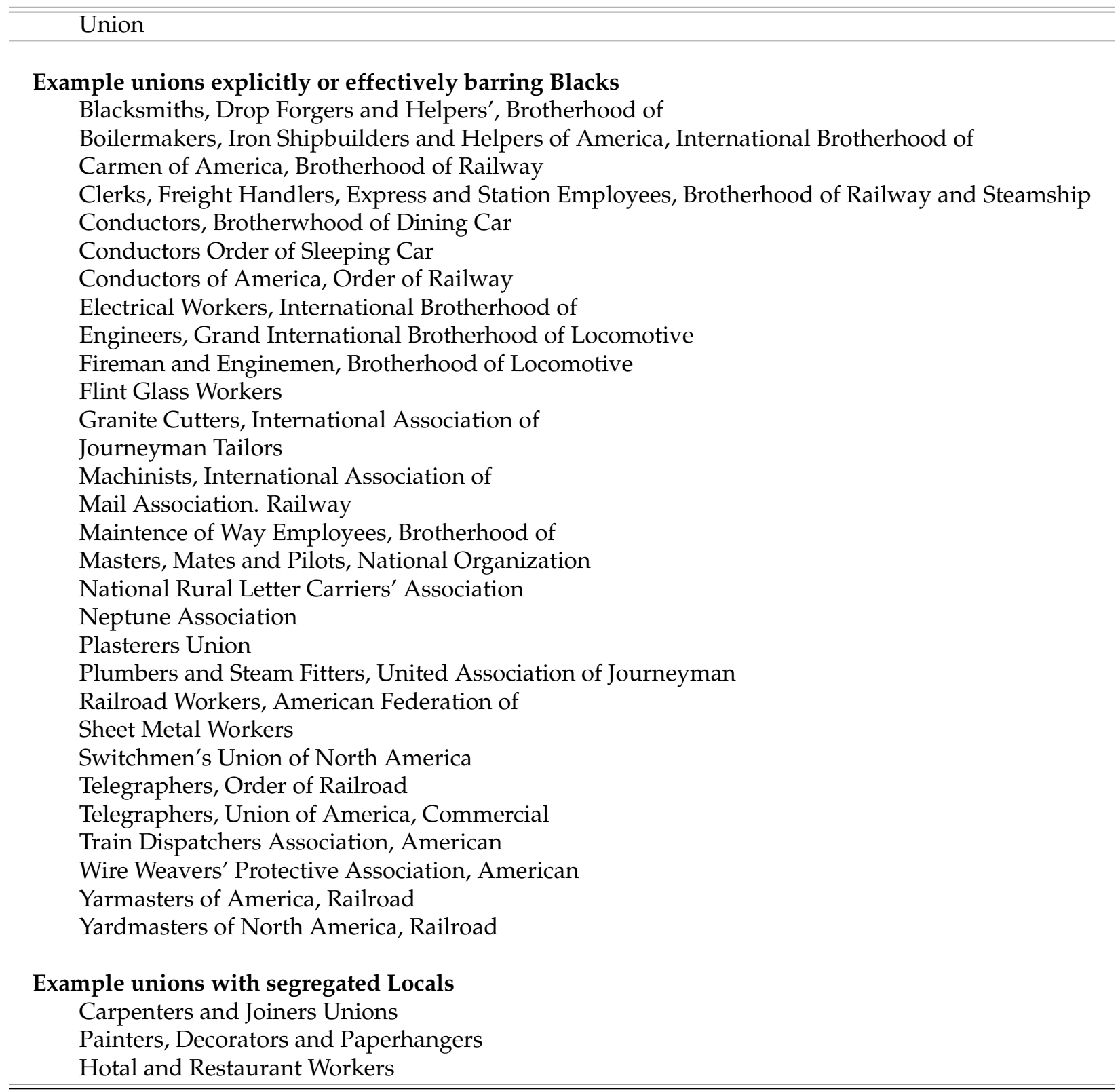

Note: Union policies are taken from "The Negro Year Book: An annual Encyclopedia of the Negro, 19371938" by Monroe Work and Jessie Guzman. The list is not complete. 
Table A3: Most over and under represented occupations for Black men, conditional on education and location (living in metro, 1940)

\begin{tabular}{|c|c|c|c|c|c|}
\hline \multicolumn{2}{|r|}{ Top 15 over-represented } & \multirow[b]{2}{*}{$\frac{\text { Actual }}{\text { Expected }}$} & \multicolumn{2}{|r|}{ Top 15 under-represented } & \multirow[b]{2}{*}{$\frac{\text { Actual }}{\text { Expected }}$} \\
\hline & Occupation & & & Occupation & \\
\hline 1 & Janitors and Porters & 3.35 & 1 & Tool Makers & 0.05 \\
\hline 2 & Clergymen & 2.93 & 2 & Motormen & 0.06 \\
\hline 3 & Private Household Workers & 2.77 & 3 & Mechanical Engineers & 0.06 \\
\hline 4 & Elevator Operators & 2.64 & 4 & Civil Engineers & 0.09 \\
\hline 5 & Musicians & 2.22 & 5 & Electrical Engineers & 0.09 \\
\hline 6 & Service Workers, Except Private Household & 2.14 & 6 & Other Technical Engineers & 0.10 \\
\hline 7 & Cooks & 2.07 & 7 & Bookkeepers & 0.10 \\
\hline 8 & Recreation Workers & 1.97 & 8 & Salesmen, Wholesale & 0.10 \\
\hline 9 & Teachers & 1.91 & 9 & Salesmen, Manufacturing & 0.10 \\
\hline 10 & Laborer - Construction & 1.86 & 10 & Tinsmiths, Coppersmiths, and Sheet Metal Workers & 0.11 \\
\hline 11 & Laundry Workers & 1.86 & 11 & Locomotive Engineers & 0.11 \\
\hline 12 & Waiters and Bartenders & 1.82 & 12 & Printing Craftsmen & 0.12 \\
\hline 13 & Mail Carriers & 1.8 & 13 & Foremen, Durable Goods & 0.15 \\
\hline 14 & Laborer - Other & 1.79 & 14 & Foremen, Non-Durable Goods & 0.15 \\
\hline 15 & Laborer - Primary Metal & 1.77 & 15 & Designers and Draftsmen & 0.15 \\
\hline
\end{tabular}

Note: For employed men living in metro areas in 1940. Expected employment is based on random assignment within educational group (5 groups) and location. For more details, see Appendix Section C.2. Occupation groupings are based on aggregations used in 1950 Census publications. Data is from the 1940 Census $(100 \%)$. 
Table A4: Relationship between actual and predicted draft rate)

\begin{tabular}{|c|c|c|c|c|}
\hline & $\begin{array}{c}\text { (1) } \\
\text { Predicted } \\
\text { draft rate }\end{array}$ & $\begin{array}{c}(2) \\
\text { Draft } \\
\text { rate }\end{array}$ & $\begin{array}{c}(3) \\
\text { War exp } \\
\text { per capita }\end{array}$ & $\begin{array}{c}(4) \\
\text { War exp } \\
\text { per capita }\end{array}$ \\
\hline Predicted draft rate & & $\begin{array}{c}0.270^{* * *} \\
(0.103)\end{array}$ & $\begin{array}{c}-0.167^{* *} \\
(0.066)\end{array}$ & \\
\hline Draft rate & & & & $\begin{array}{c}-0.146^{*} \\
(0.081)\end{array}$ \\
\hline $\ln ($ Avg yearly wage $)$ & $\begin{array}{l}-0.030 \\
(0.147)\end{array}$ & $\begin{array}{c}0.012 \\
(0.125)\end{array}$ & $\begin{array}{c}0.046 \\
(0.141)\end{array}$ & $\begin{array}{c}0.051 \\
(0.141)\end{array}$ \\
\hline$\%$ Agriculture & $\begin{array}{l}0.419^{* *} \\
(0.174)\end{array}$ & $\begin{array}{c}0.053 \\
(0.185)\end{array}$ & $\begin{array}{c}0.016 \\
(0.149)\end{array}$ & $\begin{array}{l}-0.030 \\
(0.149)\end{array}$ \\
\hline$\%$ Government & $\begin{array}{l}0.182^{* *} \\
(0.075)\end{array}$ & $\begin{array}{l}-0.147 \\
(0.111)\end{array}$ & $\begin{array}{c}0.096 \\
(0.156)\end{array}$ & $\begin{array}{c}0.052 \\
(0.141)\end{array}$ \\
\hline$\%$ Manufacturing & $\begin{array}{l}0.255^{* *} \\
(0.115)\end{array}$ & $\begin{array}{c}0.103 \\
(0.140)\end{array}$ & $\begin{array}{l}0.388^{* *} \\
(0.152)\end{array}$ & $\begin{array}{l}0.371^{* *} \\
(0.157)\end{array}$ \\
\hline $\ln ($ Mfg. value added per capita) & $\begin{array}{l}-0.174^{*} \\
(0.089)\end{array}$ & $\begin{array}{c}-0.098 \\
(0.080)\end{array}$ & $\begin{array}{l}0.153^{*} \\
(0.083)\end{array}$ & $\begin{array}{l}0.161^{* * *} \\
(0.076)\end{array}$ \\
\hline \% Skilled & $\begin{array}{l}-0.015 \\
(0.187)\end{array}$ & $\begin{array}{c}0.099 \\
(0.171)\end{array}$ & $\begin{array}{c}0.139 \\
(0.183)\end{array}$ & $\begin{array}{c}0.155 \\
(0.182)\end{array}$ \\
\hline \% Unemployed & $\begin{array}{l}0.260^{* * *} \\
(0.110)\end{array}$ & $\begin{array}{c}0.152 \\
(0.108)\end{array}$ & $\begin{array}{l}-0.029 \\
(0.102)\end{array}$ & $\begin{array}{l}-0.040 \\
(0.108)\end{array}$ \\
\hline$\%$ Black & $\begin{array}{c}0.062 \\
(0.155)\end{array}$ & $\begin{array}{c}0.114 \\
(0.150)\end{array}$ & $\begin{array}{c}0.033 \\
(0.073)\end{array}$ & $\begin{array}{c}0.042 \\
(0.072)\end{array}$ \\
\hline $\ln$ (Population) & $\begin{array}{c}0.002 \\
(0.077)\end{array}$ & $\begin{array}{l}0.143^{*} \\
(0.085)\end{array}$ & $\begin{array}{l}-0.029 \\
(0.077)\end{array}$ & $\begin{array}{l}-0.009 \\
(0.080)\end{array}$ \\
\hline Northeast & $\begin{array}{c}-0.102 \\
(0.143)\end{array}$ & $\begin{array}{l}0.268^{*} \\
(0.144)\end{array}$ & $\begin{array}{c}0.018 \\
(0.103)\end{array}$ & $\begin{array}{c}0.070 \\
(0.100)\end{array}$ \\
\hline Midwest & $\begin{array}{c}-0.529^{* * *} \\
(0.129)\end{array}$ & $\begin{array}{c}0.166 \\
(0.168)\end{array}$ & $\begin{array}{c}0.029 \\
(0.154)\end{array}$ & $\begin{array}{c}0.121 \\
(0.150)\end{array}$ \\
\hline West & $\begin{array}{c}-0.231^{* *} \\
(0.110)\end{array}$ & $\begin{array}{l}-0.121 \\
(0.117)\end{array}$ & $\begin{array}{c}0.110 \\
(0.100)\end{array}$ & $\begin{array}{c}0.122 \\
(0.100)\end{array}$ \\
\hline R2 & 0.44 & 0.36 & 0.33 & 0.33 \\
\hline $\mathrm{N}$ & 147 & 147 & 147 & 147 \\
\hline
\end{tabular}

Note: An observation is a metro area and all variables have been standardized to have $\mu=0$ and $\sigma^{2}=1$ and are based on 1940 values. Percentages are shares of employed men excpet \% unemployed is share of men in the labor force. Omitted regional category is the South. War expenditure per capita in 1940 dollars. For a discussion of the draft measures see Appendix Section B.2. Only 132 of the 147 metro areas are identified in these reports. Robust standard errors in parentheses. ${ }^{*} \mathrm{p}<.1 ;{ }^{* *} \mathrm{p}<.05 ;{ }^{* * *} \mathrm{p}<.01$ 
Table A5: Effect of war expenditures on defense industry employment (1940-1944)

\begin{tabular}{lcccc}
\hline \hline & Black & White & Men & Women \\
\hline War exp per capita (1940) & $0.041^{* * *}$ & $0.071^{* * *}$ & $0.065^{* * *}$ & $0.084^{* * *}$ \\
& $(0.014)$ & $(0.011)$ & $(0.011)$ & $(0.014)$ \\
Mean change & .06 & -.05 & -.09 & .07 \\
Mean War Exp PC (1000s) & 1.46 & 1.46 & 1.46 & 1.46 \\
Division FE & $\mathrm{X}$ & $\mathrm{X}$ & $\mathrm{X}$ & $\mathrm{X}$ \\
Baseline controls & $\mathrm{X}$ & $\mathrm{X}$ & $\mathrm{X}$ & $\mathrm{X}$ \\
Draft control & $\mathrm{X}$ & $\mathrm{X}$ & $\mathrm{X}$ & $\mathrm{X}$ \\
Metro areas & 147 & 147 & 147 & 147 \\
\hline \hline
\end{tabular}

Note: Sample is 147 metro areas. The outcome is the change in the share employed in defense industries. See Appendix Section D.1 for more details. War expenditure is $\$ 1000$ s per capita. Baseline controls are 1940 variables interacted with a post indicator: average years of education, share employed in manufacturing, share employed in agriculture, and share Black. Draft control is predicted draft rate based on 1940 demographics. Primary data sources are 1940 (100\%; 5\% sub-sample for whites) Census sample and ES-270 reports. Metro area definitions based on 1940 and 1950 Census Bureau definitions. All values are in 1940 dollars. Regressions are weighted by relevant population. Robust standard errors in parentheses. ${ }^{*} \mathrm{p}<.1 ;{ }^{* *} \mathrm{p}<.05 ;{ }^{* * *} \mathrm{p}<.01$ 
Table A6: Effect of war expenditures - State level (1940-1950)

\begin{tabular}{|c|c|c|c|c|}
\hline & \multirow{2}{*}{\multicolumn{2}{|c|}{$\begin{array}{l}(1) \\
\text { Black Men }\end{array}$}} & (3) & $(4)$ \\
\hline & & & \multicolumn{2}{|c|}{ White Men } \\
\hline & Basic & Controls & Basic & Controls \\
\hline \multicolumn{5}{|l|}{ Panel A: Share skilled } \\
\hline \multirow[t]{2}{*}{ War exp per capita * Post } & $0.040^{* * *}$ & 0.021 & -0.000 & 0.004 \\
\hline & $(0.007)$ & $(0.013)$ & $(0.005)$ & $(0.007)$ \\
\hline Mean Y - 1940 & 0.22 & 0.22 & 0.62 & 0.62 \\
\hline Mean Y - 1950 & 0.37 & 0.37 & 0.73 & 0.73 \\
\hline \multicolumn{5}{|c|}{ Panel B: $\ln$ (Average yearly wage) } \\
\hline \multirow[t]{2}{*}{ War exp per capita * Post } & $0.063^{*}$ & $0.068^{*}$ & -0.013 & -0.010 \\
\hline & $(0.032)$ & $(0.036)$ & $(0.010)$ & $(0.016)$ \\
\hline Mean Y - 1940 & 6.34 & 6.34 & 7.13 & 7.13 \\
\hline Mean Y - 1950 & 6.88 & 6.88 & 7.47 & 7.47 \\
\hline \multicolumn{5}{|c|}{ Panel C: Prime-age employment rate } \\
\hline \multirow[t]{2}{*}{ War exp per capita * Post } & -0.003 & 0.001 & -0.003 & $-0.006^{*}$ \\
\hline & $(0.009)$ & $(0.018)$ & $(0.002)$ & $(0.004)$ \\
\hline Mean Y - 1940 & 0.85 & 0.85 & 0.88 & 0.88 \\
\hline Mean Y - 1950 & 0.87 & 0.87 & 0.92 & 0.92 \\
\hline States & 49 & 49 & 49 & 49 \\
\hline Mean war exp per capita & 0.80 & 0.80 & 0.80 & 0.80 \\
\hline Metro FE & $X$ & $X$ & $X$ & $X$ \\
\hline Division-Year FE & $\mathrm{X}$ & $X$ & $\mathrm{X}$ & $\mathrm{x}$ \\
\hline Baseline controls & - & $\mathrm{X}$ & - & $\mathrm{X}$ \\
\hline Draft control & - & $X$ & - & $X$ \\
\hline
\end{tabular}

Note: Sample is 48 states plus Washington D.C.. See equation 1 for the basic specification. War expenditure is $\$ 1000$ s per capita. Share skilled is the share of employed men who are not farmers, laborers, or service workers. Wages are total wage earnings in the previous year for men who are currently employees. Primeage employment is the share of men ages 25-54 who are employed. Baseline controls are 1940 variables interacted with a post indicator: average years of education, share employed in manufacturing, share employed in agriculture, and share Black. Draft control is predicted draft rate based on 1940 demographics. Primary data sources are 1940 (100\%; 5\% sub-sample for whites) and 1950 (1\%) Census samples. Metro area definitions based on 1940 and 1950 Census Bureau definitions. All values are in 1940 dollars. Regressions are weighted by relevant population. Robust standard errors in parentheses. ${ }^{*} \mathrm{p}<.1$; ${ }^{* *} \mathrm{p}<.05 ;{ }^{* * *} \mathrm{p}<.01$ 
Table A7: Effect of war expenditures - Commuting zone level (19401950)

\begin{tabular}{|c|c|c|c|c|}
\hline & (1) & (2) & (3) & (4) \\
\hline & \multicolumn{2}{|c|}{ Black Men } & \multicolumn{2}{|c|}{ White Men } \\
\hline & Basic & Controls & Basic & Controls \\
\hline \multicolumn{5}{|l|}{ Panel A: Share skilled } \\
\hline War exp per capita * Post & $\begin{array}{c}0.023^{* * *} \\
(0.004)\end{array}$ & $\begin{array}{c}0.022^{* * *} \\
(0.005)\end{array}$ & $\begin{array}{l}-0.006^{* *} \\
(0.003)\end{array}$ & $\begin{array}{l}0.006^{*} \\
(0.003)\end{array}$ \\
\hline Mean Y - 1940 & 0.22 & 0.22 & 0.63 & 0.63 \\
\hline Mean Y - 1950 & 0.38 & 0.38 & 0.73 & 0.73 \\
\hline \multicolumn{5}{|c|}{ Panel B: $\ln$ (Average yearly wage) } \\
\hline War exp per capita * Post & $\begin{array}{c}0.034^{* * *} \\
(0.013)\end{array}$ & $\begin{array}{l}0.031^{* *} \\
(0.015)\end{array}$ & $\begin{array}{c}-0.025^{* * *} \\
(0.006)\end{array}$ & $\begin{array}{c}0.002 \\
(0.005)\end{array}$ \\
\hline Mean Y - 1940 & 6.32 & 6.32 & 7.10 & 7.10 \\
\hline Mean Y - 1950 & 6.86 & 6.86 & 7.45 & 7.45 \\
\hline \multicolumn{5}{|c|}{ Panel C: Prime-age employment rate } \\
\hline War exp per capita * Post & $\begin{array}{c}0.001 \\
(0.005)\end{array}$ & $\begin{array}{l}-0.006 \\
(0.005)\end{array}$ & $\begin{array}{c}-0.003^{* *} \\
(0.002)\end{array}$ & $\begin{array}{c}-0.005^{* * *} \\
(0.002)\end{array}$ \\
\hline Mean Y - 1940 & 0.84 & 0.84 & 0.88 & 0.88 \\
\hline Mean Y - 1950 & 0.87 & 0.87 & 0.92 & 0.92 \\
\hline Commuting Zones & 586 & 586 & 586 & 586 \\
\hline Mean war exp per capita & 0.45 & 0.45 & 0.45 & 0.45 \\
\hline Metro FE & X & $\mathrm{X}$ & X & $\mathrm{X}$ \\
\hline Division-Year FE & $\mathrm{X}$ & $\mathrm{X}$ & $\mathrm{x}$ & $\mathrm{x}$ \\
\hline Baseline controls & - & $\mathrm{X}$ & - & $\mathrm{X}$ \\
\hline Draft control & - & $X$ & - & $X$ \\
\hline
\end{tabular}

Note: Sample is 586 commuting zones after excluding commuting zones with no war expenditures. See equation 1 for the basic specification. War expenditure is $\$ 1000$ s per capita. Share skilled is the share of employed men who are not farmers, laborers, or service workers. Wages are total wage earnings in the previous year for men who are currently employees. Prime-age employment is the share of men ages 25-54 who are employed. Baseline controls are 1940 variables interacted with a post indicator: average years of education, share employed in manufacturing, share employed in agriculture, and share Black. Draft control is predicted draft rate based on 1940 demographics. Primary data sources are 1940 (100\%; 5\% subsample for whites) and 1950 (1\%) Census samples. Metro area definitions based on 1940 and 1950 Census Bureau definitions. All values are in 1940 dollars. Regressions are weighted by relevant population. Robust standard errors in parentheses. ${ }^{*} \mathrm{p}<.1 ;{ }^{* *} \mathrm{p}<.05 ;{ }^{* * *} \mathrm{p}<.01$ 
Table A8: Effect of war expenditures on occupational segregation (1940-1950)

\begin{tabular}{|c|c|c|c|c|}
\hline & \multirow{2}{*}{\multicolumn{2}{|c|}{$\begin{array}{c}(1) \\
\text { Occ dissimilarity index }\end{array}$}} & \multirow{2}{*}{\multicolumn{2}{|c|}{$\begin{array}{c}(3) \\
\ln (\text { Occ dissimilarity index })\end{array}$}} \\
\hline & & & & \\
\hline & Basic & Adjusted & Basic & Adjusted \\
\hline \multicolumn{5}{|l|}{ Panel A: All metros } \\
\hline War exp per capita * Post & $\begin{array}{c}-0.009^{* *} \\
(0.004)\end{array}$ & $\begin{array}{c}-0.011^{* *} \\
(0.004)\end{array}$ & $\begin{array}{c}-0.016^{* *} \\
(0.007)\end{array}$ & $\begin{array}{c}-0.022^{* *} \\
(0.009)\end{array}$ \\
\hline $\mathrm{N}$ & 270 & 270 & 270 & 270 \\
\hline \multicolumn{5}{|l|}{ Panel B: Excluding South } \\
\hline War exp per capita * Post & $\begin{array}{c}-0.010^{* * *} \\
(0.004)\end{array}$ & $\begin{array}{c}-0.013^{* * *} \\
(0.005)\end{array}$ & $\begin{array}{c}-0.019^{* * *} \\
(0.007)\end{array}$ & $\begin{array}{l}-0.026^{* *} \\
(0.010)\end{array}$ \\
\hline $\mathrm{N}$ & 172 & 172 & 172 & 172 \\
\hline Mean war exp per capita & 1.46 & 1.46 & 1.46 & 1.46 \\
\hline Metro FE & $X$ & $\mathrm{X}$ & $X$ & $X$ \\
\hline Division-Year FE & $X$ & $X$ & $X$ & $X$ \\
\hline Baseline controls & $x$ & $X$ & $x$ & $X$ \\
\hline Draft control & $X$ & $X$ & $X$ & $X$ \\
\hline
\end{tabular}

Note: Full sample is 147 metro areas; educational expenditures is available for only 121 metro areas. See equation 1 for the basic specification. Residential segregation indices are from Cutler et al. (1999) and are only available for 43 of our metro areas. Baseline controls are 1940 variables interacted with a post indicator: average years of education, share employed in manufacturing, share employed in agriculture, and share Black. Draft control is predicted draft rate based on 1940 demographics. Robust standard errors in parentheses. ${ }^{*} \mathrm{p}<.1 ;{ }^{* *} \mathrm{p}<.05 ;{ }^{* * *} \mathrm{p}<.01$ 


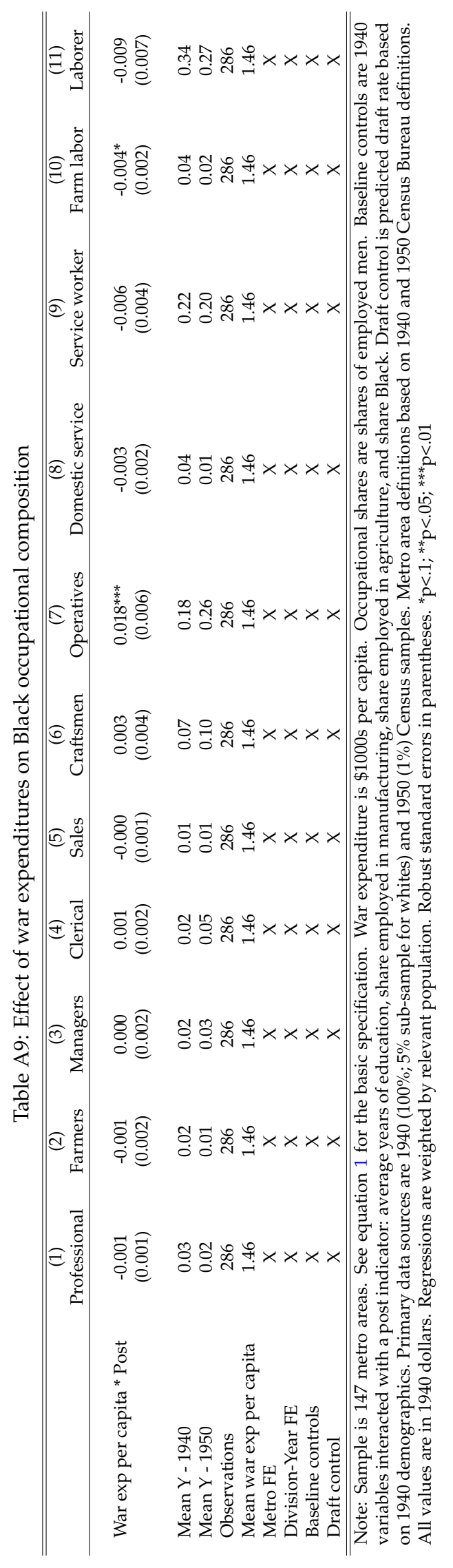


Table A10: Oaxaca-Blinder $\ln$ (yearly wage) decomposition

\begin{tabular}{|c|c|c|c|c|c|}
\hline & \multicolumn{2}{|c|}{$\ln$ (Wage) gap } & \multicolumn{3}{|c|}{$\Delta 1940-50$} \\
\hline & $\overline{1940}$ & 1950 & Pure change & Price change & Total change \\
\hline Overall & 0.63 & 0.38 & & & -0.25 \\
\hline Explained & 0.37 & 0.22 & -0.03 & -0.11 & -0.14 \\
\hline Education & 0.14 & 0.08 & -0.01 & -0.06 & -0.06 \\
\hline Occupation & 0.21 & 0.13 & -0.03 & -0.04 & -0.07 \\
\hline Industry & 0.05 & 0.02 & -0.01 & -0.02 & -0.03 \\
\hline Region & 0.02 & 0.01 & -0.01 & 0.00 & -0.01 \\
\hline Age & -0.04 & -0.01 & 0.02 & 0.01 & 0.03 \\
\hline Unexplained & 0.26 & 0.16 & & & -0.10 \\
\hline
\end{tabular}

Note: Sample includes Black and native born white men who are wage earners. See Appendix Section C.3 for more detail. Education includes years of education interacted with division of birth and dummies for high school and college completion. Occupation includes dummies for ten aggregate occupational groupings. Industry includes dummies for twelve aggregated industry groupings. Region includes dummies for nine Census divisions. Age includes a cubic polynomial in age. "Explained" gaps evaluated at coefficients for white men. "Pure" change captures compositional changes while "price' captures changing coefficients. Data comes from 1940 (100\%; 5\% sub-sample for white men) and 1950 (1\%) Census samples. 
Table A11: Effect of war expenditures on migration

\begin{tabular}{|c|c|c|c|c|c|c|}
\hline & (1) & $\begin{array}{c}(2) \\
\text { Black Men }\end{array}$ & (3) & (4) & $\begin{array}{c}\text { (5) } \\
\text { White Men }\end{array}$ & (6) \\
\hline & $1930-40$ & $1940-50$ & $1950-60$ & 1930-40 & $1940-50$ & 1950-60 \\
\hline War exp per capita * Post & $\begin{array}{c}0.007 \\
(0.013)\end{array}$ & $\begin{array}{l}0.051^{* *} \\
(0.022)\end{array}$ & $\begin{array}{c}0.001 \\
(0.015)\end{array}$ & $\begin{array}{c}0.004 \\
(0.008)\end{array}$ & $\begin{array}{c}0.023^{* * *} \\
(0.007)\end{array}$ & $\begin{array}{l}-0.000 \\
(0.017)\end{array}$ \\
\hline Observations & 286 & 286 & 274 & 294 & 294 & 282 \\
\hline Mean war exp per capita & 1.46 & 1.46 & 1.46 & 1.46 & 1.46 & 1.46 \\
\hline Metro FE & $X$ & $X$ & $x$ & $X$ & $X$ & $X$ \\
\hline Division-Year FE & $x$ & $X$ & $X$ & $X$ & $X$ & $X$ \\
\hline Baseline controls & $x$ & $X$ & $x$ & $x$ & $x$ & $x$ \\
\hline Draft control & $X$ & $X$ & $X$ & $X$ & $X$ & $X$ \\
\hline
\end{tabular}

Note: Sample is 147 metro areas. The outcome is the change in the population of men. War expenditure is $\$ 1000$ s per capita. Baseline controls are 1940 variables interacted with a post indicator: average years of education, share employed in manufacturing, share employed in agriculture, and share Black. Draft control is predicted draft rate based on 1940 demographics. Primary data sources are 1930-1960 Census data. Metro area definitions based on 1940 and 1950 Census Bureau definitions. All values are in 1940 dollars. Regressions are weighted by relevant population. Robust standard errors in parentheses. ${ }^{*} \mathrm{p}<.1 ;{ }^{* *} \mathrm{p}<.05 ;{ }^{* * *} \mathrm{p}<.01$ 
Table A12: Ability of war expenditure shocks to explain aggregate migration

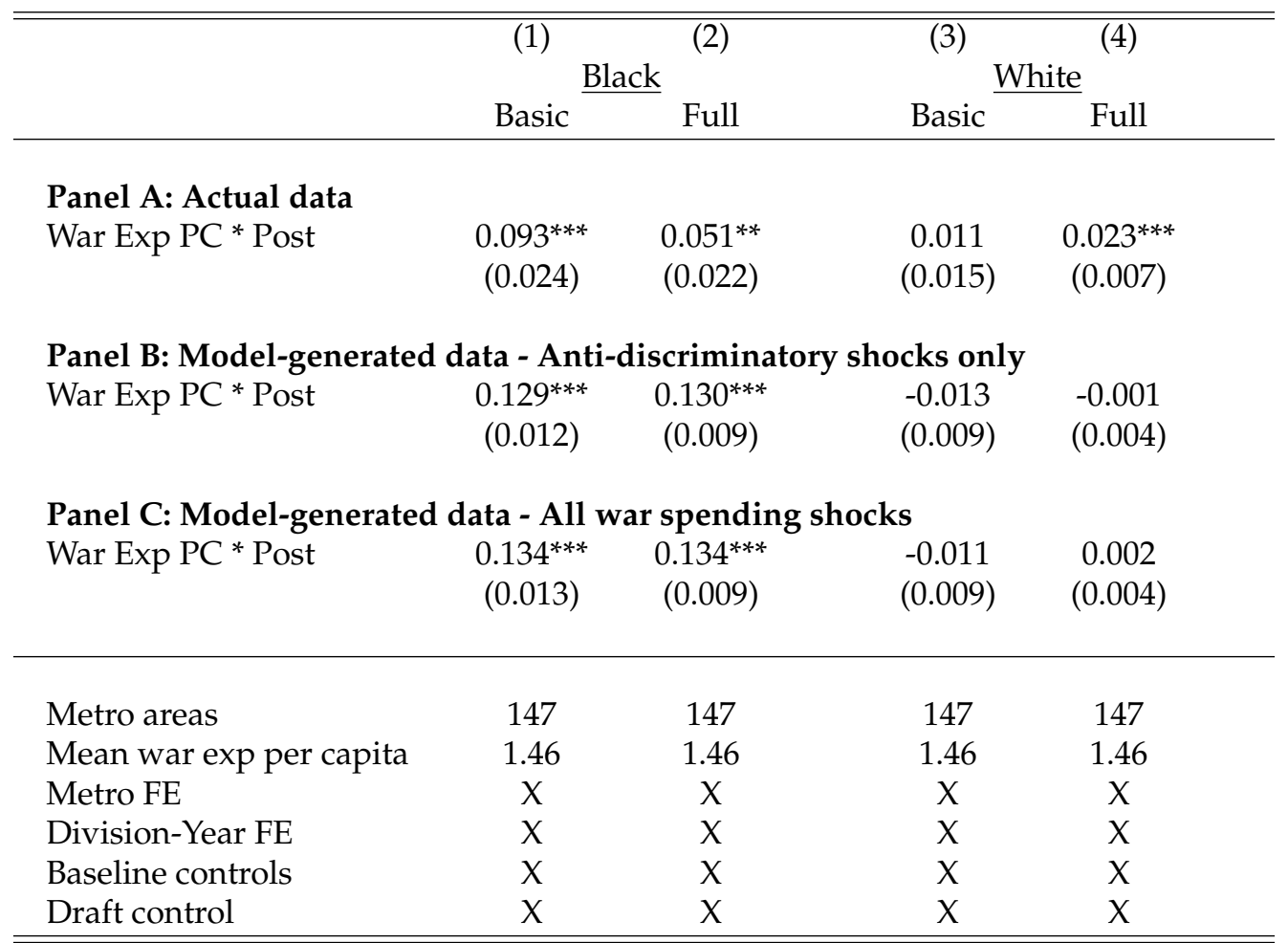

Note: Sample is 147 metro areas. For the actual data, the outcome is the change in the population of men. For the model data, the outcome is the change in the number of employed men. War expenditure is $\$ 1000$ s per capita. Baseline controls are 1940 variables interacted with a post indicator: average years of education, share employed in manufacturing, share employed in agriculture, and share Black. Draft control is predicted draft rate based on 1940 demographics. Primary data sources are 1940 and 1950 Census data. Metro area definitions based on 1940 and 1950 Census Bureau definitions. All values are in 1940 dollars. Regressions are weighted by relevant population. Robust standard errors in parentheses. ${ }^{*} \mathrm{p}<.1 ;{ }^{* *} \mathrm{p}<.05 ;{ }^{* * *} \mathrm{p}<.01$ 
Table A13: Effect of war expenditures on school attendance (1940-1960)

\begin{tabular}{|c|c|c|c|c|}
\hline & \multirow{2}{*}{\multicolumn{2}{|c|}{$\begin{array}{l}(1) \\
\text { Black Children }\end{array}$}} & \multirow{2}{*}{\multicolumn{2}{|c|}{$\begin{array}{l}\text { (3) } \\
\text { White Children }\end{array}$}} \\
\hline & & & & \\
\hline & Boys, $16-18$ & Girls, 16-18 & Boys, $16-18$ & Girls, 16-18 \\
\hline \multicolumn{5}{|l|}{ Panel A: All metros } \\
\hline \multirow[t]{2}{*}{ War exp per capita * Post } & $0.014^{*}$ & 0.004 & 0.003 & 0.003 \\
\hline & $(0.008)$ & $(0.007)$ & $(0.006)$ & $(0.006)$ \\
\hline N - Pre & 127,085 & 144,710 & 81,738 & 81,738 \\
\hline N - Post & 10,783 & 11,852 & 36,491 & 36,491 \\
\hline \multicolumn{5}{|l|}{ Panel B: Excluding South } \\
\hline \multirow[t]{2}{*}{ War exp per capita * Post } & $0.023^{* *}$ & 0.005 & -0.000 & -0.000 \\
\hline & $(0.010)$ & $(0.008)$ & $(0.006)$ & $(0.006)$ \\
\hline N - Pre & 56,707 & 62,974 & 69,176 & 69,176 \\
\hline N - Post & 6,064 & 6,868 & 29,142 & 29,142 \\
\hline Mean Y - Pre & 0.50 & 0.50 & 0.65 & 0.61 \\
\hline Mean Y - Post & 0.66 & 0.62 & 0.75 & 0.70 \\
\hline Mean war exp per capita & 1.46 & 1.46 & 1.46 & 1.46 \\
\hline Metro-Age FE & $X$ & $X$ & $X$ & $X$ \\
\hline Division-Year-Age FE & $\mathrm{X}$ & $x$ & $\mathrm{X}$ & $\mathrm{X}$ \\
\hline Draft control & $x$ & $x$ & $\mathrm{X}$ & $x$ \\
\hline
\end{tabular}

Note: Regression at the individual level and only includes children living in one of 147 metro areas. See equation 1 for the basic specification. School attendance is an indicator whether the child attended any school in the past month (1940) or two months (1960). Draft control is predicted draft rate based on 1940 demographics. Primary data sources are 1940 (100\%; 5\% sub-sample for whites) and 1960 (5\%; 40\% sub-sample for whites) Census samples. Regressions weighted by sample line weights. Standard errors clustered at the metro-year level. ${ }^{*} \mathrm{p}<.1 ;{ }^{* *} \mathrm{p}<.05 ;{ }^{* * *} \mathrm{p}<.01$ 
Table A14: Placebo effect of war expenditures on school attendance (1930-1940)

\begin{tabular}{|c|c|c|c|c|}
\hline & \multirow{2}{*}{\multicolumn{2}{|c|}{$\begin{array}{l}(1) \\
\text { Black Children }\end{array}$}} & (3) & $(4)$ \\
\hline & & & \multicolumn{2}{|c|}{ White Children } \\
\hline & Boys, $\overline{16-18}$ & Girls, $16-18$ & Boys, $\overline{16-18}$ & Girls, $16-18$ \\
\hline \multicolumn{5}{|l|}{ Panel A: All metros } \\
\hline War exp per capita * Post & $\begin{array}{l}-0.005 \\
(0.008)\end{array}$ & $\begin{array}{c}0.000 \\
(0.006)\end{array}$ & $\begin{array}{c}-0.001 \\
(0.004)\end{array}$ & $\begin{array}{c}-0.001 \\
(0.004)\end{array}$ \\
\hline N-Pre & 4,983 & 6,119 & 73,194 & 73,194 \\
\hline $\mathrm{N}$ - Post & 127,085 & 144,710 & 81,738 & 81,738 \\
\hline \multicolumn{5}{|l|}{ Panel B: Excluding South } \\
\hline War exp per capita * Post & $\begin{array}{c}-0.016 \\
(0.011)\end{array}$ & $\begin{array}{c}0.004 \\
(0.006)\end{array}$ & $\begin{array}{c}-0.004 \\
(0.004)\end{array}$ & $\begin{array}{c}-0.004 \\
(0.004)\end{array}$ \\
\hline N - Pre & 2,034 & 2,414 & 63,215 & 63,215 \\
\hline N - Post & 56,707 & 62,974 & 69,176 & 69,176 \\
\hline Mean Y - Pre & 0.38 & 0.38 & 0.50 & 0.46 \\
\hline Mean Y - Post & 0.50 & 0.50 & 0.65 & 0.61 \\
\hline Mean war exp per capita & 1.46 & 1.46 & 1.46 & 1.46 \\
\hline Metro-Age FE & $X$ & $X$ & $X$ & $X$ \\
\hline Division-Year-Age FE & $\mathrm{X}$ & $x$ & $x$ & $\mathrm{X}$ \\
\hline Draft control & $X$ & $x$ & $x$ & $\mathrm{X}$ \\
\hline
\end{tabular}

Note: Regression at the individual level and only includes children living in one of 147 metro areas. See equation 1 for the basic specification. School attendance is an indicator whether the child attended any school in the past six months (1930) or month (1940). Draft control is predicted draft rate based on 1940 demographics. Primary data sources are $1930(5 \%)$ and 1940 (100\%; 5\% sub-sample for whites) Census samples. Regressions weighted by sample line weights. Standard errors clustered at the metro-year level. ${ }^{*} \mathrm{p}<.1 ;{ }^{* *} \mathrm{p}<.05 ;{ }^{* * *} \mathrm{p}<.01$ 
Table A15: Effect of war expenditures on returns to education (1940-1950)

\begin{tabular}{lcccc}
\hline \hline & \multicolumn{2}{c}{$(1)$} & $(2)$ & \multicolumn{2}{c}{$(3)$} & $(4)$ \\
& \multicolumn{2}{c}{ Black men } & & \\
& & & & \\
& & & & \\
& & & & \\
War exp per capita * Post & $(0.013)$ & $(0.026)$ & $(0.004)$ & $(0.013)$ \\
& $0.037^{* * *}$ & $0.039^{* * *}$ & $0.074^{* * *}$ & $0.078^{* * *}$ \\
Education & $(0.001)$ & $(0.002)$ & $(0.001)$ & $(0.002)$ \\
& $-0.015^{* * *}$ & $-0.010^{* *}$ & $-0.031^{* * *}$ & $-0.033^{* * *}$ \\
Education * Post & $(0.003)$ & $(0.005)$ & $(0.002)$ & $(0.004)$ \\
& & -0.001 & & $-0.002^{* * *}$ \\
War exp per capita * Education & & $(0.001)$ & & $(0.001)$ \\
& & -0.003 & & 0.001 \\
War exp per capita * Education * Post & & $(0.002)$ & & $(0.001)$ \\
& & & & \\
N - Pre & $1,081,781$ & $1,081,781$ & 715,189 & 715,189 \\
N - Post & 5,471 & 5,471 & 54,388 & 54,388 \\
Mean war exp per capita & 1.46 & 1.46 & 1.46 & 1.46 \\
Metro FE & $X$ & $X$ & $X$ & $X$ \\
Division-Year FE & $X$ & $X$ & $X$ & $X$ \\
Baseline controls & $X$ & $X$ & $X$ & $X$ \\
Draft control & $X$ & $X$ & $X$ & $X$ \\
Individual controls & $X$ & $X$ & $X$ & $X$ \\
\hline \hline
\end{tabular}

Note: Regression at the individual level and only includes men living in one of 147 metro areas. Wages are total wage earnings (1940 dollars) in the previous year for men who are currently employees. Education is based on highest year of education completed. Individual controls include a cubic in age, whether born in the South, and whether married; all individual controls are interacted with year indicators. Baseline controls are 1940 variables interacted with a post indicator: average years of education, share employed in manufacturing, share employed in agriculture, and share Black. Draft control is predicted draft rate based on 1940 demographics. Primary data sources are 1940 (100\%; 5\% sub-sample for whites) and 1950 (1\%) Census samples. Regressions weighted by sample line weights. Standard errors clustered at the metro-year level. ${ }^{*} \mathrm{p}<.1$; ${ }^{* *} \mathrm{p}<.05$; *** $\mathrm{p}<.01$ 


\section{B Data Appendix}

\section{B.1 Census data}

Individual Census records. The primary source of Census data are individual Census records from Ruggles et al. (2020). We use the 100\% 1920, 5\% 1930, 100\% 1940, 1\% 1950, $5 \% 1960$, and 1\% 1970 (metro) samples. Due to data and processing considerations, we take a $2 \%$ random sample of whites and $20 \%$ sub-sample of Blacks from the 1920 Census. Similarly, for the 1940 Census we use a 5\% random sample of whites and for the 1960 we use a $40 \%$ sub-sample for whites (resulting in a $2 \%$ sample). Individuals in institutional group quarters are excluded.

Metro areas: Metro areas are based on the IPUMS variable "metaread". These are county based measures. Definitions vary slightly over time, but the basic qualification is the county must contain a city of at least 50,000 people or integrated with another county containing a qualifying city. Metro areas could expand or contract over time. Counties are identified in the 1940 and earlier samples so a consistent county based definition is applied. Metro definitions were relatively unchanged between 1940 and 1950. There were more significant changes in the 1960 and 1970 Censuses. Several metro areas that were split between 1950 and 1960 are re-aggregated to maintain comparability. For long-term analysis (1920-1970) consistent metro definitions are imposed by using 1990 commuting zone boundaries. Earlier geographic boundaries (counties for 1940 and earlier, SEAs for 1950, PUMAs for 1960, and 1970 county groups for 1970) are crosswalked to commuting zones based on Eckert et al. (2018). Observations are weighted based on the geographic overlap between their geographic region and the commuting zone of interest.

Employment: Employment status is based on the IPUMS variable "empstat". This variable is not available in 1920. The reference period varies slightly across Censuses. In 1930 an individual is counted as employed if they were working on the most recent regular working day. In 1940 and later, an individual was counted as employed if they worked at all during the reference week. Prime-age employment is used as an outcome measure due to concerns about how the labor force and unemployment are measured across years. Prime-age workers are defined as individuals ages 25-54. Prime-age male employment is defined as the share of men in this age range who are employed.

Occupation and industry: Occupation and industry are coded using the 1950 Census coding system. Skilled occupations are defined as occupations falling in the following categories: "Professional, Technical;" "Managers, Officials, and Proprietors;" "Clerical and Kindred;" "Sales workers;" "Craftsmen;" or "Operatives" categories. This corresponds to occupational codes 000-093, 200-690 under the 1950 IPUMS occupational coding scheme. 
Semiskilled or skilled blue-collar occupations are a sub-category of skilled occupations that fall under the "Craftsmen;" or "Operatives" categories. Occupational shares are constructed using currently employed individuals who are aged $14+.{ }^{61}$

Defense industry is defined as mining, manufacturing, transportation and government industries, following Collins (2001). These industries were most likely to be included in the War Manpower Commissions defense industry employment reports. These industries correspond to 1950 IPUMS industry codes 203-239, 306-499, 506-568, 906-946. Following Acemoglu et al. (2004), key defense industries are defined as durable goods manufacturing industries and these correspond to IPUMS 1950 industry codes 326-388.

Employee: A worker is defined as an employee based on the IPUMS variable "classwkrd". Employees are defined as individuals who are currenlty in the labor force and have classwkrd codes 20-28, which corresponds to categories "Works on Salary", "Wage/salary, private", and "Wage/salary, government".

Wage income: Yearly wage income is created using the IPUMS variable "incwage". This variable comes from the Census question asking for each person's total pre-tax wage and salary income. This question was first introduced in 1940. Yearly wage income is specifically payments for work done as an employee; it excludes self-employment income or personal business income. This restriction is especially relevant for farmers. Unfortunately, the 1940 Census did not ask for information on business or other sources of income. The wage income sample is restricted to individuals who are (1) are employees at the time of the Census, (2) are employed at the time of the Census, and (3) their primary occupation is not farmer or unpaid family farm laborer. Only sample line respondents were asked about wage income in the 1950 Census.

An additional issue is how to deal with top-coded values or implausibly low earnings totals. We follow Goldin and Katz (1992) by multiplying top-coded values by 1.4 and recoding as missing values that are less than $1 / 2$ the minimum weekly wage. This corresponds to weekly earnings below \$6 in 1940, \$8 in 1950, \$20 in 1960 and \$28 in 1970.

Education: Years of education is created based on the IPUMS variable "educ". Individuals with five or more years of college are all coded as having seventeen years of education. Individuals with twelve years of completed schooling are assumed to have completed high school. This question was first asked in the 1940 Census. Only sample line respondents were asked about highest completed grade in the 1950 Census.

The IPUMS variable "school" is used to classify whether a child is currently attending school. The question changed slightly across Census years but was relatively consistent from 1940 to 1950. The main changes across Censuses are (1) length of retrospective

\footnotetext{
${ }^{61}$ Results are robust to using share of all individuals in the labor force instead.
} 
reference period and (2) qualifying educational institutions. The retrospective reference periods are: previous four months in 1920, previous six months in 1930, previous month in 1940, and previous two months for 1950 and on. Qualifying educational institutions are: any type of school in 1920, any school or night school in 1930, any school and night school/extension programs if part of the regular school system in 1940 and 1950, any school that advances a person towards high school or college degree in 1960. Across all years the respondent only has to indicate whether the person has attended a qualifying institution in the reference period, but they do not need to regularly attend. Only sample line respondents were asked about school attendance in the 1950 Census.

Census aggregates. Census aggregates are taken from published Census volumes. County population totals by age and race are taking from ICPSR 02896 (Haines and ICPSR, 2010). Manufacturing output and value added from the Census of Manufactures are taken from the same source. We also digitized new metro-level data from the 1950 Census. The only individual level data available for 1950 is the 1\% sample. This means we limited Black observations for metro areas with small Black populations. From Volume II of the 1950 Census of Population we digitize the following: Table 77 which has total employment for each metro by race-sex-occupation, Table 83 which has total employment for each metro by race-sex-industry, and table 87 which has total counts for each metro by racesex-income bin, as well as the median income by race and sex. We use this data rather than totals from individual counts whenever possible. For heterogeneity analysis (e.g., by age or education), we rely on the individual Census data.

\section{B.2 Draft rate}

Creating a predicted draft rate. We use a predicted draft rate rather than actual draft or enlistment rate. A predicted draft rate is created for each metro area by using draft records to identify national draft rates by group and then applying these draft rates to the baseline demographics for each metro in 1940.

The drawback of the predicted draft measure as a control is that it will not control for all sources of variation in draft rates. For example, some areas might have had stricter draft boards or a higher share of individuals who did not meet minimum military standards. However, we believe we are capturing the largest source of exogenous variation in draft rates. If the predicted draft rate does not affect our estimates then it is less likely these smaller sources of variation would meaningfully alter our results. ${ }^{62}$

Our primary source of draft data are the WWII Army Enlistment Records provided by

\footnotetext{
${ }^{62}$ Our results are also robust to using the actual draft rate. Results available upon request.
} 
the National Archives and Records Administration. This data series contains the records of about nine million men and women who enlisted in the U.S. Army. The records typically contain the serial number, name, place of residence, place and date of enlistment, education, occupation, marital status, and race of the enlistee. There are several gaps in the records. First, the data is only for the U.S. Army so it excludes other service branches, such as the Navy (although the Air Force was still part of the Army during WWII). Second, some records are known to be missing. Finally, some of the scanned records are unusable due to poor scans.

The secondary source of data are Selective Service System (1956). We digitized tables reporting total inductions and enlistments by service branch, month, and race. This data identifies how many inductions are not captured in the individual enlistment data for each month. We re-weight the individual observations by the number of records missing in their enlistment month. For example, if the individual records cover half of total inductions in a given month then the observed inductions will be given double the weight. Implicitly, this also assumes that individuals drafted into the Navy in any given month have similar characteristics to individuals drafted into the Army in the same month, conditional on race. The reason we re-weight the observations within a month is that draft eligibility and probabilities changed throughout the war. For example, initially individuals younger than 21 were not eligible for the draft but later in the war the minimum age eligibility was reduced to 18 . We condition on race because there is evidence the Army was much more willing to accept Black men than the Navy. ${ }^{63}$

Only records of enlistments between January 1940 and December 1945 are included. Individuals who are younger than 17 or older than 45 at time of enlistment are dropped. We restrict the sample to individuals who were draft based on their serial codes. Serial codes that start with three or four indicate that the individual was drafted.

We next find the total number of individuals drafted each year by demographic group. We create demographic cells using race, year of birth, nativity, and marital status. All of these variables were important determinants of draft probabilities.

The next step is to create draft rates by demographic group and year. We use 1940 Census data to determine the population in each demographic cell. Most of the characteristics are time-invariant except for marital status. Marital status was one of the key determinants for whether someone was drafted. There is also significant variation across metro areas in typical age at marriage and marriage rates. We create marriage hazard rates using marriage rates across cohorts in 1940. We then follow each cohort from 1940 to 1945; first applying the marriage hazard rate and then subtracting the number of in-

\footnotetext{
${ }^{63}$ Black men served almost exclusively in mess units for much of the war in the Navy.
} 
dividuals who enlisted each year. For the next year, we apply the marriage hazard rate to the remaining single individuals and repeat the process. Therefore, for each year we have the number of married and single individuals for each demographic group in each cohort. To create the draft rate for that year and demographic group we then take the total number of individuals drafted and divide by the population in each given demographic group.

The final step is to apply these draft rates to each metro. We follow a similar process to the above to generate the number of married and single individuals for each demographic group in each year, using metro specific marriage hazard rates for whites and a national rate for Blacks. We use a national rate for Blacks because some metro areas have small Black populations which makes it difficult to calculate metro specific hazard rates. Once we have the number of individuals in each demographic group for each year we apply the national draft rates for that group and aggregate to create the total number of individuals drafted in each metro. We then divide by the male population ages 15-64 in 1940.

We also create an actual draft rate measure for comparison and to see if our predicted draft rate does predict the actual draft rate. When calculating the actual draft rate we scale the denominator by an estimate of the population growth between 1940 and 1943 . We do this to account for the fact that a large number of people migrated during the first part of the war. Without this correction, using 1940 population as a denominator would lead to higher draft rates in areas with higher net in-migration. Since war expenditure increase migration (see Appendix Section D.3 this would create a positive correlation between draft rate and war expenditures.

Results. Appendix Table A4 shows that our predicted draft rate is a strong predictor of the actual draft rate. Therefore, it seems as though it is a valid measure of draft intensity. Table A4 shows that both the predicted and actual draft rate are negatively correlated with war expenditures. Moreover, the predicted draft rate is positively correlated with labor shortages, even conditional on war expenditures. This correlation provides evidence that our predicted draft variable has the expected consequence on labor supply.

\section{B.3 Other data}

We supplement the above data with several additional data sources.

Labor shortage data. We digitized reports on the extent of labor shortages during WWII by month. These reports were from the monthly Labor Market Reports compiled by the War Manpower Commission. These classified labor markets by whether they were facing labor shortages. Labor shortages were defined based on comparing expected hiring 
versus the number of people expected to be looking for work combined with subjective adjustments by government officials.

We create our measure of labor market shortages by taking the percentage of months between 1942 and 1944 that the labor market experienced severe labor shortages (on the map this corresponded to labor markets with completely shaded circles). About $20 \%$ of metro-month observations were coded as severe labor shortages.

Defense industry employment during WWII. The War Manpower Commission regularly surveyed employers in war industries or critical labor markets on their employment. These surveys were ES-270 reports. These reports did not cover the entire labor market but did cover a large share of war industry employment. For more details and examples of usage in other research, please see Collins (2001) or Rose (2018).

\section{Labor Market Context}

\section{C.1 Occupational distribution and changes 1940-50}

First, some notes on occupational categories. The aggregate occupational categories are "Profession, Technical;" "Farmers;" "Managers, Officials, and Proprietors;" "Clerical and Kindred;" "Sales workers;" "Craftsmen;" "Operatives;" "Domestic Service;" "Service';' "Farm Laborer;" and "Laborer". Appendix Figure A.2 shows the average wages and education for white men by occupation. The occupations are colored based on which aggregate occupational category they belong to. It is clear that occupations in the "Domestic Service;" "Service';' "Farm Laborer;" and "Laborer" pay significantly less on average and also employ workers with lower education levels.

Appendix Table A1 shows the occupational distribution for white and Black men in 1940 and 1950. Several facts are immediately clear. First, Black and white men have very different occupational distributions with Black men being concentrated in unskilled occupations. As seen in Appendix Figure A.2, these are the occupations with the lowest pay and lowest education. Secondly, the occupational distribution for Black men significantly changed between 1940 and 1950 with large increases in the "Craftsmen" and "Operatives" categories. These observations are consistent with Collins (2000). The occupational distribution for white men changed as well but to a much lesser extent. These results are consistent with the finding of occupational upgrading for Black men in Collins (2000). These facts provide preliminary motivation for our focus on the impact of WWII expenditures on occupational upgrading for Black men. 


\section{C.2 Occupational segregation}

An immediate question is to what extent these occupational differences between Black and white men can be explained by differences in education or location. For example, Black men were much more likely to live in the South and less likely to live in metro areas and had significantly less education on average. However, there are plenty of examples of explicit discrimination, for example Appendix Table A2 lists a number of unions with explicit or effective bars on Black membership. There are two interesting questions to ask: first, which occupations seem to be most segregated, and second, which metro areas seem to be most segregated?

First, we compare segregation across occupations by looking at the expected number of Black workers, based on random allocation within education group and region, and compare it to the actual number of workers. We restrict the sample to men living in metro areas who are employed at the time of the Census. We define education groups as 0-5 years, 6-8 years, 9-11 years, 12-15 years, and 16+ years. Following Margo (1995), we account for school quality differences by multiplying years of education by 0.85 for Black men born in the South with less than 15 years of education. This adjustment roughly corresponds to the difference in average school term length between Blacks and whites in segregated Southern schools during the 1920s. Occupations are defined using the occupation and industry categories in Table 77 of the state breakouts in the 1950 Census Volume II. The number of expected Black workers is calculated by:

$$
\text { Expected }_{o}=\sum_{r} \sum_{e}\left(\frac{\text { Black }_{r e}}{\text { Pop }_{r e}} * \text { Positions }_{\text {ore }}\right)
$$

Where $\frac{\text { Black }}{\text { Pop } r e}$ is the share of Black men within region $r$ and educational group $e$ and Positions $_{\text {ore }}$ is the number of positions in occupation $o$ held by men in region $r$ and educational group $e$. To get a measure of the gap for each occupation we then divide by the actual number of Black men observed in occupation $o$. Appendix Table A3 reports the occupations with the top fifteen largest and smallest ratios of expected vs. actual employment.

A second question of interest is comparing occupational segregation across regions. A natural index to measure occupational segregation is the Duncan index (Duncan and Duncan, 1955). The Duncan index is defined as:

$$
\text { Duncan }_{r}=\sum_{o}\left|\frac{\text { Black }_{\text {or }}}{\text { Black }_{r}}-\frac{\text { White }_{\text {or }}}{\text { White }_{r}}\right|
$$

Fundamentally, this index is a measure of "evenness", i.e. how evenly are Black men dis- 
tributed across occupations. There are two related issues with this metric. First, if Black men are a small percentage of the population or many occupations have few positions then there will be substantial deviations from evenness due to pure chance as noted in Carrington and Troske (1997). Secondly, this metric does not distinguish between differences due to education versus occupational segregation. While occupational segregation can cause educational differences, our focus here is on occupational segregation conditional on education.

We can adjust the Duncan index by estimating the expected Duncan index, $E\left[\right.$ Duncan $\left._{r}\right]$, if workers are allocated randomly across jobs conditional on education and calculating the adjusted index:

$$
\text { Duncan }_{r}^{\text {Adj }}=\frac{1}{2} \frac{\text { Duncan }_{r}-E\left[\text { Duncan }_{r}\right]}{1-E\left[\text { Duncan }_{r}\right]}
$$

We calculate $E\left[\right.$ Duncan $\left._{r}\right]$ by simulating fifty random occupational distributions for each metro area where the number of Black individuals in each occupation and education group are simulated using binomials where the probability of "success" is the share of Black men within the relevant education group.

Appendix Figure A.1 displays a map where the shading corresponds to the value of the adjusted Duncan index. The primary results are that there is substantial occupational segregation and that the segregation is not limited to the South.

\section{C.3 Oaxaca-Blinder decomposition}

Another way of examining the labor market context is to decompose wage differences in an Oaxaca-Blinder framework. We can decompose the aggregate wage gap into the portion that can be explained by differences in observables and the portion that cannot be explained by observables. The cross-sectional regression of (log of) wage on observables is:

$$
Y_{i}=\beta X_{i}+\varepsilon_{i}
$$

Evaluating the OLS estimate at the mean values gives:

$$
\bar{Y}=\hat{\beta} \bar{X}
$$

The difference between Black and white outcomes can be decomposed into:

$$
\bar{Y}^{W h}-\bar{Y}^{B l}=\underbrace{\beta^{\hat{W} h}\left(\bar{X}^{W h}-\bar{X}^{B l}\right)}_{\text {Observables }}+\underbrace{\left(\hat{\beta}^{W h}-\hat{\beta}^{B l}\right) \bar{X}^{B l}}_{\text {Unobservables }}
$$


where the first term gives the portion of the wage gap that can be explained by observable differences and the second portion cannot be explained by observable characteristics. ${ }^{64}$ For 1940 and 1950, we regress (log of) wages on a set of variables for education (years of education interacted with region of birth, whether graduated high school, whether graduated college), occupation (indicators for eleven aggregate occupation categories), industry (indicators for twelve aggregate industry categories), region, and a cubic in age. The resulting decompositions are given in the first two columns of Appendix Table A10. We restrict the sample to native born men living in metro areas.

There are several key results. First, there is a large wage gap but it declines significantly between 1940 and 1950 - declining from 0.63 log points in 1940 to 0.38 log points in 1950. Second, education and occupation differences are the most important observable factors. Third, there is still a large portion of the gap that cannot be explained by observable characteristics.

We can take this decomposition a step further and decompose the changes between 1940 and 1950. We focus on decomposing the change in the explained gap into a "price" effect and "pure" effect. The price effect is due to changing coefficient values that benefit one race relatively more than the other (changes in $\beta$ ). The pure effect is due to relative changes in observables (changes in $\bar{X}$ ).

$$
\Delta_{40-50} \beta^{\hat{W} h}\left(\bar{X}^{W h}-\bar{X}^{B l}\right)=\underbrace{\beta^{W h, 50}\left(\Delta_{40-50} \bar{X}^{W h}-\Delta_{40-50} \bar{X}^{B l}\right)}_{\text {Pure }}+\underbrace{\Delta_{40-50} \hat{\beta}^{W h}\left(\bar{X}^{W h, 40}-\bar{X}^{B l, 40}\right)}_{\text {Price }}
$$

The results are given in the last three columns of Appendix Table A10. Overall, education and occupation changes explain most of the decline in the wage gap due to observables. The change in the gap due to education is almost entirely due to price effects (lower returns to education). On the other hand, the change in the gap due to occupation is due to both price effects (relatively higher returns for occupations with more Black men) and pure effects (Black men changing occupation). The price effects are consistent with the finding in Margo (1995) of wage compression across education groups and occupations that relatively benefited Black men. However, we also observe meaningful changes in the wage gap due to changes in the occupational composition of Black men, which is consistent with occupational upgrading.

\footnotetext{
${ }^{64}$ We evaluate the gap at the coefficient values for white men. We could have evaluated the gap at the coefficients for Black men or some combination of the two but alternative approaches do not change our qualitative findings.
} 


\section{Robustness and Supplementary Analysis}

\section{D.1 Impact of war expenditures on labor market outcomes during WWII}

ES-270. Our main analysis looks at changes between 1940 and 1950 but it is also instructive to look at how war expenditures impacted employment during the war. The first way we can analyze the impact during the war is to look at the impact on employment in war industries using the ES-270 reports. For more discussion on the data please see Appendix Section B.3. We use our standard difference-in-differences strategy and our outcome is the share employed in defense industries. There are several issues with this outcome variable. First, not all establishments are included in the ES-270 reports. Second, we do not have a concurrent estimate of the employed population. Finally, the ES-270 data is split by race or gender but not by race and gender.

Despite these issues it is still useful to look at the impact of war expenditures on outcomes during the war. First, our hypothesized mechanism requires employment changes during the war so if we do not see concurrent effects then we might question our results. Secondly, it is useful to compare the impact on whites and Blacks during the war. If there are effects on both during the war but only on Blacks after the war then it strengthens the hypthesis that it is due to changes in discrimination rather than experience gained during the war.

Appendix Table A5 has the results. Higher war expenditure is strongly associated with higher defense industry employment for Blacks and whites. Therefore, it seems as though war expenditures did affect both Blacks and whites during the war.

\section{D.2 Short-term labor market outcomes}

Geographic unit of analysis. Another concern is that our results might be dependent on the geographic unit of analysis. We repeat our main Table (Table 2) but for states and commuting zones. The results for states are presented in Appendix Table A6 and the results for commuting zones are presented in Appendix Table A7. In both cases our findings are similar to our main results at the metro level.

Occupational segregation. Another interpretation consistent with our results on occupational upgrading is that white men changed occupations within the skilled occupation group and Black men moved into those vacated occupations. In this scenario there is no decrease in occupational segregation. Therefore we want to check to see if the occupational distribution of Black men and white men became more similar in areas with higher war expenditures at a more granular level. We two measures for occupational segrega- 
tion. First, we use a Duncan index to measure deviations from evenness. Second, we use an adjusted Duncan index that is deviations from the expected evenness after accounting for randomness. We use our standard difference-in-differences approach:

$$
Y_{r t}=\beta_{1} \text { WarExp }_{r} \times \text { Post }_{t}+\beta_{2} \text { Draft }_{r} \times \text { Post }_{t}+\text { Post }_{t}+\gamma_{r}+X_{\text {irt }} \rho+\varepsilon_{\text {irt }}
$$

The results are presented in Appendix Table A8. Higher war expenditures are associated with lower occupational segregation for both measures. Therefore, it does seem as though the occupational composition for white and Black men became more similar in places with higher expenditures.

Excluding likely migrants. Our results could potentially be explained by selective migration. Black men with better skills and/or education could have migrated to metropolitan areas with higher war expenditures. They then stayed in these metropolitan areas after the war which could explain higher wages and occuptional upgrading. In order to test this theory, we re-run our main results but exclude potential interstate migrants in 1950. We define potential interstate migrants as anyone who was born in a different state that their state of residence and does not have a child eight years or older born in their current state of residence. If they have a child who was eight years or older and born in the same state then it is likely they did not move to their current state after WWII started. We validate this approach using the 1940 Census which asked for the place of residence five years prior and find it is highly accurate in identifying non-migrants. ${ }^{65}$

We use our standard difference-in-differences approach, except at the individual level with additional controls for age (cubic polynomial), marital staus, and region of birth:

$$
Y_{\text {irt }}=\beta_{1} \text { WarExp }_{r} \times \text { Post }_{t}+\beta_{2} \text { Draft }_{r} \times \text { Post }_{t}+\text { Post }_{t}+\gamma_{r}+X_{\text {irt }} \rho+\varepsilon_{\text {irt }}
$$

The results are presented in Table 3. The results excluding potential migrants are very similar to our main results. Therefore, it does not seem as though our results can be solely explained by selective migration.

Impact on younger cohorts. One potential explanation for the persistence of our results is that Black men gained valuable work experience during World War II which led to persistent productivity improvements. If this explains the persistence then workers who move to metropolitan area with higher war expenditures or future generations would not benefit from the accumulated experience. A way to test this explanation is to see occupational gains for cohorts who were too young to have gained significant experience

\footnotetext{
${ }^{65}$ The 1950 Census only asks for the place of residence on year prior. Validation results available upon request.
} 
during the war.

Men who are ages 18-24 in 1950 would have been 18 or younger in $1944^{66}$ and therefore would have not been able to accumulate significant experience or would have done so at the cost of reduced education. We compare 18-24 year olds in 1950 versus 1940 and then repeat the exercise using 18-34 year olds in 1960 versus 1940. We use our standard difference-in-differences approach, except at the individual level with additional controls for age, marital staus, and region of birth:

$$
Y_{\text {irt }}=\beta_{1} \text { WarExp }_{r} \times \text { Post }_{t}+\beta_{2} \text { Draft }_{r} \times \text { Post }_{t}+\text { Post }_{t}+\gamma_{r}+X_{\text {irt }} \rho+\varepsilon_{\text {irt }}
$$

The results are presented in Table 4 . The coefficients for the full sample and the restricted age samples are very similar. It does not seem as though the results can be explained purely by the experience gained during the war. One note of caution when interpreting the results is that younger cohorts could have benefitted from increased education; however, results are similar if education is included as a control.

Who upgraded? A natural question is who upgraded? Our robustness Figure 5 provides some preliminary evidence that upgrading occured across demographic groups. At an aggregate level, we can examing how occupational upgrading varied with age or educational status. Appendix Figure A.5 shows the share of men who are in skilled occupation by age for 1930, 1940, and 1950. The shares are roughly constant between 1930 and 1940 but then there is a major shift between 1940 and 1950. The most interesting finding is that the upgrading occured in all age groups. This suggests that changes in discrimination, rather than compositional changes, might be important. Similar results can be seen when looking at upgrading by educational groups. The upgrading occured for all educational groups, with the smallest changes for the highest education group. Again, large changes in occupational skill level even for the lowest levels of education (0-5 years) is most consistent with declines in discrimination rather than compositional changes.

A related question is what occupations within the skilled category did Black men enter? Table A9 gives the relationship between war expenditures and changes in employment shares for 11 aggregate occupation categories. Black men left domestic service, service worker, farm labor and common laborer occupations and primarily entereted operateives and craftsmen occupations (semi-skilled / skilled blue-collar). These occupations are both very common in manufacturing which was the key defense industry.

\footnotetext{
${ }^{66}$ War expenditures were ramping down in 1945.
} 


\section{D.3 Effect of war expenditures on migration}

First, the migration of Black families cannot be understood without discussing the Great Migration. This overview paragraph draws heavily from Collins (2020), an excellent review of economic research on the Great Migration. Prior to WWI, around 90\% of Black individuals lived in the South. Over the next six decades, millions migrated out of the South until less than half of Black individuals lived in the South in 1970. This migration took place in two waves; the first starting due to labor shortages during $\mathrm{WWI}^{67}$ and ending with the Great Depression. The second wave was precipated by WWII and ended in the 1960s. Collins and Wanamaker (2014) show that migrants had large earning gains. Migrants also had major impacts on the receiving Northern cities. Boustan (2009) shows how migrants impacted the labor market outcomes of Black and white workers in the North. Large influxes of new migrants also reduced intergenerational mobility for Black individuals (Derenoncourt, 2019). Finally, Black migrants also caused "white flight" to the suburbs (Boustan, 2010).

World War II expenditures were an important influence on the decision to migrate. Boustan (2010) and Derenoncourt (2019) instrument for migrant flows to Northern cities by using pre-existing migration networks interacted with "push" shocks in Southern counties. One of these shocks they use is war expenditures per capita. They find that war expenditures do predict migrant outflows, with higher expenditure areas associated with less out-migration. For this project, our concern is how war expenditures worked as a "pull" factor - i.e. were migrants more likely to go to areas with higher war expenditures. Figure A.6 shows the correlation between the change in (log of) population and war expenditures per capita. War expenditures are strongly associated wtih population increases for Black men between 1940 and 1950 but not between 1930 and 1940. For white men they are not strongly associated in 1940 to 1950 but there is a negative association in the pre-period which might indicate a positive impact relative to the existing trend.

Table A11 uses our basic specification 1. After adding controls there is still a strong relationship between migration and war expenditure for Black and white men. The effect appears to be larger for Black men. Therefore, migration does seem to be an important response. The importance of migration provides motivation for our quantitative model. Finally, Table A12 compares actual migration with model predicted migration. The model does a good job of predicting migration when minimal controls are used; however, it predicts higher rates of migration once more detailed controls are added. Potentially, there is some region level shocks that could account for this difference.

\footnotetext{
${ }^{67}$ Labor shortages were caused due to war demands combined with the sudden halt to European immigrant flows - see Collins (1997).
} 


\section{D.4 Education of the next generation}

School attendence 1930-40 and 1940-60. We repeat our analysis of the effect of war expenditures on school enrollment for the periods 1930-40 and 1940-60 instead of 1940-50. We follow our main difference-in-differences approach.

The results for 1930-40 are presented in Appendix Table A14. We do not see any significant relationship between war expenditures and changes in school enrollment. Therefore, there does not seem to be significant positive pre-trends or a slight negative trend.

The results for 1940-60 are presented in Appendix Table A13. We see a positive relationship between war expenditures and schooling for Black boys but no significant effect for Black girls. This result is consistent with our 1940-50 results that find stronger impacts on Black boys. The effect size is smaller which does indicate the effect could fade with time. An alternative explanation could be that attendance of 16-18 year olds increased with time which reduces our ability to measure the treatment effect because there are fewer potential "switchers".

High school graduation rates. One concern with the effect of war expenditures on high school graduation rates (Figure 7) is the potential presence of pre-trends. The 5\% sample for 1960 might not have sufficient power to rule out pre-trends. One alternative is to conduct the same analysis using the 1940 Census to see if there were pre-existing trends. Appendix Figure A.7 shows these results. For boys, the coefficients on "War exp * Black" seem to be consistently close to zero. For girls, there is little evidence of a positive trend in the years immediately leading up to WWII. There is potentially some trend in the early 1930s at the onset of the Great Depression that is driven by differential changes in the education of white girls. These results are consistent with our estimates for girls being noisier and less significant than our estimates for boys.

\section{E Quantitative Appendix}

\section{E.1 Equilibrium}

Consumption. First, consider the consumption side. Because trade is costless and preferences are identical across regions, consumption prices are equalized across space.

Consumption of industry $i$ in region $r$ is given by

$$
C_{\text {rit }} P_{\text {rit }}^{C}=\mu_{i} P_{t}^{C} C_{r t}
$$


where

$$
P_{t}^{C}=\prod_{i}\left(\frac{P_{i t}^{C}}{\mu_{i}}\right)^{\mu_{i}}
$$

denotes the final good price and where $P_{i t}^{C}$ denotes the consumption price of industry $i$. Consumption of industry $i$ from origin $j$ in destination $r$ is given by

$$
C_{j r i t}=\mu_{j i t}\left(\frac{P_{j i t}^{Y}}{P_{i t}^{C}}\right)^{-\rho} C_{r i t}
$$

where $P_{j i t}^{Y}$ is the production price in region $j$ of industry $i$ and where the consumption price of industry $i$ in all regions is

$$
P_{i t}^{C}=\left(\sum_{j} \mu_{j i t}\left(P_{j i t}^{Y}\right)^{1-\rho}\right)^{\frac{1}{1-\rho}}
$$

Production. Next, consider the production side. Industry $i$ profit maximization implies that in region $r$ the output of industry-occupation io pair is given by

$$
Y_{\text {riot }}=\mu_{\text {riot }}\left(\frac{P_{\text {riot }}^{Y}}{P_{\text {rit }}^{Y}}\right)^{-\eta} Y_{\text {rit }}
$$

where $Y_{r i t}$ is the region $r$ output of industry $i$, where the output price in region $r$ of industry $i$ is

$$
P_{\text {rit }}^{Y}=\left(\sum_{o} \mu_{\text {riot }}\left(P_{\text {riot }}^{Y}\right)^{1-\eta}\right)^{\frac{1}{1-\eta}}
$$

and where $P_{\text {riot }}^{Y}$ denotes the region $r$ output price of industry-occupation pair io.

The share of workers in group $g$ who choose to live in region $r$, denoted by $\pi_{r g t}^{N} \equiv$ $N_{r g t} / N_{g t}$ is given by

$$
\pi_{r g t}^{N}=\frac{\left(U_{r g t} \text { Wage }_{r g t}\right)^{v}}{\sum_{r^{\prime}}\left(U_{r^{\prime} g t} \text { Wage }_{r^{\prime} g t}\right)^{v}}
$$

where $N_{r g t}$ denotes the measure of group $g$ workers who choose to live in region $r$ and where Wage $_{\text {rgt }}$ is the average wage earned by those in group $g$ conditional on choosing region $r$. The share of workers in group $g$ and region $r$ who choose to work in industry- 
occupation io, denoted by $\pi_{\text {riogt }}^{L} \equiv N_{\text {riogt }} / N_{\text {rgt }}$, is given by

$$
\pi_{\text {riogt }}^{L}=\frac{\left(T_{\text {riogt }} P_{\text {riot }}^{Y}\right)^{\theta}}{\sum_{i^{\prime} o^{\prime}}\left(T_{r i^{\prime} o^{\prime} g t} P_{r i^{\prime} o^{\prime} t}^{Y}\right)^{\theta}}
$$

which is also the share of income earned within industry-occupation io for group $g$ in region $r$. The total efficiency units supplied by group $g$ in industry-occupation io in region $r$ is

$$
L_{\text {riogt }}=\gamma T_{\text {riogt }}\left(\pi_{\text {riogt }}^{L}\right)^{\frac{\theta-1}{\theta}} \pi_{r g t}^{N} N_{g t}
$$

where $\gamma \equiv \Gamma\left(1-\frac{1}{\theta}\right)$ and $\Gamma$ is the gamma function. The average wage of group $g$ in region $r$ is given by

$$
\text { Wage }_{\text {rgt }}=\gamma\left(\sum_{\text {io }}\left(T_{\text {riogt }} P_{\text {riot }}^{Y}\right)^{\theta}\right)^{\frac{1}{\theta}}
$$

Market clearing. Region $r$ 's output of industry $i$ must equal the sum of consumption across all regions for each ri pair

$$
Y_{\text {rit }}=\sum_{j} C_{\text {rjit }}
$$

Locally, markets must clear in each rio triplet

$$
Y_{\text {riot }}=\sum_{g} L_{\text {riogt }}
$$

Market clearing and balanced trade link production and consumption

$$
P_{t}^{C} C_{r t}=\sum_{g} \text { Wage } e_{r g t} \pi_{r g t}^{N} N_{g t}
$$

Equilibrium. An equilibrium is a vector of consumption prices $\left\{P_{t}^{C}, P_{i t}^{C}\right\}$, production prices $\left\{P_{\text {rit }}^{Y}, P_{\text {riot }}^{Y}\right\}$, wages $\left\{\right.$ Wage $\left.e_{\text {rgt }}\right\}$, quantities produced $\left\{Y_{r t}, Y_{\text {rit }}, Y_{\text {riot }}\right\}$, consumption levels $\left\{C_{r t}, C_{\text {rit }}, C_{\text {jrit }}\right\}$, and labor allocations $\left\{\pi_{r g t}^{N}, \pi_{\text {riogt }}^{L}, L_{\text {riogt }}\right\}$ for all region pairs jr, industries $i$, occupations $o$, and worker groups $g$ that satisfy (16)-(28).

Solution algorithm. The system has 13 equations (16) - (28) and 13 unknowns:

$$
\left\{P_{\text {riot }}^{Y}, P_{\text {rit }}^{Y}, \text { Wage } \text { rgt }, \pi_{\text {riogt }}^{L}, \pi_{\text {rgt }}^{N}, L_{\text {riogt }}, Y_{\text {riot }}, Y_{\text {rit }}, P_{i t}^{C}, P_{t}^{C}, C_{r t}, C_{\text {rit }}, C_{\text {jrit }}\right\}
$$

In each region and time period, guess industry-occupation output prices $\left\{P_{\text {riot }}^{Y}\right\}$. Then, in the following order, solve for all remaining endogenous variables. Solve for (i) pro- 
duction prices $\left\{P_{\text {rit }}^{Y}\right\}$ using (21), (ii) average wages $\left\{\right.$ Wage $\left._{\text {rgt }}\right\}$ using (25), (iii) allocations $\left\{\pi_{r g t}^{N}\right\}$ using (22) and $\left\{\pi_{\text {riogt }}^{L}\right\}$ using (23), (iv) efficiency units of labor $\left\{L_{\text {riogt }}\right\}$ using (24), (v) industry-occupation output $\left\{Y_{\text {riot }}\right\}$ using (27), and (vi) industry output $\left\{Y_{\text {rit }}\right\}$ using (20). Solve for (vii) industry consumption prices $\left\{P_{i t}^{C}\right\}$ using (19), (viii) aggregate consumption prices $\left\{P_{t}^{C}\right\}$ using (17), (ix) aggregate consumption $\left\{C_{r t}\right\}$ using (28), (x) industry consumption $\left\{C_{r i t}\right\}$ using (16), and (xi) bilateral consumption $\left\{C_{\text {jrit }}\right\}$ using (18). Finally, iterate over the initial guess of industry-occupation output prices $\left\{P_{\text {riot }}^{Y}\right\}$ using (26).

\section{E.2 Decomposition}

In this section, we provide the system of equations with which to solve for the implications of shocks and show how to measure these shocks. We define $\hat{x}=x_{t+1} / x_{t}$ for any variable $x$; it is the relative value of a variable in a "new equilibrium" $(t+1)$ relative to in the initial equilibrium $(t)$. The point of writing the system in changes is that it dramatically reduces the set of parameters we need to estimate to conduct our decomposition and counterfactuals.

In practice, the shocks that we feed into the system are changes in productivity, $T_{\text {riogt }}$, and changes in amenities, $U_{r g t}$, across time. Here, however, we allow for a more general set of shocks, including in addition shocks to demand across origin and industry pairs, $\mu_{j i t}$, changes in demand across occupations within industries, $\mu_{\text {riot }}$, and changes in the number of workers in each group at the national level, $N_{g t}$. We show here that for given values of $\rho \neq 1$ and $\eta \neq 1$, it is without loss of generality to normalize $\mu_{j i t}$ and $\mu_{\text {riot }}$ to be fixed over time, since any changes in these parameters can be absorbed by changes in $T_{\text {riogt }}$ without affecting any results.

\section{E.3 System in changes}

We express our system of 13 equations (16) - (28) and 13 unknowns in changes as follows:

$$
\begin{gathered}
\hat{P}_{i t}^{C} \hat{C}_{r i t}=\hat{P}_{t}^{C} \hat{C}_{r t} \\
\hat{P}_{t}^{C}=\prod_{i}\left(\hat{P}_{i t}^{C}\right)^{\mu_{i}} \\
\hat{C}_{j r i t}=\hat{\mu}_{j i t}\left(\frac{\hat{P}_{j i t}^{Y}}{\hat{P}_{i t}^{C}}\right)^{-\rho} \hat{C}_{r i t}
\end{gathered}
$$




$$
\begin{aligned}
& \hat{\Upsilon}_{\text {riot }}=\hat{\mu}_{\text {riot }}\left(\frac{\hat{P}_{\text {riot }}^{Y}}{\hat{P}_{\text {rit }}^{Y}}\right)^{-\eta} \hat{Y}_{\text {rit }} \\
& \hat{P}_{i t}^{C}=\left(\sum_{j} S_{j i t}^{C} \hat{H}_{j i t}\left(\hat{P}_{j i t}^{Y}\right)^{1-\rho}\right)^{\frac{1}{1-\rho}} \\
& \hat{P}_{\text {rit }}^{Y}=\left(\sum_{o} S_{\text {riot }}^{Y} \hat{\mu}_{\text {riot }}\left(\hat{P}_{\text {riot }}^{Y}\right)^{1-\eta}\right)^{\frac{1}{1-\eta}} \\
& \hat{\pi}_{r g t}^{N}=\frac{\left(\hat{U}_{r g t} \text { Wâge }_{r g t}\right)^{v}}{\sum_{r^{\prime}} \pi_{r^{\prime} g t}^{N}\left(\hat{U}_{r^{\prime} g t} \text { Wâge } e_{r^{\prime} g t}\right)^{v}} \\
& \hat{\pi}_{\text {riogt }}^{L}=\frac{\left(\hat{T}_{\text {riogt }} \hat{P}_{\text {riot }}^{Y}\right)^{\theta}}{\sum_{i^{\prime} o^{\prime}} \pi_{r i^{\prime} o^{\prime} g t}^{L}\left(\hat{T}_{r i^{\prime} o^{\prime} g t} \hat{P}_{r i^{\prime} o^{\prime} t}^{Y}\right)^{\theta}} \\
& \hat{L}_{\text {riogt }}=\hat{T}_{\text {riogt }}\left(\hat{\pi}_{\text {riogt }}^{L}\right)^{\frac{\theta-1}{\theta}} \hat{N}_{\text {rgt }} \\
& \widehat{W a g e}_{\text {rgt }}=\left(\sum_{\text {io }} \pi_{\text {riogt }}^{L}\left(\hat{T}_{\text {riogt }} \hat{P}_{\text {riot }}^{Y}\right)^{\theta}\right)^{\frac{1}{\theta}} \\
& \hat{Y}_{\text {rit }}=\sum_{j} s_{j t} \hat{C}_{r j i t} \\
& \hat{Y}_{\text {riot }}=\sum_{g} s_{\text {riogt }} \hat{L}_{\text {riogt }} \\
& \hat{P}_{t}^{C} \hat{C}_{r t}=\sum_{g} s_{r g t} \widehat{W a g} e_{r g t} \hat{N}_{r g t}
\end{aligned}
$$

In this system of equations, $S_{j i t}^{C} \equiv \frac{\mu_{j i t}\left(P_{j i t}^{Y}\right)^{1-\rho}}{\sum_{r} \mu_{r i t}\left(P_{r i t}^{Y}\right)^{1-\rho}}$ denotes the share of each region's expenditure on industry $i$ that is produced in region $j ; S_{\text {riot }}^{Y} \equiv \frac{\mu_{\text {riot }}\left(P_{\text {riot }}^{Y}\right)^{1-\eta}}{\sum_{o^{\prime}} \mu_{\text {rio }}\left(P_{\text {rio }}^{Y}\right)^{1-\eta}}$ denotes region $r^{\prime}$ s share of expenditure within industry $i$ on occupation $o ; s_{j t} \equiv \frac{C_{r j i t}}{\sum_{j^{\prime}} C_{r j^{\prime} i t}}$ is the share of region $r^{\prime}$ s industry $i$ output shipped to $j$, which equals region $j$ 's share of total income (or expenditure), $s_{j t}=\frac{P_{t} C_{j t}}{\sum_{r} P_{t} C_{r t}} ; s_{\text {riogt }} \equiv \frac{L_{\text {riogt }}}{\sum_{g^{\prime}} L_{\text {riog }} t}$ is the share of output in $r$ of io produced by group $g$; and $s_{r g t} \equiv \frac{\text { Wage }_{r g t} N_{r g t}}{\sum_{g^{\prime}} \text { Wage }_{r g^{\prime} t} N_{r^{\prime} t}}$ is the share of labor income in $r$ that accrues to $g$.

The system has 13 equations (29)-(41) and 13 unknowns:

$$
\left\{\hat{P}_{\text {riot }}^{Y}, \hat{P}_{\text {rit }}^{Y}, \widehat{W a g e}_{\text {rgt }}, \hat{\pi}_{\text {riogt }}^{L}, \hat{\pi}_{\text {rgt }}^{N}, \hat{L}_{\text {riogt }}, \hat{Y}_{\text {riot }}, \hat{Y}_{\text {rit }}, \hat{P}_{i t}^{C}, \hat{P}_{t}^{C}, \hat{C}_{r t}, \hat{C}_{\text {rit }}, \hat{C}_{\text {jrit }}\right\}
$$


Given shocks $\left(\hat{\mu}_{j i t}, \hat{\mu}_{\text {riot }}, \hat{T}_{\text {riogt }}, \hat{U}_{\text {rgt }}\right.$, and $\left.\hat{N}_{g t}\right)$, elasticities $(\theta, v, \rho$, and $\eta)$, and initial equilibrium shares $\left(\mu_{i}, S_{j i t}^{C}, S_{\text {riot }}^{Y}, \pi_{\text {riogt }}^{L}, \pi_{\text {rgt }}^{N}, s_{j t}, s_{\text {riogt }}\right.$, and $\left.s_{r g t}\right)$, we can solve for all changes using the previous system as follows. In each region and time period, guess industryoccupation changes in output prices $\left\{\hat{P}_{\text {riot }}^{Y}\right\}$. Use (34) to solve for $\left\{\hat{P}_{\text {rit }}^{Y}\right\}$, (38) to solve for $\left\{\widehat{W a g e}_{\text {rgt }}\right\}$, (36) to solve for $\left\{\hat{\pi}_{\text {riogt }}^{L}\right\}$, (35) to solve for $\left\{\hat{\pi}_{\text {rgt }}^{N}\right\}$, (33) to solve for $\left\{\hat{P}_{\text {it }}^{C}\right\},(30)$ to solve for $\left\{\hat{P}_{t}^{C}\right\},(37)$ to solve for $\left\{\hat{L}_{\text {riogt }}\right\},(41)$ to solve for $\left\{\hat{C}_{r t}\right\},(29)$ to solve for $\left\{\hat{C}_{r i t}\right\}$, (31) to solve for $\left\{\hat{C}_{\text {jrit }}\right\}$, (32) to solve for $\left\{\hat{Y}_{\text {riot }}\right\}$, and (39) to solve for $\left\{\hat{Y}_{\text {rit }}\right\}$. Finally, we iterate over the values of $\left\{\hat{P}_{\text {riot }}^{Y}\right\}$ until we satisfy (40).

\section{E.3.1 Calibrating the model to 1940 data}

In constructing each share, we are only using data from the regions that we are considering. As an example, if we require total labor income earned in industry $i$ across all regions, then we are summing total labor income earned in industry $i$ across all regions in our sample (rather than across all regions in U.S.).

$\mu_{i}: \mu_{i}$ is the share of expenditure on industry $i$, which we assume is constant across time and regions. To measure $\mu_{i}$ in our model in a given year, the numerator is the sum of labor income (since labor is the only factor of production) across regions in industry $i$ and the denominator is the sum of labor income across regions and industries (in the same year).

$S_{j i t}^{C}: S_{j i t}^{C}$ is the share of national industry $i$ expenditure that is produced in region $j$ in year $t$. Since labor is the only factor of production and there is no trade with the outside world, the numerator is labor income earned in industry $i$ in region $j$ in year $t$ and the denominator is labor income earned in industry $i$ summed across all regions in year $t$.

$S_{\text {riot }}^{Y}: S_{\text {riot }}^{Y}$ is region $r^{\prime}$ s year $t$ share of labor income within industry $i$ earned in occupation $o$. To measure $S_{\text {riot }}^{Y}$, the numerator is labor income earned within $i o$ in region $r$ in year $t$ and the denominator is labor income earned within $i$ in region $r$ in year $t$.

$\pi_{\text {riogt }}^{L}: \pi_{\text {riogt }}^{L}$ is both the share of labor income (and the share of employment) within region $r$ for group $g$ at time $t$ that is earned (or worked) within io. We can measure $\pi_{\text {riogt }}^{L}$ two ways according to our model. In the first approach, we use employment. In the second approach, we use labor income. In the first approach, the numerator of $\pi_{\text {riogt }}^{L}$ is employment of group $g$ in region $r$ at time $t$ in $i o$ and the denominator is the sum of employment of group $g$ in region $r$ at time $t$ across all io pairs. In the second approach, the numerator of $\pi_{\text {riogt }}^{L}$ is the income of group $g$ in region $r$ at time $t$ earned in $i o$ and the denominator is the sum of income of group $g$ in region $r$ at time $t$ across all io pairs. 
$\pi_{r g t}^{N}: \pi_{r g t}^{N}$ is the share of the population within group $g$ that lives in region $r$ at time $t$. The numerator is the population of $g$ in $r$ at $t$ and the denominator is the population of $g$ across all regions at $t$.

$s_{j t}: s_{j t}$ is the share of total labor income earned in region $r$ at time $t$. The numerator is labor income in $r$ at $t$ and the denominator is labor income across all regions at $t$.

$s_{\text {riogt }}: s_{\text {riogt }}$ is the share of labor income in region $r$ and industry-occupation io that is paid to group $g$. The numerator is labor income in region $r$ and industry-occupation io that is paid to group $g$ and the denominator is the sum of labor income in region $r$ and industry-occupation io across all $g$.

$s_{r g t}: s_{r g t}$ is the share of labor income in $r$ that accrues to $g$ at time $t$. The numerator is labor income in $r$ that accrues to $g$ at time $t$ and the denominator is the sum of labor income in $r$ at $t$ across all groups.

\section{E.3.2 Calibrating eta}

To choose the value of $\eta$, we calibrate the model to 1940 data, matching the initial shares described in E.3.1. Then we take the following steps.

i. We pick a value of $\eta$.

ii. We measure shocks, as described in E.3.3, where the value of two of these six shocks, $\beta_{1}^{T}$ and $\beta_{2}^{T}$, depend on the choice of $\eta$.

iii. We feed into the model the government spending shocks (associated with all $\beta^{T}$ and $\beta^{U}$ parameters) and solve for the new equilibrium of the model.

iv. We estimate regressions of the form in (1) in Section 3.3 using actual data and, separately, using model-generated data, where the dependent variables, $Y_{r t}$ are the share of employment in skilled occupations and the ln average wage of Black and white workers in each metro area and year (for 1940 and 1950).

v. For each of the four coefficients of interest in the data, $\beta_{1, \text { race, }, \text {, }}^{\text {data }}$ and in the model, $\beta_{1, \text { race, } Y \text {, where }}^{\text {model }} Y$ indicates the dependent variable and race indicates the sample, we construct the sum of squared differences

$$
\mathcal{L}(\eta)=\sum_{Y, \text { race }} \omega_{\text {race }}\left(\beta_{1, \text { race }, Y}^{\text {data }}-\beta_{1, \text { race }, Y}^{\text {model }}\right)^{2}
$$

where $\omega_{\text {race }}$ is a weight that we set to 1 if race $=$ white and we set to 2 if race $=$ Black, given our focus on explaining Black labor market outcomes. 
Finally, we iterate over values of $\eta$ to minimize $\mathcal{L}(\eta)$. This procedure yields $\eta=1.7$. Panels A and C of Table 6 display the resulting values of $\beta_{1, \text { race, },}^{\text {data }}$ and $\beta_{1, \text { race, }, \text { red }}^{\text {, respectively. }}$

\section{E.3.3 Measuring shocks}

In addition to the shocks included in the body of the paper, we include two additional shocks:

$$
\begin{aligned}
\ln \mu_{\text {rit }} & =\gamma_{r i}^{i}+\gamma_{i t}^{i}+G_{r} \mathbb{I}_{t} \mathbb{I}_{i} \beta_{1}^{i}+\iota_{\text {rit }}^{i} \\
\ln \mu_{\text {riot }} & =\gamma_{\text {rio }}^{o}+\gamma_{\text {iot }}^{o}+G_{r} \mathbb{I}_{t} \mathbb{I}_{i}\left[\beta_{1}^{o}+\beta_{2}^{o} \mathbb{I}_{o}\right]+\iota_{\text {riot }}^{o}
\end{aligned}
$$

We will show that it is without loss of generality to assume that $\beta_{1}^{i}, \beta_{1}^{o}$, and $\beta_{2}^{o}$ are all set to zero for given values of $\rho \neq 1$ and $\eta \neq 1$.

Anti-discriminatory shocks. From (23), we have

$$
\ln \pi_{\text {riogt }}^{L}=\theta \ln T_{\text {riogt }}+\theta \ln P_{\text {riot }}^{Y}-\ln \left(\sum_{i^{\prime} o^{\prime}}\left(T_{r i^{\prime} o^{\prime} g t} P_{\text {ri' }{ }^{\prime} o^{\prime} t}^{Y}\right)^{\theta}\right)
$$

The previous expression and (8) yield

$$
\begin{aligned}
\ln \pi_{\text {riogt }}^{L}= & \theta \gamma_{\text {riog }}^{T}+\theta \gamma_{\text {iogt }}^{T}+G_{r} \mathbb{I}_{t} \mathbb{I}_{i}\left[\theta \beta_{1}^{T}+\theta \beta_{2}^{T} \mathbb{I}_{o}+\theta \beta_{3}^{T} \mathbb{I}_{g}+\theta \beta_{4}^{T} \mathbb{I}_{o} \mathbb{I}_{g}\right] \\
& +\theta r_{\text {riogt }}^{T}+\theta \ln P_{\text {riot }}^{Y}-\ln \left(\sum_{i^{\prime} o^{\prime}}\left(T_{r i^{\prime} o^{\prime} g t} P_{\text {ri' }{ }^{\prime} o^{\prime} t}^{Y}\right)^{\theta}\right)
\end{aligned}
$$

which can be re-expressed as (10), where $\gamma_{r g t} \equiv-\ln \left(\sum_{i^{\prime} o^{\prime}}\left(T_{r i^{\prime} o^{\prime} g t} P_{r^{\prime} o^{\prime} t}^{Y}\right)^{\theta}\right), \gamma_{\text {riot }} \equiv \theta \ln P_{\text {riot }}^{Y}+$ $G_{r} \mathbb{I}_{t} \mathbb{I}_{i}\left[\theta \beta_{1}^{T}+\theta \beta_{2}^{T} \mathbb{I}_{o}\right], \gamma_{\text {riog }} \equiv \theta \gamma_{\text {riog, }}^{T}, \gamma_{\text {iogt }} \equiv \theta \gamma_{\text {iogt }}^{T}$, $\iota_{\text {riogt }} \equiv \theta \iota_{\text {riogt }}^{T} \beta_{3} \equiv \theta \beta_{3}^{T}$, and $\beta_{4} \equiv \theta \beta_{4}^{T}$. We estimate (10) once measuring the dependent variable using employment shares (see column 1 of Table 5) and, for robustness, another time using labor income shares (see column 2 of Table 5).

From (22), we obtain

$$
\frac{1}{v} \ln \pi_{r g t}^{N}-\ln \text { Wage }_{r g t}=\ln U_{r g t}+\gamma_{g t}
$$

where $\gamma_{g t} \equiv-\frac{1}{v} \ln \left(\sum_{r^{\prime}}\left(U_{r^{\prime} g t} W a g e_{r^{\prime} g t}\right)^{v}\right)$. The previous expression and (9) yield

$$
\frac{1}{v} \ln \pi_{r g t}^{N}-\ln \text { Wage }_{r g t}=\gamma_{r g}+G_{r} \mathbb{I}_{t}\left[\beta_{1}^{U}+\beta_{2}^{U} \mathbb{I}_{g}\right]+\gamma_{g t}+\iota_{r g t}^{U}
$$


The previous equation can be expressed as (11), where $\gamma_{r t} \equiv \beta_{1}^{U} G_{r} \mathbb{I}_{t}$. We report our estimate from (11) in column 7 of Table 5 . This concludes the baseline identification of the anti-discriminatory effects of wartime spending.

Compositional shock I: amenity parameter $\beta_{1}^{U}$ (or all amenity parameters). Both amenity parameters are estimated using variants of (44). In our baseline approach, first estimate (11) to identify $\beta_{2}^{U}$, subtract this estimate from both the left- and right-hand side of (44), and estimate

$$
\frac{1}{v} \ln \pi_{r g t}^{N}-\ln \text { Wage }_{r g t}-\hat{\beta}_{2}^{U} \mathbb{I}_{g}=\gamma_{r g}+\gamma_{g t}+\beta_{1}^{U} G_{r} \mathbb{I}_{t}+\iota_{r g t}^{U}
$$

See column 8 of Table 5 for the resulting estimate of $\beta_{1}^{U}$. We also estimate $\beta_{U}^{1}$ and $\beta_{U}^{2}$ together in a single step by estimating (44) directly; see column 9 of Table 5 .

Compositional shock II: productivity parameter $\beta_{2}$ (or productivity parameters $\beta_{2}, \beta_{3}, \beta_{4}$ ). From (20), we obtain

$$
\ln \left(P_{\text {riot }}^{Y} Y_{\text {riot }}\right)=\ln \mu_{\text {riot }}+(1-\eta) \ln P_{\text {riot }}^{Y}+\eta \ln P_{\text {rit }}^{Y}+\ln Y_{\text {rit }}
$$

From (23) and (25), we have

$$
\ln P_{\text {riot }}^{Y}=\ln \text { Wage }_{\text {rgt }}+\frac{1}{\theta} \ln \pi_{\text {riogt }}-\ln T_{\text {riogt }}-\ln \gamma
$$

Combining the previous two expressions yields

$$
v_{\text {riogt }}=\frac{\theta}{1-\eta}\left[-\ln \mu_{\text {riot }}+(1-\eta) \ln T_{\text {riogt }}-\eta \ln P_{\text {rit }}^{Y}-\ln Y_{\text {rit }}+(1-\eta) \gamma\right]
$$

where we have defined

$$
v_{\text {riogt }} \equiv-\frac{\theta}{1-\eta} \ln \left(P_{\text {riot }}^{Y} Y_{\text {riot }}\right)+\theta \ln \text { Wage } \text { rgt }+\ln \pi_{\text {riogt }}
$$

Combining the (46) with (8) and (43) yields

$$
v_{\text {riogt }}=\gamma_{\text {riog }}+\gamma_{\text {iogt }}+\gamma_{\text {rit }}+\beta_{2} G_{r} \mathbb{I}_{t} \mathbb{I}_{i} \mathbb{I}_{o}+\beta_{3} G_{r} \mathbb{I}_{t} \mathbb{I}_{i} \mathbb{I}_{g}+\beta_{4} G_{r} \mathbb{I}_{t} \mathbb{I}_{i} \mathbb{I}_{g} \mathbb{I}_{o}+\iota_{\text {riogt }}
$$

where $\gamma_{\text {rit }} \equiv-\frac{\theta}{1-\eta} \eta \ln P_{\text {rit }}^{Y}-\frac{\theta}{1-\eta} \ln Y_{\text {rit }}+\theta \gamma-\frac{\theta}{1-\eta} \beta_{1}^{o}+\theta \beta_{1}^{T}, \iota_{\text {riogt }} \equiv-\frac{\theta}{1-\eta} l_{\text {riot }}^{o}+\theta l_{\text {riogt }}^{T}$, $\gamma_{\text {riog }} \equiv-\frac{\theta}{1-\eta} \gamma_{\text {rio }}^{o}+\theta \gamma_{\text {riog }}^{T} \gamma_{\text {iogt }} \equiv-\frac{\theta}{1-\eta} \gamma_{\text {iot }}^{o}+\theta \gamma_{\text {iogt }}^{T} \beta_{2} \equiv-\frac{\theta}{1-\eta} \beta_{2}^{o}+\theta \beta_{2}^{T}, \beta_{3} \equiv \theta \beta_{3}^{T}$, and $\beta_{4} \equiv \theta \beta_{4}^{T}$.

In practice, we could estimate the previous expression directly or we could subtract 
our estimates of $\hat{\beta}_{3} G_{r} \mathbb{I}_{t} \mathbb{I}_{i} \mathbb{I}_{g}$ and $\hat{\beta}_{4} G_{r} \mathbb{I}_{t} \mathbb{I}_{i} \mathbb{I}_{g} \mathbb{I}_{o}$ from the left- and right-hand sides of the previous expression and instead estimate

$$
\tilde{v}_{\text {riogt }}=\gamma_{\text {riog }}+\gamma_{\text {iogt }}+\gamma_{\text {rit }}+\beta_{2} G_{r} \mathbb{I}_{t} \mathbb{I}_{i} \mathbb{I}_{o}+\iota_{\text {riogt }}
$$

where $\tilde{v}_{\text {riogt }} \equiv v_{\text {riogt }}+\hat{\beta}_{3} G_{r} \mathbb{I}_{t} \mathbb{I}_{i} \mathbb{I}_{g}+\hat{\beta}_{4} G_{r} \mathbb{I}_{t} \mathbb{I}_{i} \mathbb{I}_{g} \mathbb{I}_{o}$. In our baseline approach, we estimate $\beta_{2}$ using (48), and report results in column 3 of Table 5 , whereas in robustness we estimate $\beta_{2}, \beta_{3}$, and $\beta_{4}$ using (47), and report results in column 4 of Table 5.

Compositional shock III: productivity parameter $\beta_{1}$ (or all productivity parameters). Equations (16), (18), and (26) yield

$$
P_{j i t}^{Y} Y_{j i t}=\mu_{j i t}\left(P_{j i t}^{Y}\right)^{1-\rho} \times\left(P_{i t}^{C}\right)^{\rho-1} \mu_{i} \sum_{r} P_{t}^{C} C_{r t}
$$

The previous expression and (21) yield

$$
P_{j i t}^{Y} Y_{j i t}=\mu_{j i t}\left(\sum_{o} \mu_{j i o t}\left(P_{j i o t}^{Y}\right)^{1-\eta}\right)^{\frac{1-\rho}{1-\eta}} \times\left(P_{i t}^{C}\right)^{\rho-1} \mu_{i} \sum_{r} P_{t}^{C} C_{r t}
$$

The previous expression and the definition of $S_{j i o t}^{Y}$, which implies

$$
\sum_{o} \mu_{j i o t}\left(P_{j i o t}^{Y}\right)^{1-\eta}=\frac{\mu_{j i o^{\prime} t}\left(P_{j i o^{\prime} t}^{Y}\right)^{1-\eta}}{S_{j i o^{\prime} t}^{Y}} \text { for any } o^{\prime}
$$

yield

$$
P_{j i t}^{Y} Y_{j i t}\left(S_{j i o t}^{Y}\right)^{\frac{1-\rho}{1-\eta}}=\mu_{j i t} \mu_{j i o t}^{\frac{1-\rho}{1-\eta}}\left(P_{j i o t}^{Y}\right)^{1-\rho} \times\left(P_{i t}^{C}\right)^{\rho-1} \mu_{i} \sum_{r} P_{t}^{C} C_{r t}
$$

Combining the previous expression with (23) and (25), which imply

$$
\ln P_{j i o t}^{Y}=\ln W a g e_{j g t}+\frac{1}{\theta} \ln \pi_{j i o g t}-\ln T_{j i o g t}-\ln \gamma
$$

yields

$$
\begin{aligned}
\ln \left(P_{j i t}^{Y} Y_{j i t}\right)+\frac{1-\rho}{1-\eta} \ln S_{j i o t}^{Y} & =\ln \mu_{j i t}+\frac{1-\rho}{1-\eta} \ln \mu_{j i o t}+\ln \left[\left(P_{i t}^{C}\right)^{\rho-1} \mu_{i} \sum_{r} P_{t}^{C} C_{r t}\right] \\
& +(1-\rho)\left[\ln W a g e_{j g t}+\frac{1}{\theta} \ln \pi_{j i o g t}-\ln T_{j i o g t}-\ln \gamma\right]
\end{aligned}
$$


which is equivalent to

$$
v_{j i o g t}^{\prime}=-\frac{\theta}{1-\rho} \ln \mu_{j i t}-\frac{\theta}{1-\eta} \ln \mu_{j i o t}+\gamma_{i t}+\theta \ln T_{j i o g t}
$$

where $\gamma_{i t} \equiv \theta \ln \gamma-\frac{\theta}{1-\rho} \ln \left[\left(P_{i t}^{C}\right)^{\rho-1} \mu_{i} \sum_{r} P_{t}^{C} C_{r t}\right]$ and where

$$
v_{j i o g t}^{\prime} \equiv-\frac{\theta}{1-\rho} \ln \left(P_{j i t}^{Y} Y_{j i t}\right)-\frac{\theta}{1-\eta} \ln S_{j i o t}^{Y}+\theta \ln W a g e_{j g t}+\ln \pi_{j i o g t}
$$

We substitute out $\ln \mu_{j i t}, \ln \mu_{j i o t}$ and $\ln T_{j i o g t}$ using (8), (42), and (43) to obtain

$$
\begin{aligned}
v_{j i o g t}^{\prime} & =-\frac{\theta}{1-\rho}\left[\gamma_{j i}^{i}+\gamma_{i t}^{i}+G_{j} \mathbb{I}_{t} \mathbb{I}_{i} \beta_{1}^{i}+\iota_{j i t}^{i}\right] \\
& -\frac{\theta}{1-\eta}\left[\gamma_{j i o}^{o}+\gamma_{i o t}^{o}+G_{j} \mathbb{I}_{t} \mathbb{I}_{i}\left[\beta_{1}^{o}+\beta_{2}^{o} \mathbb{I}_{o}\right]+\iota_{j i o t}^{o}\right]+\gamma_{i t} \\
& +\theta\left[\gamma_{j i o g}^{T}+\gamma_{i o g t}^{T}+G_{j} \mathbb{I}_{t} \mathbb{I}_{i}\left[\beta_{1}^{T}+\beta_{2}^{T} \mathbb{I}_{o}+\beta_{3}^{T} \mathbb{I}_{g}+\beta_{4}^{T} \mathbb{I}_{o} \mathbb{I}_{g}\right]+\iota_{j i o g t}^{T}\right]
\end{aligned}
$$

which can be simplified to

$$
v_{j i o g t}^{\prime}=\gamma_{j i o g}+\gamma_{i o g t}+\beta_{1} G_{j} \mathbb{I}_{t} \mathbb{I}_{i}+\beta_{2} G_{j} \mathbb{I}_{t} \mathbb{I}_{i} \mathbb{I}_{o}+\beta_{3} G_{j} \mathbb{I}_{t} \mathbb{I}_{i} \mathbb{I}_{g}+\beta_{4} G_{j} \mathbb{I}_{t} \mathbb{I}_{i} \mathbb{I}_{o} \mathbb{I}_{g}+\iota_{j i o g t}
$$

where $\gamma_{i o g t} \equiv \gamma_{i t}-\frac{\theta}{1-\rho} \gamma_{i t}^{i}-\frac{\theta}{1-\eta} \gamma_{i o t}^{o}+\theta \gamma_{i o g}^{T}{ }^{\prime} \gamma_{j i o g} \equiv-\frac{\theta}{1-\rho} \gamma_{j i}^{i}-\frac{\theta}{1-\eta} \gamma_{j i o}^{o}+\theta \gamma_{j i o g}^{T}, \iota_{j i o g t} \equiv$ $-\frac{\theta}{1-\rho} l_{j i t}^{i}-\frac{\theta}{1-\eta} l_{j i o t}^{o}+\theta \iota_{\text {jiogt }}^{T}, \beta_{1} \equiv-\frac{\theta}{1-\rho} \beta_{1}^{i}-\frac{\theta}{1-\eta} \beta_{1}^{o}+\theta \beta_{1}^{T}, \beta_{2} \equiv-\frac{\theta}{1-\eta} \beta_{2}^{o}+\theta \beta_{2}^{T}, \beta_{3} \equiv \theta \beta_{3}^{T}$, and $\beta_{4} \equiv \theta \beta_{4}^{T}$. In robustness, we estimate $\beta_{1}, \beta_{2}, \beta_{3}$, and $\beta_{4}$ all together using (50) and report results in column 6 of Table 5 . In our baseline approach, we instead estimate

$$
\tilde{v}_{j i o g t}^{\prime}=\gamma_{j i o g}+\gamma_{i o g t}+\beta_{1} G_{j} \mathbb{I}_{t} \mathbb{I}_{i}+\iota_{j i o g t}
$$

where

$$
\tilde{v}_{j i o g t}^{\prime} \equiv v_{j i o g t}^{\prime}-\hat{\beta}_{2} G_{j} \mathbb{I}_{t} \mathbb{I}_{i} \mathbb{I}_{o}-\hat{\beta}_{3} G_{j} \mathbb{I}_{t} \mathbb{I}_{i} \mathbb{I}_{g}-\hat{\beta}_{4} G_{j} \mathbb{I}_{t} \mathbb{I}_{i} \mathbb{I}_{o} \mathbb{I}_{g}
$$

In (51), we have subtracted from the left- and right-hand side the terms associated with $\beta_{2}, \beta_{3}$, and $\beta_{4}$ which we have previously estimated. We report results in column 5 of Table 5 . 